\title{
Arabian Sea Mixed Layer Deepening during the Monsoon: Observations and Dynamics
}

\author{
by \\ Albert S. Fischer \\ S.B., Physics (1994) \\ Massachusetts Institute of Technology \\ Submitted to the Massachusetts Institute of Technology / Woods Hole \\ Oceanographic Institution Joint Program in Physical Oceanography \\ in Partial Fulfillment of the Requirements for the Degree of

\section{MASTER OF SCIENCE} \\ at the

\begin{abstract}
MASSACHUSETTS INSTITUTE OF TECHNOLOGY
and the

WOODS HOLE OCEANOGRAPHIC INSTITUTION
\end{abstract}

September 1997

(C) Albert S. Fischer 1997. All rights reserved.

The author hereby grants MIT and WHOI permission to reproduce and to distribute publicly paper and electronic copies of this thesis document in whole or in part.

Signature of Author

Joint Program in Physical Oceanography

Massachusetts Institute of Technology

Woods Hole Oceanographic Institution

18 June 1997

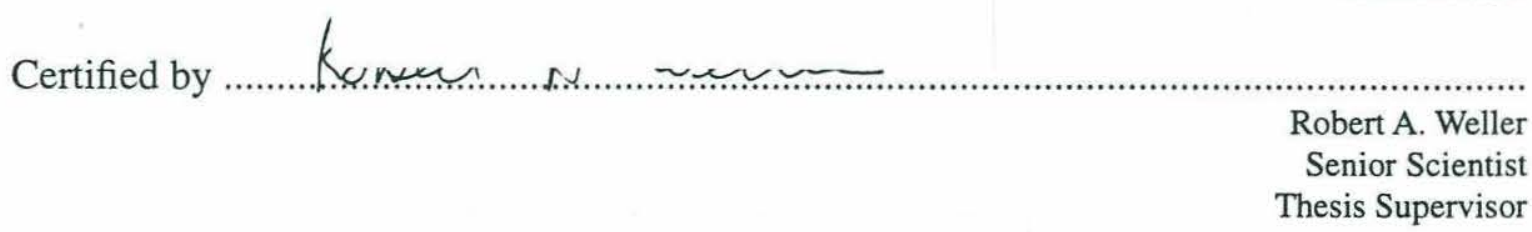

Accepted by ...........

Chairman, Joint Committee for Physical Oceanography

Massachusetts Institute of Technology

Woods Hole Oceanographic Institution 


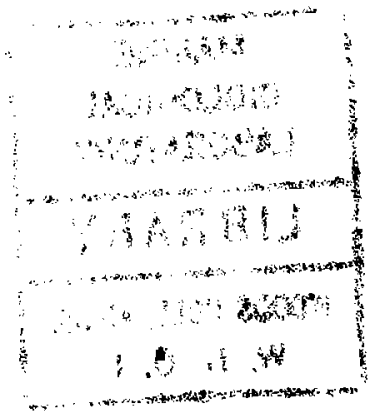




\title{
Arabian Sea Mixed Layer deepening during the Monsoon: Observations and Dynamics
}

by

\author{
Albert S. Fischer \\ Submitted in partial fulfillment of the requirements for the degree \\ of Master of Science at the Massachusetts Institute of Technology \\ and the Woods Hole Oceanographic Institution
}

\begin{abstract}
The unusual twice-yearly cycle of mixed layer deepening and cooling driven by the monsoon is analyzed using a recently collected (1994-95) dataset of concurrent local air-sea fluxes and upper ocean dynamics from the Arabian Sea. The winter northeast monsoon has moderate wind forcing and a strongly destabilizing surface buoyancy flux, driven by large radiative and latent heat losses at the sea surface. Convective entrainment is the primary local mechanism driving the observed mixed layer cooling and deepening, although horizontal advection of thermocline depth variations affect the depth which the mixed layer attains. Modifications of a one-dimensional mixed layer model and heat balance show that the primary nonlocal forcing of the upper ocean is the horizontal advection of temperature gradients below the mixed layer base. The summer southwest monsoon has strong wind stresses and a neutral to stabilizing surface buoyancy flux, limited by the extreme humidity of the atmosphere, which suppresses both the radiative and latent heat losses at the surface. Wind-driven shear instabilities at the base of the mixed layer, which entrain cooler and fresher water primarily produces the observed mixed layer cooling and deepening. Horizontal advection of cooler water within the mixed layer influences the local heat balance at the mooring site. Ekman pumping velocities play only a small role in the upper ocean evolution during both monsoon seasons.
\end{abstract}

\section{Thesis Advisor:}

Dr. Robert A. Weller, Senior Scientist

Physical Oceanography Department

Woods Hole Oceanographic Institution 


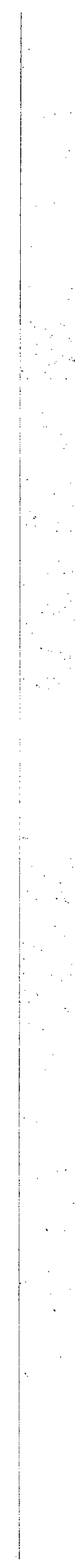




\section{Table of Contents}

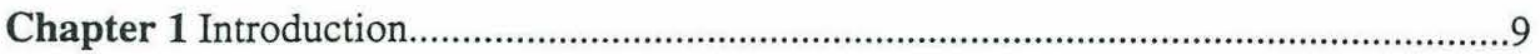

1.1 Outline 10

1.2 Atmospheric Forcing: The Monsoon 11

1.3 The oceanic response: Arabian Sea circulation and climatology 16

1.4 Objectives 20

Chapter 2 Data and Processing.

2.1 Mooring Location 21

2.2 Instrumentation 23

2.3 Bulk calculation of air-sea fluxes 27

2.4 Overview of Atmospheric data 31

2.5 Overview of Oceanic response 36

Chapter 3 Northeast Monsoon

3.1 Oceanographic setting 43

3.2 Surface Forcing 46

3.3 Characterizing the upper ocean response 49

3.4 The dominant physical mechanism for deepening 56

3.5 Local forcing of upper ocean response 63

3.6 Investigating nonlocal upper ocean forcing 72

3.7 Summary 88

Chapter 4 Southwest Monsoon.

4.1 Oceanographic setting 91

4.2 Surface Forcing 93

4.3 Upper ocean response 97

4.4 The dominant physical mechanisms for deepening 104

4.5 Local forcing of upper ocean response 106

4.6 Investigating nonlocal upper ocean forcing 114

4.7 Summary 119

Chapter 5 Discussion and Conclusions

References 


\section{Acknowledgements}

First I'd like to thank my advisor, Bob Weller, for his gentle support and encouragement, as well as the opportunity to work on this project. I'm happy I found them both. I must thank Tom Dickey, John Marra, Dan Rudnick and Charlie Eriksen for generously providing part of the data that went into this thesis, and the rest of the Upper Ocean Processes group here at WHOI, whose expertise gave me this beautiful dataset to analyze, and whose humor constantly tickles. Mark, Nanc and Nan gave me particular support in processing the data. I've profited tremendously from conversations with Craig Lee, Jim Price, and Steve Anderson. Craig, Melissa, and Joanna devoted great energy and time into giving me helpful feedback on drafts, as did Jochem Marotzke, Terry Joyce, and Karl Helfrich, members of my defense committee.

And for providing food for the soul and countless hours of distraction as well as inspiration, I must thank my classmates Stephanie, Lou, and Brian, and my officemate François. Sandra provided particular advice in getting through this process, and Sameera was an always willing recipient for vents, so long as I was willing to be the same.

My parents and Heidi and Max have supported me with their unbelievable faith in me.

This research was funded by ONR grant N00014-94-1-0161, and I was supported during this time by a generous NDSEG fellowship. 


\section{Chapter 1 Introduction}

The upper ocean is driven into motion by the atmosphere through fluxes of momentum, heat, and freshwater, whose combined effect controls the characteristics of the well-mixed oceanic boundary layer. The mixed layer temperature and depth are set by the competition of various processes including the penetrative radiation of the sun, heat loss-driven convection, vertical mixing due to shear-flow instabilities, surface and wave-driven turbulence, and Ekman divergences and convergences, all set upon and interacting with a background of mesoscale flow. Mixed layer depth and temperature play an important role in driving such larger-scale ocean processes as subduction and frontogenesis. The resulting sea surface temperature forms an important boundary condition driving the atmosphere and our weather. Additionally, biogeochemical cycles and the attendant biological productivity are profoundly affected by the mixed layer depth, which controls the amount of nutrient input to the euphotic zone through vertical mixing and entrainment.

In this thesis I analyze a recently collected upper ocean dataset from the Arabian Sea, the first long-term surface mooring in the area. The data collected provide a unique opportunity to study the processes at work in the upper ocean under a wide variety of surface 
forcing conditions, including very strong wind forcing. The semi-annual reversal of the monsoonal winds over the Arabian Sea drive two seasons of deepening and cooling of the mixed layer, with predominantly different physical deepening mechanisms. During the winter monsoon, cool, dry and moderate winds blow from the northeast, the surface heat loss from the ocean is high, and there is significant Ekman pumping in the northern part of the basin. During the summer monsoon, strong, moist winds blow from the southwest, the ocean experiences a net heat gain, and the Ekman transports diverge, favoring upwelling. The Arabian basin also harbors high mesoscale activity, driven by the Somali current and coastal upwelling instabilities during the southwest monsoon. Despite the disparity in the forcing, the mixed layer response has been observed to be similar in each season: a deepening and cooling.

Previous observational studies of the Arabian Sea mixed layer have been hampered by a lack of data, and variously attribute different physical processes as being dominant in each of the two monsoon seasons. The dataset examined here is a coincident year-long timeseries of air-sea fluxes and upper ocean response, obtained from a surface mooring in the north central Arabian Sea. The main questions I address are: What physical processes are responsible for the deepening of the mixed layer in each monsoon? How much of the response can be understood as a local response to the local fluxes of momentum, heat, and salt? What role do nonlocal processes such as Ekman pumping, and horizontal and vertical advection play in the local balances of heat and salt?

\subsection{Outline}

The remainder of this chapter will present a context for the observations and analyses found in the rest of this document. Both local atmospheric forcing and nonlocal oceanic 
forcing are important at the data collection site. Their sources are examined in the following two sections, which focus on the monsoon and the resulting atmospheric forcing, and the general oceanic response in the Arabian Sea. The final section outlines the objectives of this study. The data collected and the processing applied to it are described in Chapter 2 , along with an overview of the oceanic response at the study site over one full monsoonal cycle. The focus then concentrates on the unusual twice-yearly cycle of mixed layer deepening and cooling that is the hallmark of the Arabian Sea. The winter northeast (NE) monsoon is a period of moderate winds and oceanic heat loss, leading to a primarily convectively-deepened mixed layer. This is examined in Chapter 3, where an assessment of the relative importance of local and nonlocal processes in the mixed layer evolution is made. The summer southwest (SW) monsoon is characterized by strong wind forcing and a moderate oceanic heat gain. The observed mixed layer deepening and cooling is primarily a function of wind-induced vertical mixing and entrainment, and is examined in Chapter 4. An assessment of how well the concerns outlined above have been addressed and what questions remain is presented in the concluding Chapter 5 .

\subsection{Atmospheric Forcing: The Monsoon}

The monsoon is perhaps the most dramatic and powerful of the atmospheric circulations, unrivalled in its geographic and temporal extent. The principal monsoon systems are shown in Fig. 1.1, and reach far across the equator from the winter to summer hemisphere in the Asian landmass-dominated eastern hemisphere. Focusing on the Indian Ocean, where the effects of the monsoon are strongest, one sees the hallmarks of monsoonal circulations: a seasonal reversal in the wind direction, and dry winters followed by wet summers. 

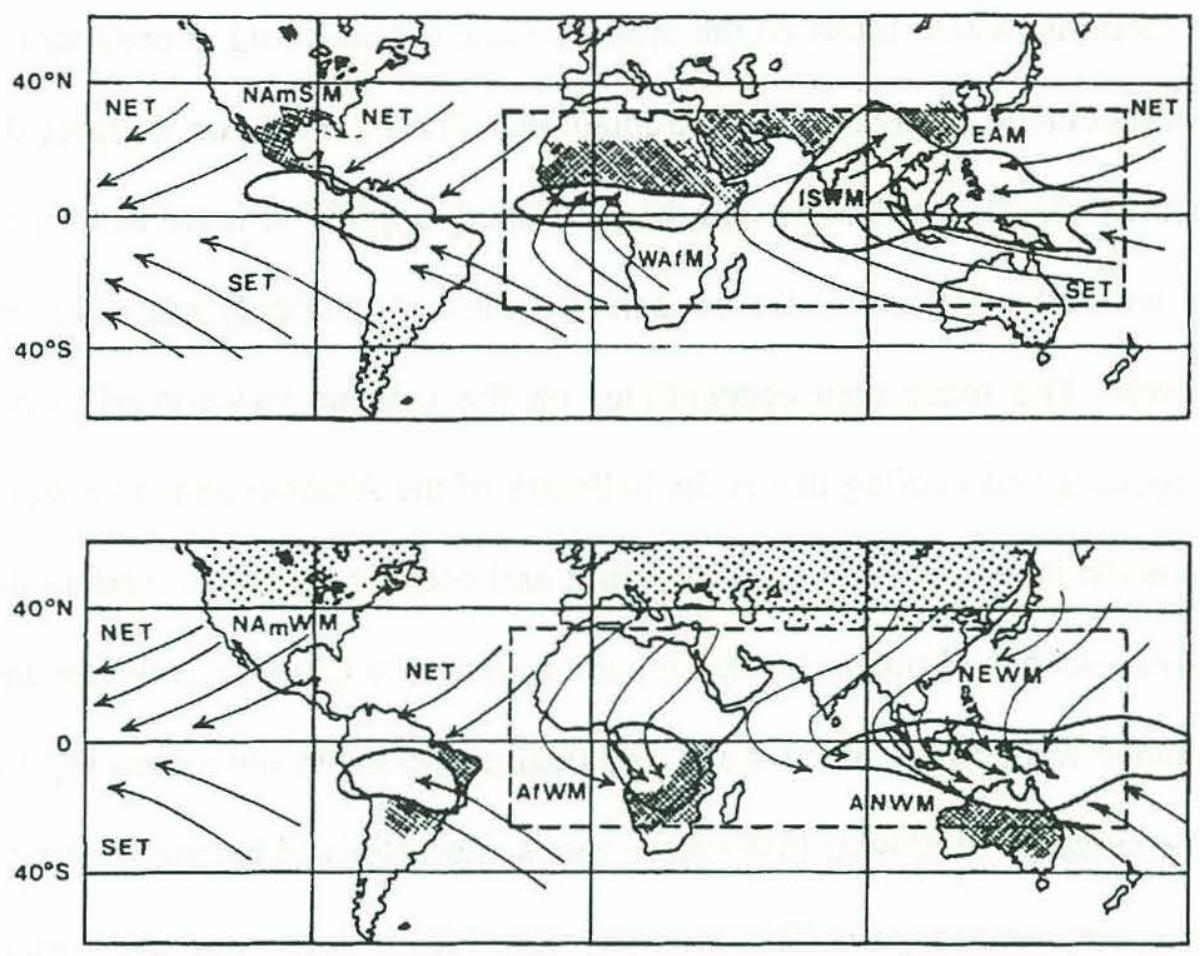

Figure 1.1 The principal monsoon systems (Webster, 1987) in the boreal summer (top) and winter (bottom). Shaded areas indicate maxima in rainfall. Cross-hatched areas indicate the highest surface temperatures, while stippling indicates cold surface temperatures. The mean winds are marked by arrows.

The major driving forces of the atmospheric monsoon circulations are differential heating compounded by effects of compressibility, moisture, and the Coriolis force. Differential solar heating of the earth's surface drives the general circulation of the atmosphere in the tropics first observed and explained by Hadley. The Hadley cell consists of heated and therefore less dense air rising at the equator in the intertropical convergence zone (ITCZ), drawing air from higher latitudes equatorwards. With the effect of rotation, this leads to the familiar northeasterly and southeasterly trade winds of the tropics. The highly different heat capacities of the ocean and dry land, which differ by many orders of magnitude (Webster, 1987), distort the Hadley circulation into the monsoon. The landmass 
of Asia dominates the hemisphere north of the Indian Ocean, and during the boreal summer, differential heating between land and sea creates a large pressure gradient at the surface that directs winds northward. Because of the compressibility of the atmosphere, this gradient is reversed at height. Moisture in the atmosphere adds another component to the strength of the monsoon. As water vapor condenses to form clouds, it releases the latent energy of vaporization, heating the atmosphere. In the rising air above the continental landmass, water vapor then not only condenses to form the characteristic monsoon rains, but provides an additional driving force through heating. The final ingredient in understanding the elementary monsoonal circulation is the rotation of the earth, which directs the winds into the broad patterns indicated in Fig. 1.1.

Over the Arabian Sea, which is bounded by the landmasses of East Africa, the Arabian peninsula and the Indian Subcontinent, and the Indian Ocean to the south, this leads to a seasonal cycle of cold, dry northeasterly winds during the winter (NE) monsoon, and warm, moist southwesterly winds during the summer (SW) monsoon. An unique feature of the southwest monsoon over the Arabian Sea is the development of a remarkably strong and steady jet first described by Findlater (1971). The Findlater jet (see Fig. 1.2) is bound in part by the topography of the East African highlands, and the surface winds under the jet in the Arabian Sea are some of the strongest and steadiest in the world (Knox, 1987), with speeds in excess of $15 \mathrm{~m} \mathrm{sec}^{-1}$ common.

During the SW monsoon, this strong jet imposes a wind stress curl that leads to Ekman upwelling to the north and west of the jet, off the coast of the Arabian peninsula, and Ekman downwelling to the south and east, in the central Arabian Sea. Hastenrath and Lamb (1979) note Ekman pumping velocities (derived from wind stress curls) implying an upwelling on the order of $1.1 \mathrm{~m} \mathrm{day}^{-1}$ near the Omani coast, and a downwelling on the order of $-1.1 \mathrm{~m} \mathrm{day}^{-1}$ in the south central Arabian Sea. The wind also drives coastal 


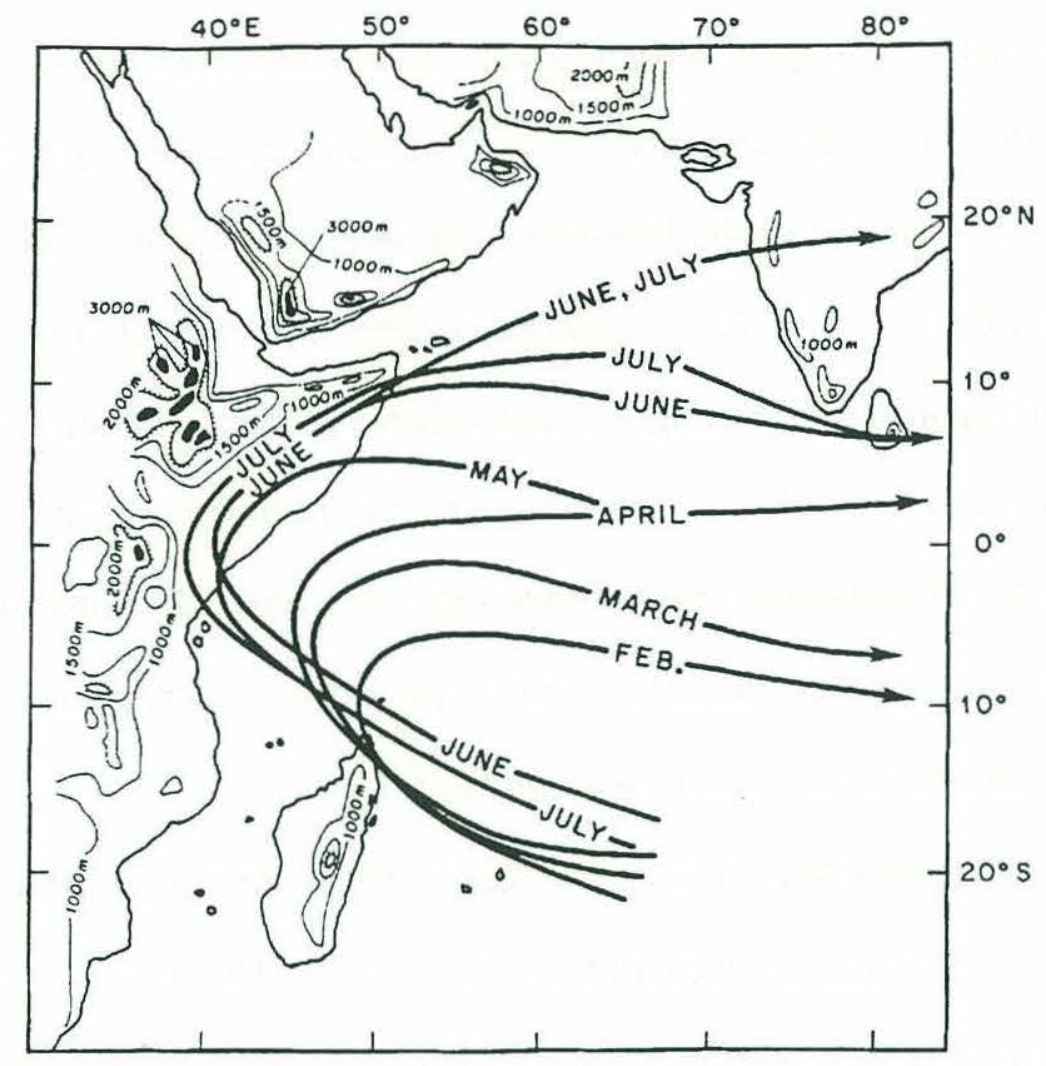

Figure 1.2 The climatological mean of the maximum in the Findlater Jet over the Arabian Sea, and its progression through the monsoon season (from Knox, 1987).

upwelling along the southern flank of the Arabian Peninsula. While the NW monsoon does not produce such a strong and well-defined jet, the wind direction is equally steady, and implied Ekman velocities in the central Arabian Sea are about $-0.2 \mathrm{~m} \mathrm{day}^{-1}$. The curl is negative, driving downwelling. The general circulation in the Arabian basin is controlled by this seasonal change in Ekman pumping, which also contributes to mixed layer depth.

Climatologies of air-sea fluxes over the Arabian Sea have been hampered by a lack of data, but nonetheless give a general impression of the relevant processes (see Fig. 1.3). At the site of the mooring in the north central Arabian Sea, one climatology (Hastenrath and Lamb, 1979) shows a net heat loss from the ocean during the SW monsoon (which peaks in June and July), thought to be due to a combination of reduced heat losses from cloud 

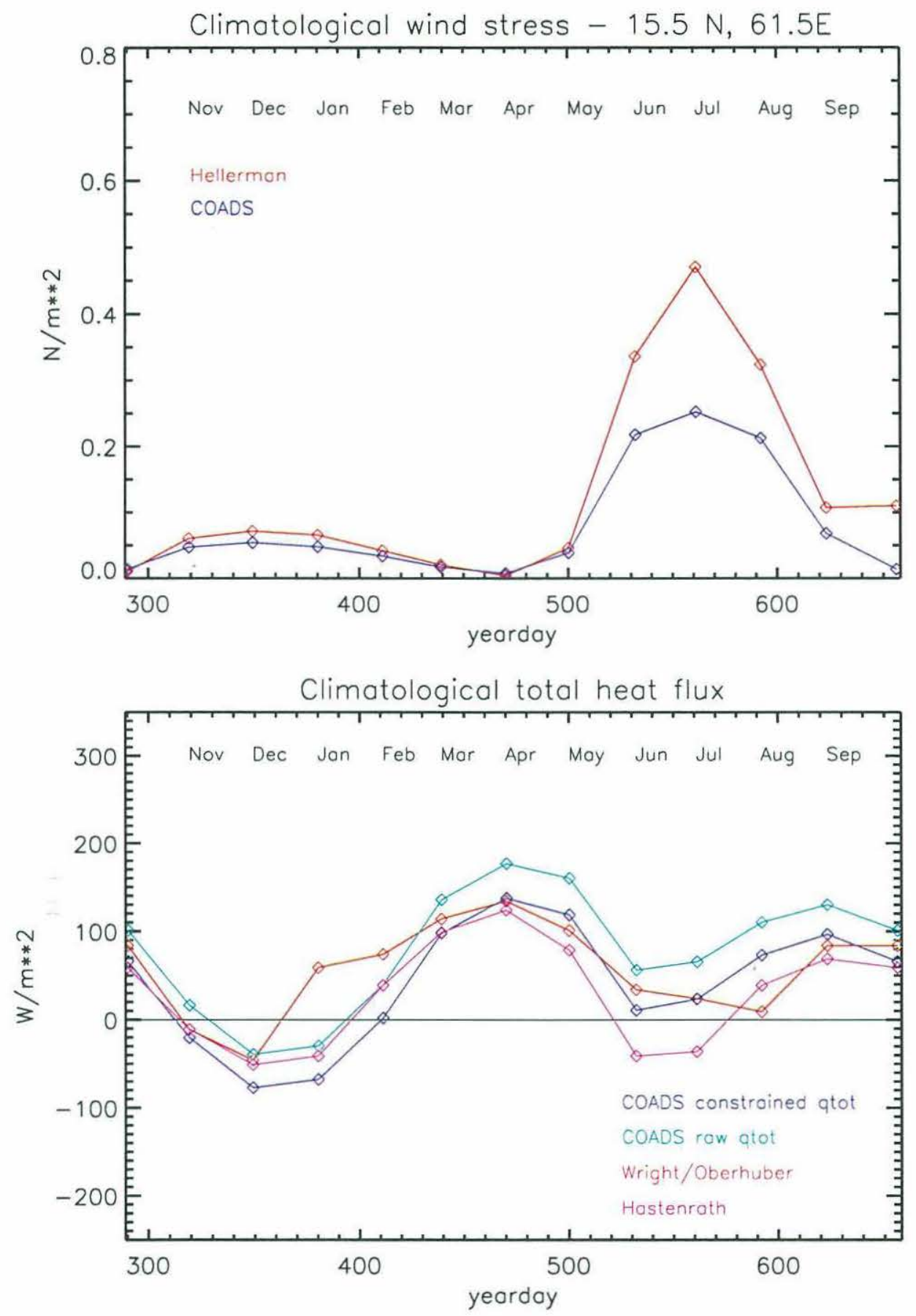

Figure 1.3 A summary of the wind stress (top) and total heat flux (bottom) over the Arabian Sea from different climatologies (Hellerman and Rosenstein, 1983; da Silva et al., 1994 (COADS), with heat flux based on the data or constrained so the global net is zero; Wright and Oberhuber, 1988; and Hastenrath and Lamb, 1980). The net oceanic heat gain has a signature twice-yearly cycle. During the NE monsoon (Nov-Dec) the winds are moderate and the ocean loses heat. During the SW monsoon (Jun-Jul) the winds are very strong. From Weller et al. (1997). 

cover and extremely strong winds increasing the latent and sensible heat losses. This has been hypothesized as the driver of the observed twice-yearly cycle of mixed layer deepening and cooling, which is in great contrast to the once-annual cycle typical in midlatitudes (see for example, Martin, 1985). But more recent climatologies (Wright and Oberhuber, 1988; da Silva et al., 1994, see Fig. 1.3), show a net heat gain at the mooring site during the SW monsoon, and demand a different explanation for SW monsoon mixed layer cooling and deepening. By contrast, there is no doubt in the climatologies that the net heat flux is a loss during the NE monsoon, which peaks in December and January, driven by the cool and dry, but only moderately strong winds of the northeast monsoon. These lead to large latent and longwave heat losses, and an overall net heat loss.

The atmospheric forcing of the ocean during each monsoon season can be briefly summarized: during the winter NE monsoon, there is a net heat loss, the wind is moderately strong, and the wind stress curl drives a moderate downwelling in the northern part of the Arabian basin. During the summer SW monsoon, the winds are extremely strong and sustained, the surface heat gain by the ocean is reduced but positive, and strong wind stress curls drive upwelling in the northern part of the basin and downwelling to the south and east.

\subsection{The oceanic response: Arabian Sea circulation and climatology}

The dramatically changing forcing over the Arabian Sea leads to a dramatic response in the basin's western boundary current, the Somali Current. During the SW monsoon the northward flowing Somali current has a strong transport of 65 Sv, mostly confined to the

upper $200 \mathrm{~m}$, and reported currents up to $3.7 \mathrm{~m} \mathrm{sec}^{-1}$ (Schott, 1983; Swallow et al. 1983). During the NE monsoon, the surface current is southwards, but is weaker and more diffuse 


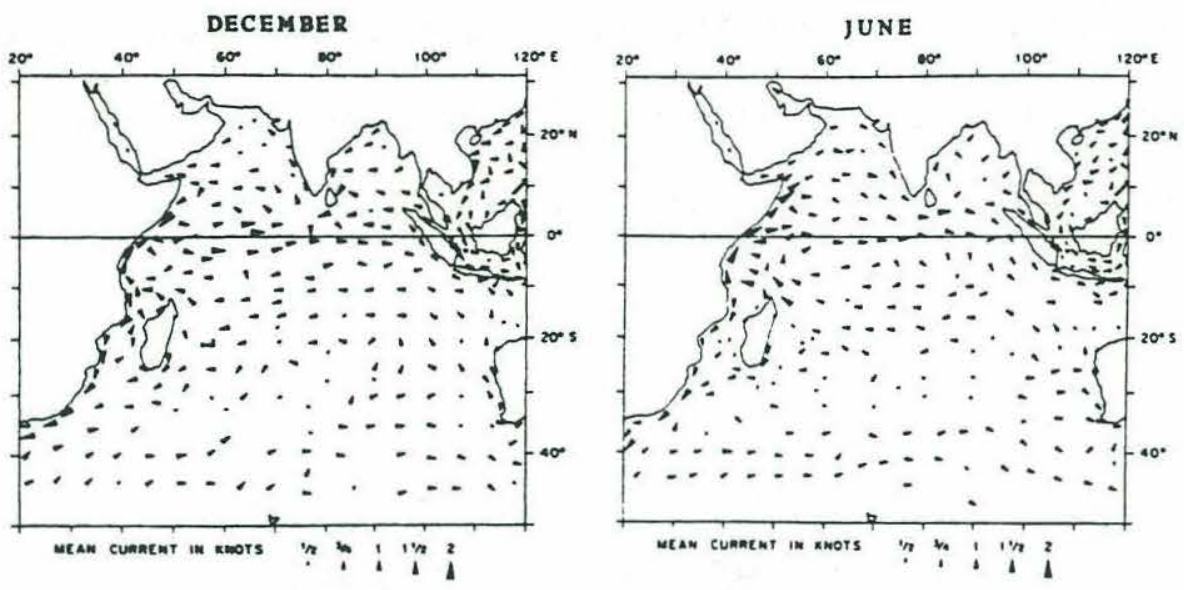

Figure 1.4 General circulation of the Arabian Sea from shipdrift data, at the height of the NE monsoon (December) and the SW monsoon (June). From Knox (1987)

(Knox, 1987, see Fig. 1.4). During the SW monsoon, this dynamic current system gives rise to a strong mesoscale eddy field, which has been reported around the basin from the Somali coast to Pakistan (Bruce, 1979; Brown et al., 1980; Evans and Brown, 1981, Bruce and Beatty, 1985; Simmons et al., 1988). The southwesterly winds during the summer monsoon also lead to upwelling along the coast of Oman. The result is persistent jets and squirts of cold, upwelled water which extend from the capes of the Omani coast, often extending far into the interior. These have been observed in satellite SST images, as well as surveyed by SeaSoar (Brink, Lee, Arnone, pers. comm.). During the NE monsoon, Bruce et al. (1994) have reported the persistent formation of a large anticyclonic eddy in the eastern Arabian Sea, with a subsequent westward propagation and decay. The mean current system and in particular the strong mesoscale eddy field, primarily generated during the SW monsoon, will play an important role in the upper ocean evolution at our site.

While affected by these large-scale circulatory patterns the upper ocean also has a more direct observable response to the wind in the form of Ekman transport convergences and divergences. Especially during the southwest monsoon, the effects of Ekman pumping can be seen in shallow mixed layers, on the order of $20-50 \mathrm{~m}$, and high biological produc- 
tivity to the north and west of the Findlater jet (Brock et al., 1992), and in deep mixed layers, up to $100 \mathrm{~m}$, to the south and east (Bauer et al, 1991), with reduced biological productivity. Bauer et al. (1991) found that Ekman pumping plays a first order role in the evolution of the mixed layer and productivity, during both the NE and SW monsoons (see Fig. 1.5).
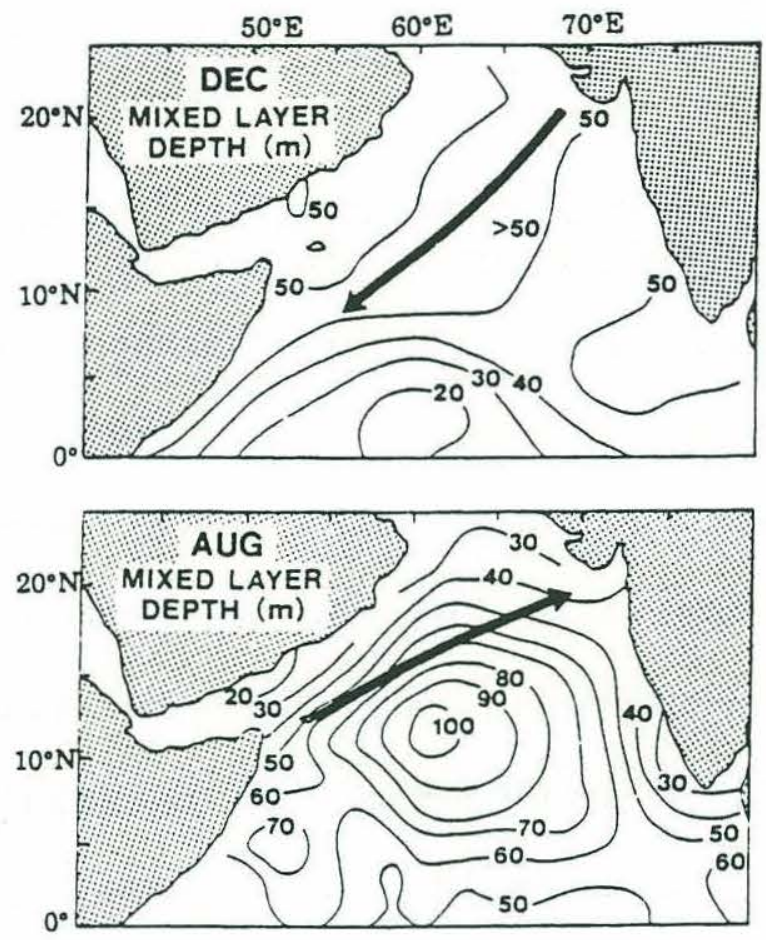

Figure 1.5 Climatological mixed layer depths in the Arabian Sea during each monsoon, after Rao et al. (1989). The arrow marks the maximum in the wind speed.

Upper ocean transports play an important role in the overall heat balance of the Arabian Basin, which reverses seasonally with the monsoon. Düing and Leetmaa (1980) estimated that during the SW monsoon there are three important components to the heat balance: a positive heat gain from the atmosphere, a negative northward heat flux across the equator (in the Somali current), and a heat loss due to upwelling which is the dominant 
term. Hastenrath and Lamb (1979) found that during the SW monsoon the Arabian Sea as a whole gains $0.5 \mathrm{PW}$ of heat from the atmosphere, but loses $0.83 \mathrm{PW}$ due to advection, leading to a net loss. During the NE monsoon, they also found a heat gain of $0.5 \mathrm{PW}$, of which $2 / 3$ is stored and $1 / 3$ advected out of the basin. In a modeling study by Wacongne and Pacanowski (1996) the Ekman transport played a large role in the meridional heat transport. During the SW monsoon an Ekman transport of $20 \mathrm{~Sv}$ across the equator was compensated by a cooler northward deep western boundary current at intermediate depths, implying upwelling as an important driver of the SW monsoon Arabian Sea cooling. During the NE monsoon a northward interior flow at the surface was compensated by southward deep western boundary currents in the deepest layer. Lee and Marotzke (1997) also found the dominant balance in the north Indian Ocean is between heat storage and heat transport convergences driven by the monsoon. Several layer models of the Arabian Sea and Indian Ocean (McCreary and Kundu, 1989; McCreary et al., 1993) suggest that the process of mixed layer entrainment mediates the large-scale heat balance.

The heat balance in the Arabian Sea has a strong potential for feedbacks with the atmospheric circulation. Because of comparable oceanic and atmospheric timescales in the Arabian Sea, Düing and Leetmaa (1980) suggested that there might be a feedback between upwelling and the monsoon winds. Gadgil et al. (1984) found in a climatological study that correlations exist between Arabian Sea sea surface temperatures and organized convection over the Indian Ocean, an indicator of rainfall. Studies using general circulation models (Kershaw, 1985; Shukla, 1987) have also shown that rainfall over India and the onset of the SW monsoon are affected by sea surface temperature anomalies in the Arabian Sea. In light of these studies, a better understanding of the evolution of the sea surface temperature and the heat content of the upper ocean in the Arabian Sea is a desirable goal. 


\subsection{Objectives}

In this thesis, I will focus first on answering some questions that arising from a direct look at the data: Is there net sea surface cooling during the southwest monsoon? What is the dominant physical process causing mixed layer deepening in each monsoon season?

. I will then examine what part of the observed upper ocean mixed layer deepening in each monsoon season is locally driven, and what part is nonlocally driven. To clarify these concepts, consider the Reynolds-averaged equation for the evolution of temperature:

$$
\frac{\partial T}{\partial t}+\mathbf{u} \cdot \nabla T+w \frac{\partial T}{\partial z}=\frac{\partial}{\partial z}\left(q-\overline{w^{\prime} T}\right)
$$

where $T$ is the local temperature, $\mathbf{u}$ is the horizontal velocity vector, $\nabla$ is the horizontal gradient operator, $w$ is the vertical velocity, $q$ is a downwards radiation of heat, and $\overline{w^{\prime} T}$ represents a turbulent transport of temperature. I ignore horizontal radiative and turbulent fluxes of heat, which are small compared to other processes in the open ocean. This equation is subject to boundary conditions at the air-sea interface. Processes defined as local include penetrative solar heating, vertical mixing due to vertical shear-flow instabilities, and surface buoyancy flux-driven convection. In locally-driven processes, the Eulerian temperature evolution $\partial T / \partial t$ is exactly balanced by the flux terms on the right hand side. Processes defined as nonlocal involve nonzero horizontal or vertical advection terms, and include the obvious horizontal advection of horizontal gradients, as well as vertical advection induced by Ekman pumping or other vertical velocities, like those induced by internal waves, tides, and longer-period waves. Internal waves and tides have periods shorter than the diurnal, and the signal is removed through lowpass filtering. 


\section{Chapter 2 Data and Processing}

This thesis focuses on data collected from a surface mooring and subsurface instruments deployed in the Arabian Sea during a full monsoon season. The first two sections of this chapter summarize the collection of the data. The processing used to derive the surface fluxes from the bulk atmospheric measurements is outlined in the third section. And finally, the last two sections give an overview of the surface forcing and the oceanic response at the site through the full monsoonal cycle.

\subsection{Mooring Location}

A five-mooring array was deployed in the central Arabian Sea at $61^{\circ} 30^{\prime} \mathrm{E}, 15^{\circ} 30^{\prime} \mathrm{N}$ in October 1994 from the Thomas G. Thompson (see Fig. 2.1). The central mooring, the one I focus on primarily, consisted of a surface buoy with a full suite of meteorological measurements and subsurface elements. It was recovered and redeployed with new instrumentation in the space of 50 hours in April 1995, then finally recovered in October 1995. The two western elements of the array (also recovered and reset after six months) were deployed by D. L. Rudnick, SIO, and consisted of surface buoys supporting a reduced set 


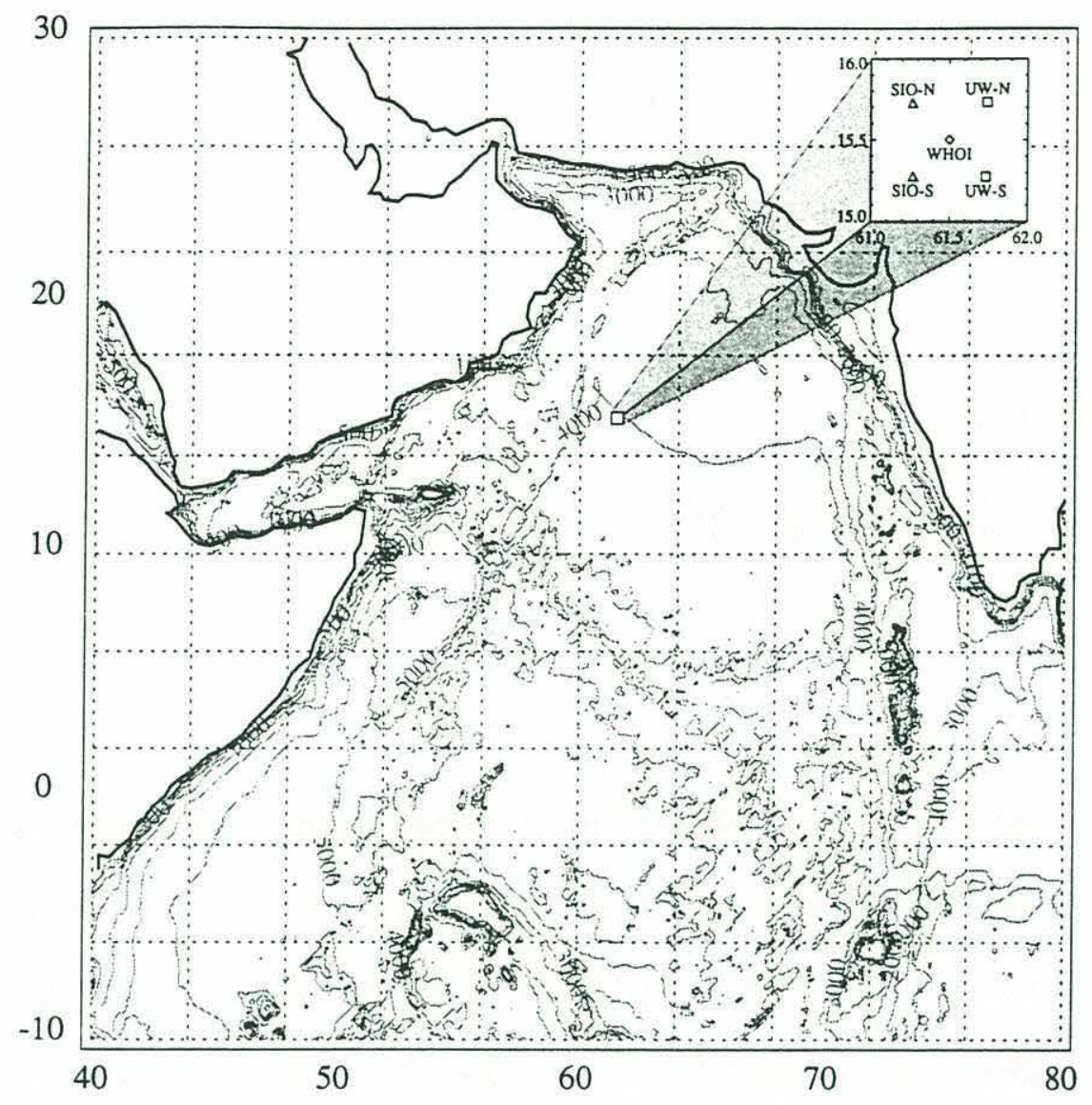

Figure 2.1 The Arabian Sea with the moored array location. Bathymetry is contoured in meters. The mooring elements created a square $50 \mathrm{~km}$ on a side.

of meteorological measurements, subsurface temperature recorders, and one subsurface acoustic doppler current profiler (ADCP). The two eastern elements were designed for one-year deployments, came from C. C. Eriksen, UW, and consisted of subsurface profiling current meters (PCM) which profiled from 30 to $200 \mathrm{~m}$ depth. The northern PCM mooring parted and was lost. The deployment lasted through a full seasonal cycle of both the northeast and southwest monsoons.

A location just south of the climatological mean maximum of the Findlater jet during the SW monsoon was picked to maximize the surface forcing that would be encountered. 


\subsection{Instrumentation}

The surface element of the central mooring was a $3 \mathrm{~m}$ discus buoy, shown in Fig. 2.2. The tower supported two redundant sets of meteorological instruments, one vector-averaging wind recorder (VAWR) and one improved meteorological (IMET) suite. These each measured wind speed and direction at a height of about $3.2 \mathrm{~m}$ above the waterline. Each also measured air temperature, relative humidity, and barometric pressure about $2.5 \mathrm{~m}$ above the mean waterline. Both measured the incoming shortwave and longwave radiation, and

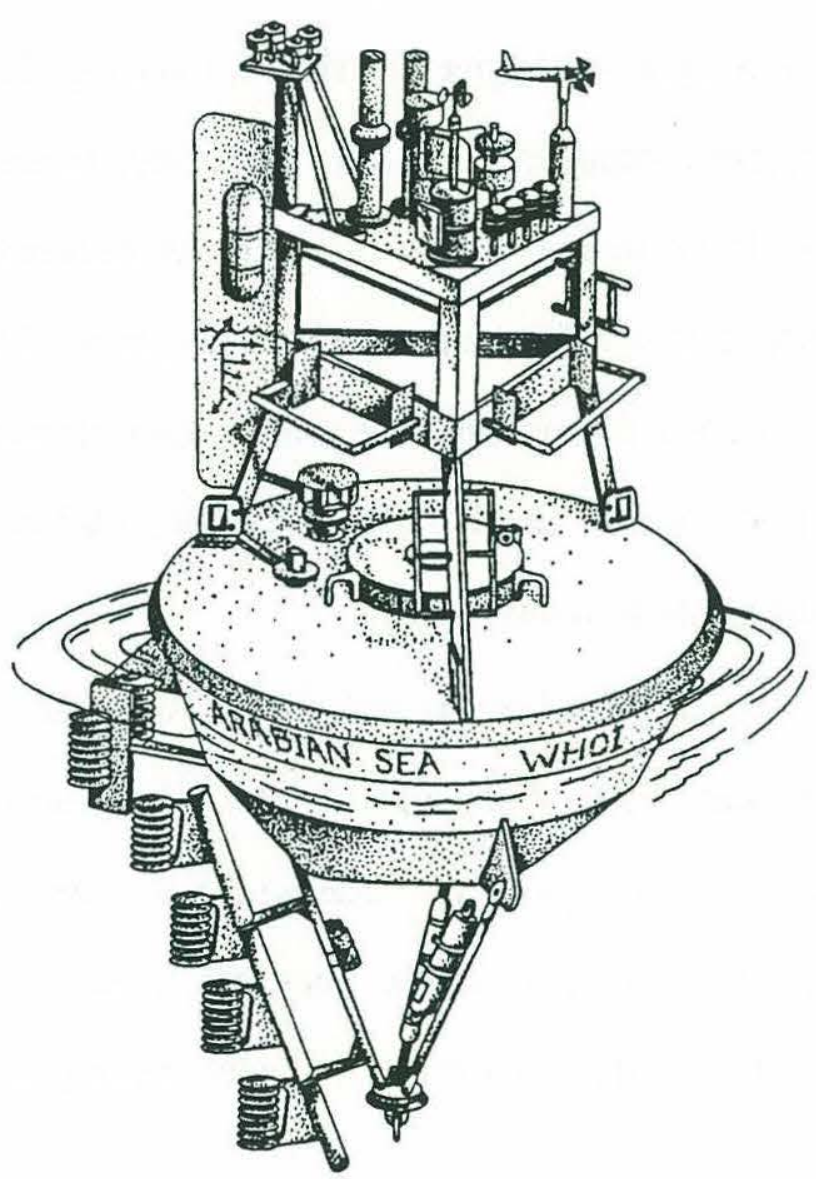

Figure 2.2 The Arabian Sea mooring surface element, a $3 \mathrm{~m}$ discus buoy. Instrumented with two sets of redundant meteorological sensor suites, including wind speed and direction, air temperature, relative humidity, barometric pressure, precipitation, and incoming shortwave and longwave radiation. The buoy also supported a subsurface array or temperature sensors attached to the buoy bridle. 
the IMET package included a precipitation gauge. An aspirated air temperature sensor was also included to investigate daytime radiative heating errors. Due to power limitations, aspiration stopped part way through each deployment, but an algorithm developed using the data that was collected (Anderson and Baumgartner, 1997) to correct the naturally aspirated sensors for radiative heating is applied here.

The subsurface instrumentation on the central mooring measured temperature, velocity and salinity in the upper $300 \mathrm{~m}$. Instrumentation included vector-measuring current meters (VMCM), moored CTDs (Seacats), temperature sensors (TPods), and multi-variable moored sensors (MVMS, from T. Dickey and J. Marra) which measured temperature, velocity, and salinity. A summary is given in Table 2.1 and Fig. 2.3. Subsequent analysis of SeaSoar data (Lee, pers. comm.) showed that large salinity inversions, generally density compensated, existed in the thermocline, which were not resolved by the spacing of the salinity sensors on the mooring. The temperature sensors provided good resolution of both the mixed layer and the main thermocline. The velocity measurements provided good coverage of the mixed layer for all of the deployment except for when the mixed layer was at its deepest, during the northeast monsoon.

Each instrument was calibrated before and after its six-month deployment. The estimated error in each measurement is detailed in Table 2.2. These estimates are based on calibrations, as well as intercomparisons made with the same instruments in previous experiments (Weller and Anderson, 1996). They are given for instantaneous values, although they are generally better at night when radiative heating does not compromise the sensors. 
Table 2.1: Subsurface instrumentation on the central mooring.

\begin{tabular}{|c|c|c|c|}
\hline Depth (m) & Temperature & Velocity & Salinity \\
\hline 0.17 & $\bullet$ & & \\
\hline 0.43 & - & & \\
\hline 0.92 & - & & \\
\hline 1.37 & - & & \\
\hline 1.41 & $\bullet$ & & \\
\hline 1.8 & - & & - \\
\hline 1.91 & - & & \\
\hline 2.4 & $\bullet$ & & \\
\hline 3.5 & 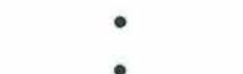 & & \\
\hline $\begin{array}{l}4.5 \\
5\end{array}$ & : & - & \\
\hline 10 & - & • & - \\
\hline 15 & - & - & \\
\hline 20 & - & & \\
\hline 25 & - & - & \\
\hline 30 & - & & \\
\hline 35 & - & - & - \\
\hline 40 & - & & \\
\hline 45 & - & - & \\
\hline 50 & - & & \\
\hline 55 & - & - & \\
\hline 60 & - & & \\
\hline 65 & $\bullet$ & - & - \\
\hline 72 & $\bullet$ & ? & - \\
\hline 80 & • & $\cdot$ & - \\
\hline 90 & • & & - \\
\hline $\begin{array}{l}100 \\
125\end{array}$ & . & & \\
\hline 150 & - & & - \\
\hline 200 & - & & - \\
\hline 225 & - & & \\
\hline 250 & - & & - \\
\hline 300 & - & & \\
\hline
\end{tabular}




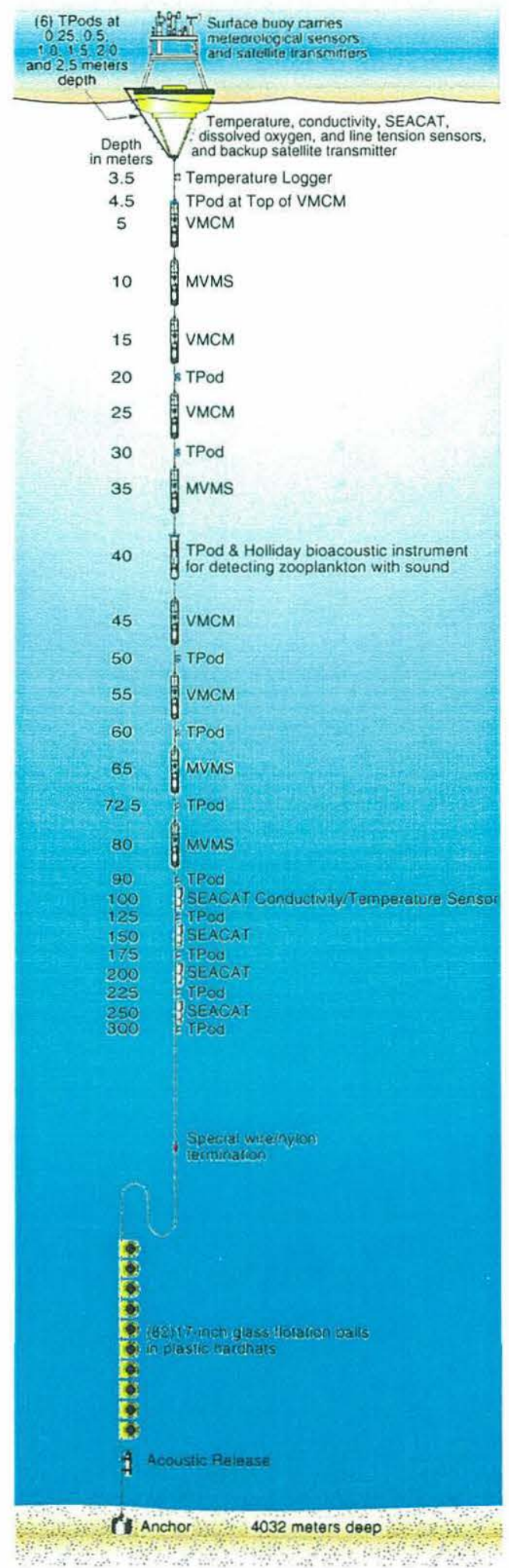

Figure 2.3 A schematic of the subsurface elements on the Arabian Sea mooring. The upper $300 \mathrm{~m}$ had multiple instruments measuring temperature, salinity, and velocity, as well as a variety of bio-optical parameters, not discussed here. 
Table 2.2: Estimated accuracy of measurements.

\begin{tabular}{ll}
\hline \multicolumn{1}{c}{ Variable } & \multicolumn{1}{c}{ Instantaneous accuracy } \\
\hline wind speed & $5 \%$ \\
wind direction & $10^{\circ}$ \\
barometric pressure & $0.5 \mathrm{mb}$ \\
air temperature & $0.2^{\circ} \mathrm{C}$ \\
sea surface temperature & $0.1{ }^{\circ} \mathrm{C}$ \\
incoming shortwave & $3 \%$ \\
incoming longwave & $10 \mathrm{~W} \mathrm{~m}^{-2}$ \\
relative humidity & $4 \%$ \\
subsurface temperature & $0.01{ }^{\circ} \mathrm{C}$ \\
subsurface salinity & $0.01 \mathrm{psu}^{-1}$ \\
subsurface velocity & $1 \mathrm{~cm} \mathrm{sec}^{-1}$ \\
\hline
\end{tabular}

\subsection{Bulk calculation of air-sea fluxes}

The air-sea fluxes of heat, momentum, and freshwater are calculated with a bulk formulation, since these fluxes are not measured directly. Here the formulation developed for the TOGA COARE experiment (see Fairall et al., 1996a) is used, which is valid under a large variety of forcing conditions. The essentials of the bulk flux formulation and Fairall et al.'s method are described below. The accuracy of the computed fluxes is presented in the last section below.

The net heat flux across the air-sea interface is computed as the sum of four components: the net shortwave radiation absorbed by the ocean, the net longwave heat loss due to radiation, the latent heat flux due to evaporation, and the sensible heat flux. The time series of these components is presented in Fig. 2.5.

The net shortwave radiation across the air-sea interface was calculated as 


$$
Q_{S W}=\left(1-\alpha_{s}\right) S W \downarrow
$$

where $\alpha_{s}$ is the albedo of the sea surface, calculated according to Payne's (1972) algorithm, and has a nominal value of 0.06 . The daily peak in the net shortwave heat flux was quite strong, about $1000 \mathrm{~W} \mathrm{~m}^{-2}$, although the daily average varied seasonally from about $200 \mathrm{~W} \mathrm{~m}^{-2}$ to $300 \mathrm{~W} \mathrm{~m}^{-2}$, with two yearly peaks due to the location in the tropics. Values were reduced during the cloud cover of the SW monsoon, and the deployment average was $243 \mathrm{~W} \mathrm{~m}^{-2}$.

- Incoming longwave radiation from atmospheric water vapor and clouds is measured on the buoy. The net longwave heat transfer across the air-sea interface is the sum of this measured incoming LW radiation and the outgoing radiation from the sea surface. The sea surface is assumed to radiate as a gray body, so the net longwave heat flux is

$$
Q_{L W}=\mathrm{LW} \downarrow-\varepsilon_{s s} \sigma T_{s k i n}^{4}-\left(1-\varepsilon_{s s}\right) L W \downarrow
$$

where $\varepsilon_{s s}$ is the longwave emissivity of the sea surface, taken to be $0.97, \sigma$ is the StefanBoltzmann constant, $T_{\text {skin }}$ is the sea surface skin temperature (computed according to Fairall et al.'s (1996b) warm layer/cool skin algorithm; more about this below), and the albedo of the sea surface is taken as one minus the emissivity. The net longwave heat loss from the sea surface was generally on the order of $-60 \mathrm{~W} \mathrm{~m}^{-2}$, but was greatly reduced during the cloud cover of the SW monsoon. The deployment average was $-58 \mathrm{~W} \mathrm{~m}^{-2}$.

The latent heat flux is due to the evaporation of water off the sea surface. The turbulent latent heat flux is defined by the Reynolds average, and is $Q_{\text {lat }}=\rho_{a} L_{\nu} \overline{w^{\prime} q^{\prime}}$, where $\rho_{a}$ is the density of air, $L_{v}$ is the latent heat of vaporization, $w^{\prime}$ and $q^{\prime}$ represent turbulent fluctuations of vertical velocity and specific humidity, and the overbar denotes a time average. The bulk representation is: 


$$
Q_{\text {lat }}=\rho_{a} L_{v} c_{e}\left|\mathbf{u}_{w}\right|\left(q_{s}-q\right)
$$

where $c_{e}$ is the latent heat transfer coefficient, $\mathbf{u}_{w}$ is the average wind at the reference height, and $q_{s}$ is the saturation specific humidity at the air-sea interface. The latent heat transfer coefficient is a nonlinear and semi-empirical function of the wind speed, atmospheric stability, surface roughness, and measurement height, and is computed using the Fairall et al. (1996a) algorithm. The latent heat flux was strong during the NE monsoon, on the order of $-200 \mathrm{~W} \mathrm{~m}^{-2}$ due to reasonable winds and low relative humidity, but despite stronger winds it was reduced during the SW monsoon as the air became saturated, ranging between -50 and $-150 \mathrm{~W} \mathrm{~m}^{-2}$. The deployment average was $-122 \mathrm{~W} \mathrm{~m}^{-2}$.

The sensible heat flux, due to direct conduction of heat from the atmosphere into the ocean, can be written in turbulent flux form as $Q_{\text {sens }}=\rho_{a} C_{p a} \overline{w^{\prime} T}$, where $C_{p a}$ is the heat capacity of air, and $T$ represents a turbulent fluctuation of temperature. The bulk representation is

$$
Q_{\text {sens }}=\rho_{a} C_{p a} c_{h}\left|\mathbf{u}_{w}\right|\left(T_{\text {skin }}-\theta\right)
$$

where $c_{h}$ is the sensible heat transfer coefficient and $\theta$ is the potential temperature of the air directly above the interface, corrected for reference height. The Fairall et al. (1996a, 1996b) algorithm again estimates the transfer coefficient, as well as the skin temperature of the ocean. The sensible heat flux ranged from values of about $-10 \mathrm{~W} \mathrm{~m}^{-2}$, during the NE monsoon as cooler continental air flowed over the ocean, to about $+10 \mathrm{~W} \mathrm{~m}^{-2}$ during the SW monsoon, as warm oceanic air passed over a newly entrained, cooler sea surface. The average over the deployment was $-1.5 \mathrm{~W} \mathrm{~m}^{-2}$.

The net heat flux is then the sum of these components,

$$
Q_{n e t}=Q_{s w}+Q_{l w}+Q_{l a t}+Q_{\text {sens }}
$$


There is an additional effect due to the heat flux of rainfall, but this is neglected here (although not in the freshwater budget) since the rainfall amount was so small. Daily averages of the net heat flux varied between about $-200 \mathrm{~W} \mathrm{~m}^{-2}$ and $+250 \mathrm{~W} \mathrm{~m}^{-2}$, although the balance was strongly towards an oceanic heat gain, with a deployment average of +61 $\mathrm{W} \mathrm{m}^{-2}$.

The wind stress exerted at the air-sea interface can be written in turbulent form, $\tau=\rho_{a} \overline{w^{\prime} u_{w}{ }^{\prime}}$, where $u_{w}{ }^{\prime}$ is a turbulent fluctuation of the magnitude of the horizontal wind. The bulk formulation is

$$
\tau=\rho_{a} c_{d} \mathbf{u}_{w}\left|\mathbf{u}_{w}\right|
$$

where $c_{d}$ is the stress transfer coefficient, also known as the drag coefficient. In this case, and in all cases above, $\mathbf{u}_{w}$ refers to the wind speed at the reference height with respect to the surface current. The VMCM measured velocity at $5 \mathrm{~m}$ was subtracted from all wind measurements. The drag coefficient was again calculated using the TOGA COARE bulk flux algorithm. During the NE monsoon, daily averaged values of the wind stress ranged from 0.1 to $0.2 \mathrm{~N} \mathrm{~m}^{-2}$, while during the $\mathrm{SW}$ monsoon they peaked as high as $0.6 \mathrm{~N} \mathrm{~m}^{-2}$. The deployment average was $0.1 \mathrm{~N} \mathrm{~m}^{-2}$.

The freshwater flux through the air-sea interface is the difference between a gain through precipitation, which was measured directly, and a loss through evaporation. The evaporative loss is calculated from the latent heat flux, and is

$$
E=\frac{Q_{\text {lat }}}{\rho_{0} L_{v}}
$$

where $\rho_{0}$ is the density of seawater and the latent heat of vaporization $L_{v}$ is taken to be a constant $2.434 \times 10^{6} \mathrm{~J} \mathrm{~kg}^{-1}$. The freshwater flux is then just $E-P$, expressed as a veloc- 
ity.

The Fairall et al. (1996a) bulk flux algorithm was developed and tuned through direct comparisons with inertial-dissipation methods of measuring fluxes in the warm pool region of the equatorial Pacific. Weller and Anderson (1996) reported conditions during TOGA COARE with wind speeds that range from $0.01-17.17 \mathrm{~m} \mathrm{sec}^{-1}$, comparing favorably with the $0.04-18.34 \mathrm{~m} \mathrm{sec}^{-1}$ recorded in the Arabian Sea, and similar ranges in air temperature and relative humidity. The largest difference in ranges come from the SST. Weller and Anderson computed estimates of month-long accuracies in the air-sea fluxes for low wind and high wind situations, reported in Table 2.3, adjusted for the level of calibrations and intercomparisons used in this experiment.

Table 2.3: Estimates of the month-long accuracy in the calculated air-sea fluxes, after Weller and Anderson (1996).

\begin{tabular}{lll}
\hline \multicolumn{1}{c}{ Flux } & \multicolumn{1}{c}{ low-wind accuracy } & \multicolumn{1}{c}{ high-wind accuracy } \\
\hline wind stress magnitude & 0.001 & $0.002 \mathrm{~N} \mathrm{~m}-2$ \\
wind stress direction & 5 & $2 \circ$ \\
net shortwave & 6 & $6 \mathrm{~W} \mathrm{~m}^{-2}$ \\
net longwave & 4 & $4 \mathrm{~W} \mathrm{~m}^{-2}$ \\
latent & 2 & $5 \mathrm{~W} \mathrm{~m}^{-2}$ \\
sensible & 1 & $1 \mathrm{~W} \mathrm{~m}^{-2}$ \\
net heat & 13 & $16 \mathrm{~W} \mathrm{~m}^{-2}$ \\
\hline
\end{tabular}

\subsection{Overview of Atmospheric data}

The measured atmospheric data is shown in Fig. 2.4, and the record is dominated by the signal of the two monsoon seasons, each with dramatically different forcing.

The mooring was deployed not long before the start of the winter northeast monsoon. After an initial storm in late October, which is noted by spikes in the wind speed, humid- 

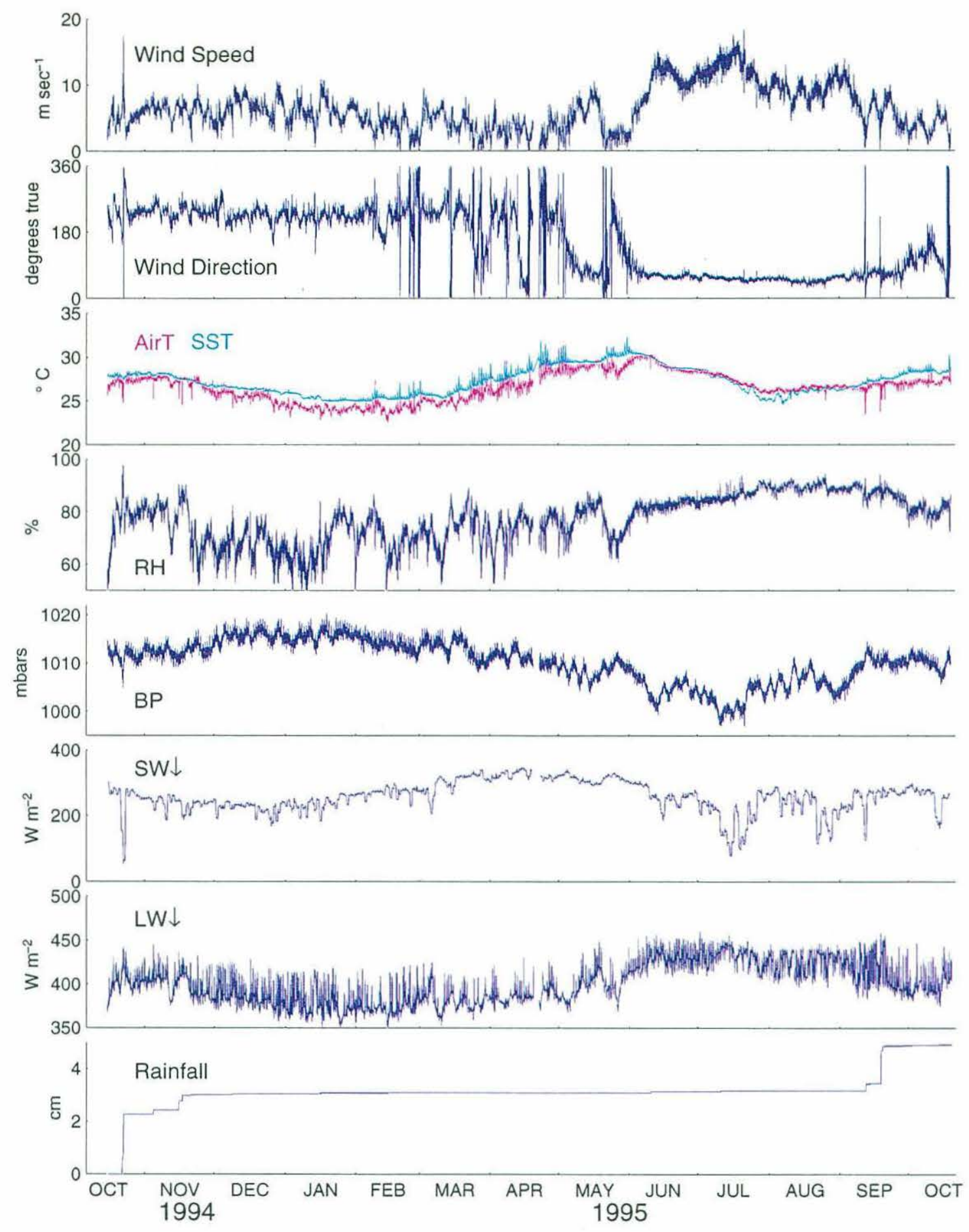

Figure 2.4 The measured meteorological variables for the full deployment of the Arabian Sea surface mooring. From top to bottom: first, the wind speed and direction, then air temperature (after correction for radiative heating) and sea surface temperature (at $17 \mathrm{~cm}$ depth). Then the relative humidity, barometric pressure, daily-averaged incoming shortwave radiation, incoming longwave radiation, and cumulative rainfall. 
ity, barometric pressure, solar radiation, and rainfall records, the first few months of the deployment are dominated by the NE monsoon. The wind speeds during this period, which extends roughly from October 1994 through January 1995 at the mooring site, were moderately strong, ranging from about $5-10 \mathrm{~m} \mathrm{sec}^{-1}$. But they were not completely steady, showing a modulation, with periods of higher winds lasting about five days appearing approximately every 15-20 days. The direction, which marks the monsoon seasons well, was very steady and from the northeast, with a mean true direction of 226 degrees. During this period, the relative humidity was fairly low and the barometric pressure high, indicative of drier continental air being forced off the Asian continent. The air temperature and sea surface temperature both dropped during this period, although SST remained higher than the air temperature throughout. The slightly reduced levels of incoming solar radiation are due primarily to reduced levels of insolation in the winter season, rather than cloud cover. And finally, the reduced levels of downwelling longwave radiation are in keeping with the low cloud cover and relatively low moisture the atmosphere.

From February through May 1995, intermonsoon conditions predominated. The wind speed reduced and wind direction shows variations that tend to remain on the northeastsouthwest axis, but exhibit clockwise rotations due to low pressure systems to the south, which generally move westward (Kindle, pers. comm.). The air temperature and sea surface temperature both climb during this period, with evidence of strong diurnal heating.

The southwest monsoon dominates the record from May through the end of September 1995 , although the start date of the SW monsoon is difficult to pin down. Certainly at the beginning of May the stronger (up to $10 \mathrm{~m} \mathrm{sec}^{-1}$ ) and steady southwesterly direction of the winds, along with increased humidity, would indicate a beginning of the monsoon, but it appears to falter for the first week of June. By the second week of June, however, the southwest monsoon has reestablished itself, and does not relinquish its hold until the end 
of September. Wind speeds are strong, ranging from $10-15 \mathrm{~m} \mathrm{sec}^{-1}$, with gusts up to 18 $\mathrm{m} \mathrm{sec}^{-1}$. The direction is extremely steady from the southwest, with a mean true direction of 52 degrees. The air temperature and sea surface temperature again diminish, although this time the sea surface is for the most part cooler than the air temperature. The relative humidity is very high, hovering near $90 \%$, and the barometric pressure is reduced, consistent with maritime air being pulled towards the Asian continent. The incoming solar radiation record is sharply reduced, in part due to the natural yearly cycle which has two peaks in the tropics, but primarily showing the strong influence of clouds (Weller et al., 1997). The high levels of moisture in the atmosphere are further reflected in the high levels of incoming longwave radiation. Precipitation during this period at the site is negligible.

The record ends going into another intermonsoon period, as the winds relax, and the air and sea surface temperature recover somewhat before the start of a new cycle.

The computed air-sea fluxes of heat and momentum are shown as daily averages in Fig. 2.5. During the northeast monsoon, a combination of factors led to a net heat loss from the ocean. The strongest latent heat losses of the deployment are observed during this period, driven by the moderate flow of dry air over the sea surface. The sensible heat loss, while small as always contributes to this heat loss as the ocean is warmer than the cold continental air. The net shortwave heat flux is weak, due to reduced winter insolation. And the net longwave heat flux remains strong as there is little moisture in the atmosphere to reduce it. The heat loss is modulated by the characteristic modulation of the wind speed. This can also clearly be seen in the wind stress record, as broad peaks of wind stress approaching $0.2 \mathrm{~N} \mathrm{~m}^{-2}$ are followed by periods of reduced wind stress.

As mentioned before, a net heat loss at this site has been reported during the southwest monsoon (Hastenrath and Lamb, 1979), although this is disputed by other climatologies. The record shows that at the mooring site, the net heat flux stays positive for the large 

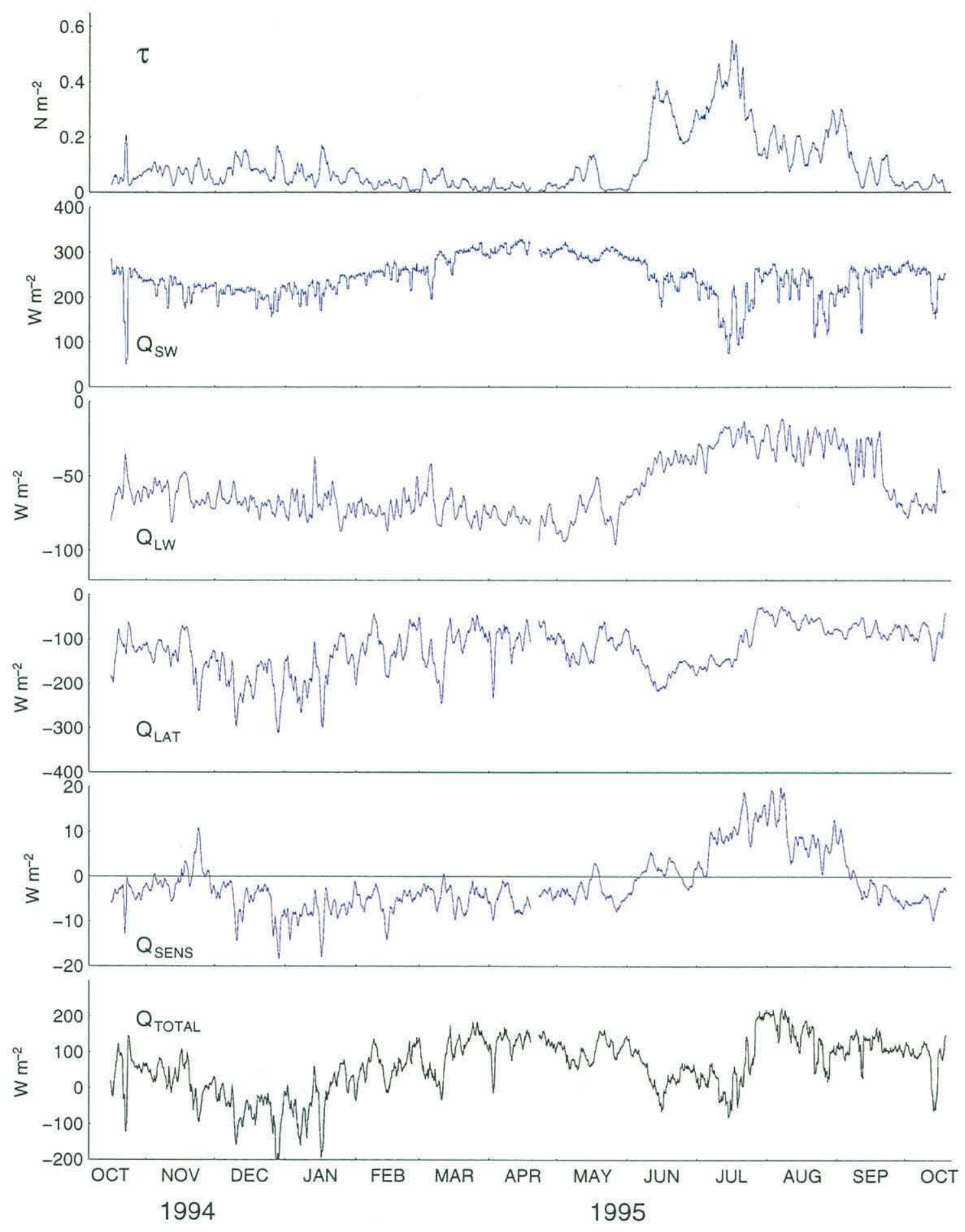

Figure 2.5 The calculated air-sea fluxes of momentum and heat at the Arabian Sea mooring site for the entire deployment. From top to bottom: the wind stress, the net shortwave heat flux, the net longwave heat flux, the latent heat flux, the sensible heat flux, and finally the total heat flux. All have been passed through a daily running average. 
majority of the southwest monsoon. Despite extremely strong winds, the latent heat loss is quite low due to the high humidity of the air. While cloud cover does lead to a reduced shortwave heat flux, the net longwave heat flux is held very low due again to the high atmospheric water vapor content. With a sensible heat flux now reversed due to the reversal in the air-sea temperature gradient, the net heat flux is primarily positive, with only two short periods of reversal in the daily average. The average heat flux over the whole SW monsoon period (May-September) is $62 \mathrm{~W} \mathrm{~m}^{-2}$ into the ocean.

\subsection{Overview of Oceanic response}

The subsurface record of temperature, salinity, and density during the full year deployment is presented in Fig. 2.6. Like the atmospheric record, it is dominated by the signal of the two monsoon seasons. Unlike the atmospheric record, the primary manifestation of the monsoon, a cooling and deepening of the mixed layer, is very similar in each season.

The dominant signal in the mixed layer depth record is the twice-annual cycle of deepening and shoaling. During the NE monsoon, which peaks in November, December and January, the mixed layer, at least as defined by temperature, deepens from approximately $20 \mathrm{~m}$ to a maximum of nearly $100 \mathrm{~m}$. As the winds die down and the net heat flux reverses sign into January, the mixed layer begins to shoal quickly, as the upper water column restratifies. The residual deep mixed layer is left behind, underneath the newly formed mixed layer. During the intermonsoon season the mixed layer remains shallow as weak winds and a strong positive heat flux strongly stratify the upper part of the water column. When the SW monsoon picks up in June, the mixed layer again deepens, this time only reaching a maximum depth of about $75 \mathrm{~m}$. Although winds continue to blow strongly, the mixed layer shoals slowly through the end of July and into August in an advective event. 

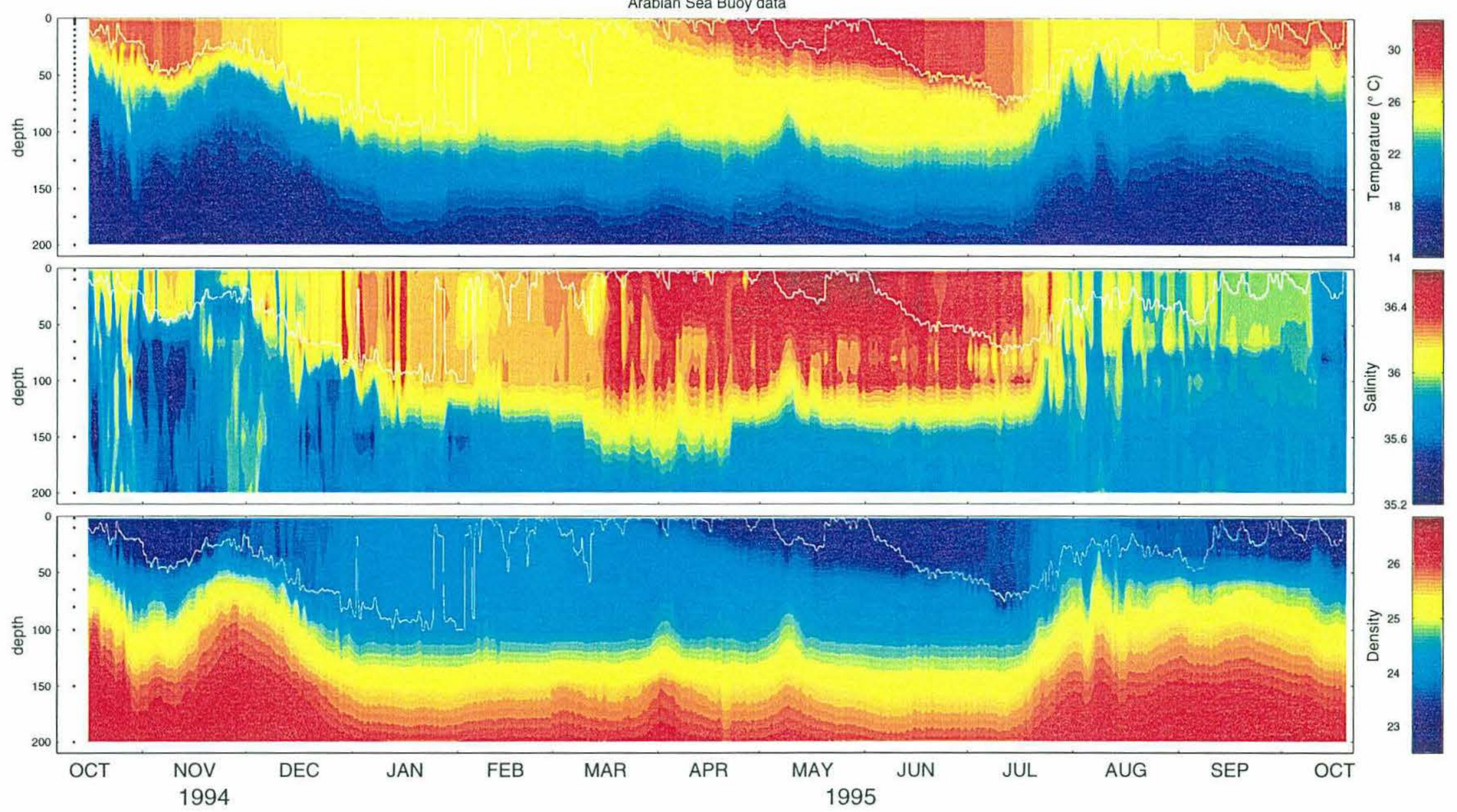

Figure 2.6 The upper ocean in the Arabian Sea. Contours of (from top): temperature, salinity, and density anomaly as they evolved in time, lowpass filtered to remove the tides. The mixed layer, as defined by a $0.1^{\circ} \mathrm{C}$ difference from the SST, is plotted in white. Dots at left indicate sensor depths. 
Intermonsoon conditions return in September, and the mixed layer remains shallow for the rest of the deployment.

The temperature of the mixed layer cools during each monsoon season as the mixed layer deepens. During each intermonsoon period, as the water column restratifies and the mixed layer remains shallow, the temperature climbs. The subsurface temperature gradient, which dominates the calculation of density, shows a remarkable vertical migration throughout the year. During the mixed layer deepening phase of the NE monsoon, the thermocline deepens, in concert with the base of the mixed layer. It remains deep, without much apparent vertical motion, through the intermonsoon leading into the SW monsoon. It does not move as the SW monsoon mixed layer deepens, but does migrate upwards, concurrent with the mixed layer shoaling at the end of July and into August.

The salinity signal is marked by patchiness, following the small horizontal and vertical scale over which salinity varies. The sensor spacing does not fully resolve all the structure in the salinity. The mean conditions over the year are strongly evaporative, and the salinity of the mixed layer does generally increase through the NE monsoon, the intermonsoon, and into the SW monsoon. Then an abrupt freshening of the mixed layer occurs, concurrent with the slow shoaling of both the mixed layer and the thermocline. The density signal is largely dependent on the temperature, and follows a similar evolution.

The subsurface velocity record is presented in Fig. 2.7 and in Fig. 2.8. The general velocities are quite strong, of the order of $1 \mathrm{~m} \mathrm{sec}^{-1}$ during the NE monsoon and in the latter half of the SW monsoon. The strongest velocities are roughly correlated with the observed changes in the thermocline depth, suggesting that these could be the result of horizontal advection of gradients. The velocities in the NE monsoon are remarkably coherent throughout the water column, largely not the local response to the wind, but a velocity mode that is nearly barotropic. Intermonsoon periods have much smaller velocities in gen- 


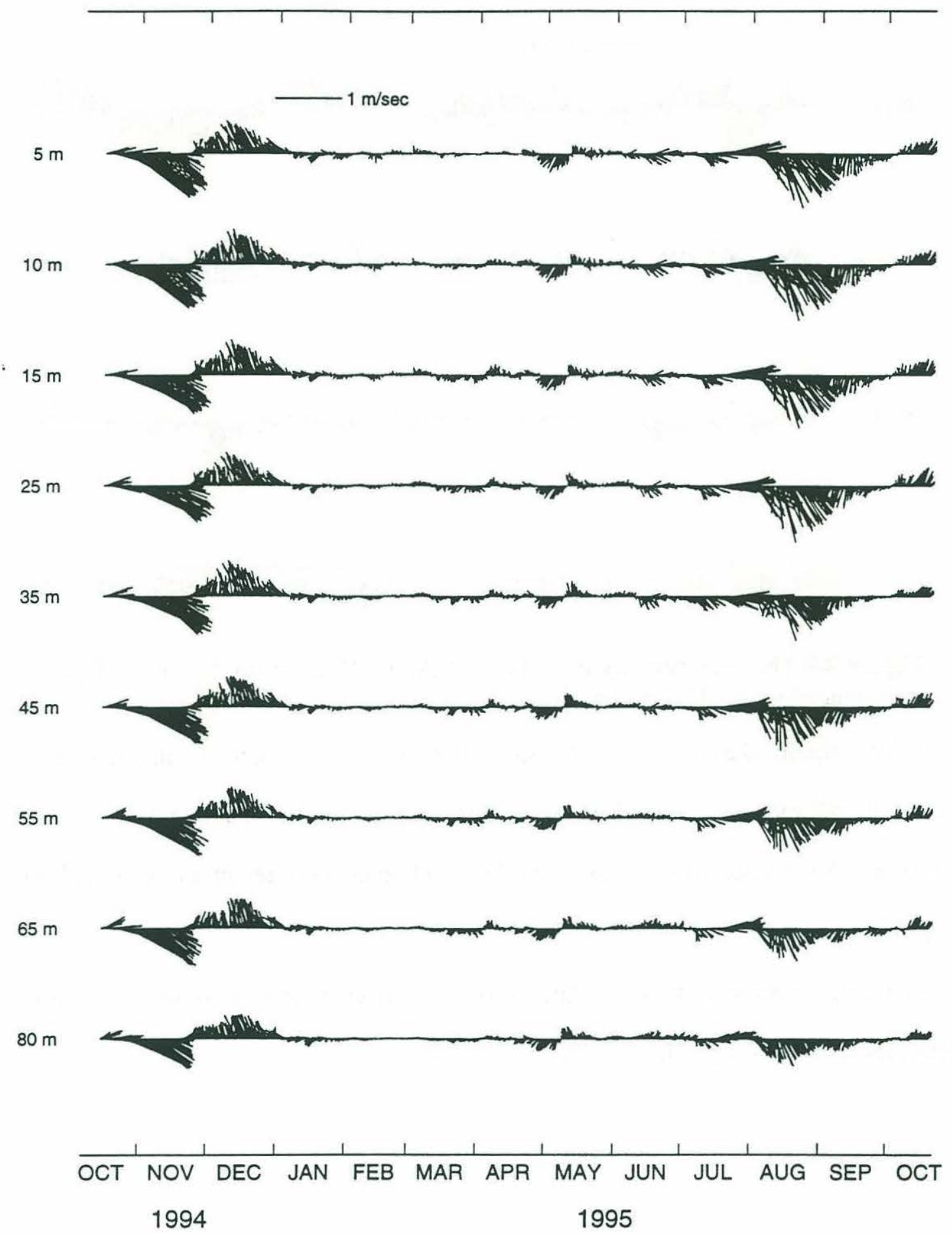

Figure 2.7 The velocity record in the upper ocean as stickplots. North is up, and velocities have been daily averaged. 


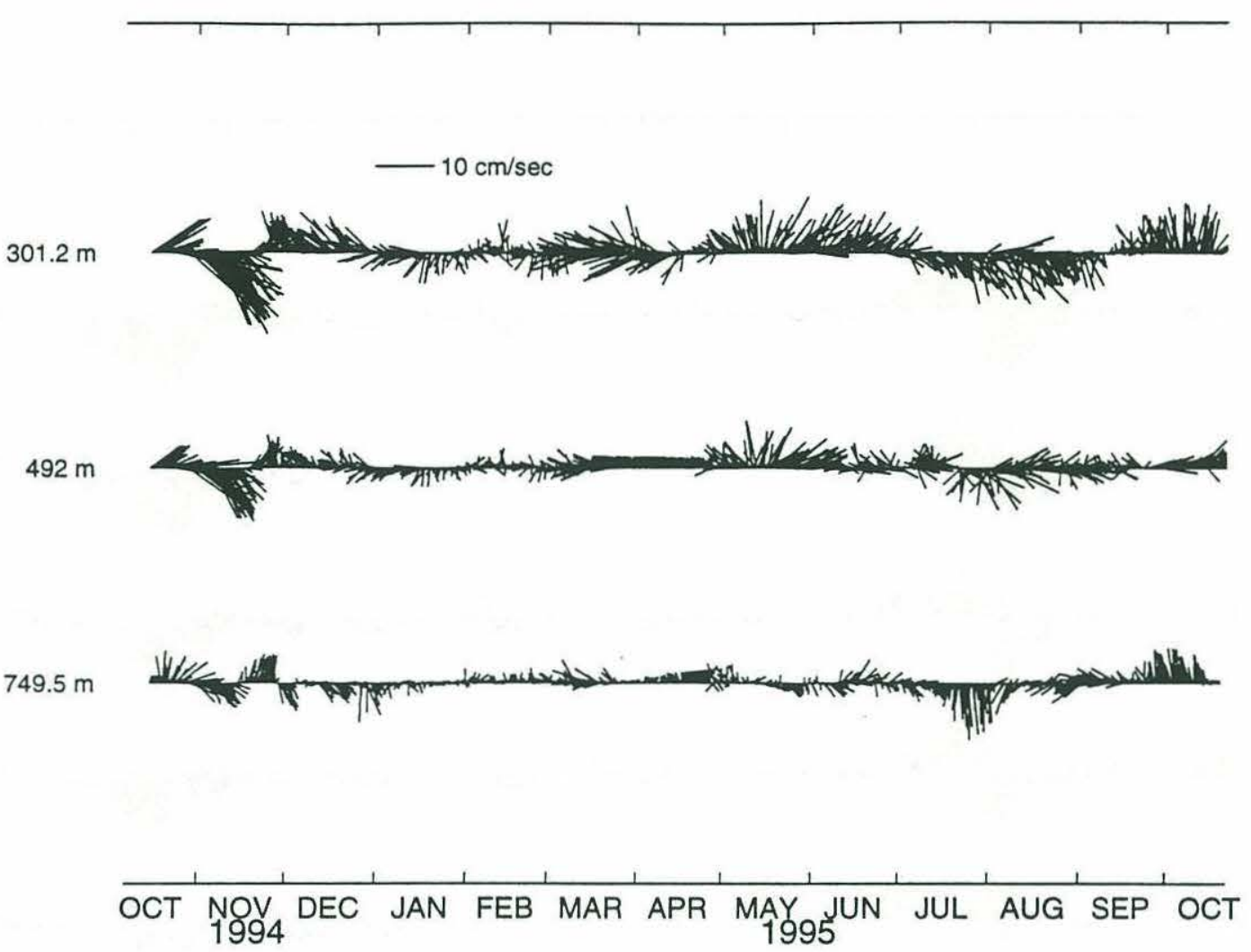

Figure 2.8 The deep velocity record as a stickplot. North is up. These VMCMs were placed on the UW-S mooring.

eral. The velocity during the SW monsoon is more depth dependent than that observed during the NE monsoon, implying that a larger part of it is the local response to the wind. But again, the strongest velocities are tied to the biggest changes in the water column, in August.

Our task is now to examine in further detail the deepening and cooling seasons of the mixed layer responding to the NE and SW monsoons. 


\section{Chapter 3}

\section{Northeast Monsoon}

The northeast, or winter, monsoon is in some ways the more quiescent of the two. The winds are quite steady in direction, but are moderate. The winter Asian landmass is the progenitor of what the winds carry: relatively cool and dry air. Without an insulating blanket of atmospheric moisture the longwave heat loss at the sea surface is high, and the latent heat loss is large as evaporation reaches is at its yearly peak. This makes the overall net heat flux across the air-sea boundary destabilizing in the ocean, and combined with the addition of a salt flux into the ocean, the daily average of the buoyancy flux is always destabilizing.

The aim here is to look at the observed deepening and cooling of the upper ocean during the northeast monsoon, and determine what physical processes, local and nonlocal, are primarily responsible. A six week period of the year-long time series is extracted and examined in isolation. This is a period of characteristic northeast monsoon forcing, and the period over which the majority of the deepening occurs. The approach will be to run a series of tests, first to determine the dominant local mechanism driving deepening, then to test the idea that the upper ocean evolution is a local response to the local surface forcing. 
Other mechanisms of upper ocean forcing which have been postulated to be important include vertical motions due to Ekman pumping and other vertical velocities and horizontal advection of gradients in properties. The first section of this chapter frames the upper ocean in its larger-scale oceanic background. The next two sections examine the local forcing and characterize the upper ocean response. Then the dominant local mechanism for deepening is examined through a look at the surface forcing. The impact of local and nonlocal processes are then analyzed through budgets and one-dimensional modeling. Finally the results are summarized in the last section. One finds that although the upper ocean evolution is not entirely inconsistent with a local response, horizontal advection is crucial in understanding the mixed layer depth evolution. The primary role that horizontal advection plays here is not in direct fluxes of heat and salt into the mixed layer, but in advecting a changing mixed layer depth past the site.

Strict monsoon seasons are difficult to define, although perhaps the clearest indication is the steadiness in the direction of the wind. By that definition (see Fig. 2.4), the northeast monsoon would extend from the last week of October through mid-January. Since my interest here is in the deepening and cooling of the mixed layer in response to the monsoon, I restrict my view to a shorter period of time which encompasses the majority of this response. In mid-November, the sea surface temperature (SST) has already cooled slightly to $27.5^{\circ} \mathrm{C}$ from the deployment SST of $28^{\circ} \mathrm{C}$. But a sustained temperature drop to $25.5^{\circ} \mathrm{C}$ occurs through the beginning of January, at which point the SST levels off and slowly begins to climb again. The mixed layer depth, as defined by a $0.1^{\circ} \mathrm{C}$ difference from the SST, is relatively shallow in mid-November, with diurnal stratification reaching to within a few meters of the surface and nighttime values of the mixed layer depth around $30 \mathrm{~m}$ (see Fig. 2.6). By the beginning of January, the mixed layer has reached its northeast monsoon maximum depth of just under $100 \mathrm{~m}$, and after this periods of shallow diurnal stratification 
become more frequent and last longer, decreasing the mean mixed layer depth. To examine this period of deepening and cooling, I extract a six week period extending from November 20 through January 1.

\subsection{Oceanographic setting}

The northeast monsoon shares with the southwest monsoon the broad scale of forcing over the Arabian Sea, although the strength of the momentum forcing is much reduced. The mesoscale activity in the basin is largely generated during the more energetic SW monsoon (Kantha, pers. comm.), and the broad even forcing of the NE monsoon, including a diurnal restratification, appears to horizontally homogenize the mixed layer, reducing horizontal SST gradients. Satellite AVHRR imagery of the sea surface (Arnone, pers. comm.) shows broad horizontal homogeneity at the surface in the NE monsoon. A SeaSoar survey (Brink, Lee, pers. comm.) in September-October also revealed broad horizontal homogeneity in the mixed layer in a line extending from the Omani coast southeast past the mooring site into the central Arabian Sea. Before the moorings were set in October 1994, shortly before the NE monsoon season, an extensive XBT survey, covering a diamondshaped pattern $100 \mathrm{~km}$ by $100 \mathrm{~km}$ centered on the mooring site, revealed near-homogeneity in the horizontal direction at depths up to $300 \mathrm{~m}$. Observed gradients were smaller than $0.01{ }^{\circ} \mathrm{C} / \mathrm{km}$. While the mixed layer appeared to be horizontally homogeneous, the remnants of the previous season's SW monsoon eddy activity were evident, noted as large vertical excursions in the thermocline in the SeaSoar data, and as sea surface height anomalies in TOPEX data.

An estimation of the horizontal gradient in temperature made possible by the data from the mooring array reveals that the horizontal homogeneity in the mixed layer was 
maintained during the period on which I focus. To generate this estimate, data from three moorings, the central WHOI mooring, and the two SIO moorings (see Fig. 2.1), were used. Temperature and velocity data at each mooring were 48-hour lowpass filtered to remove signals at tidal and inertial frequencies. Salinity was not available on the SIO moorings. Since the moorings record data for all spatial scales, including those not resolved by the array, an EOF decomposition for the specified time period was made, after which the data was represented in a truncated EOF expansion, only retaining the most dominant modes to capture the signal coherent across the array (following the technique of Rudnick et al., 1993). In temperature, the first four EOFs were retained, accounting for $98.7 \%$ of the variability in the lowpass filtered fields. In velocity, only the first two EOFs were retained, for $95.4 \%$ of the variability. The temperature data at each mooring was spline fitted onto a $5 \mathrm{~m}$ resolution vertical grid common to all three moorings, and the

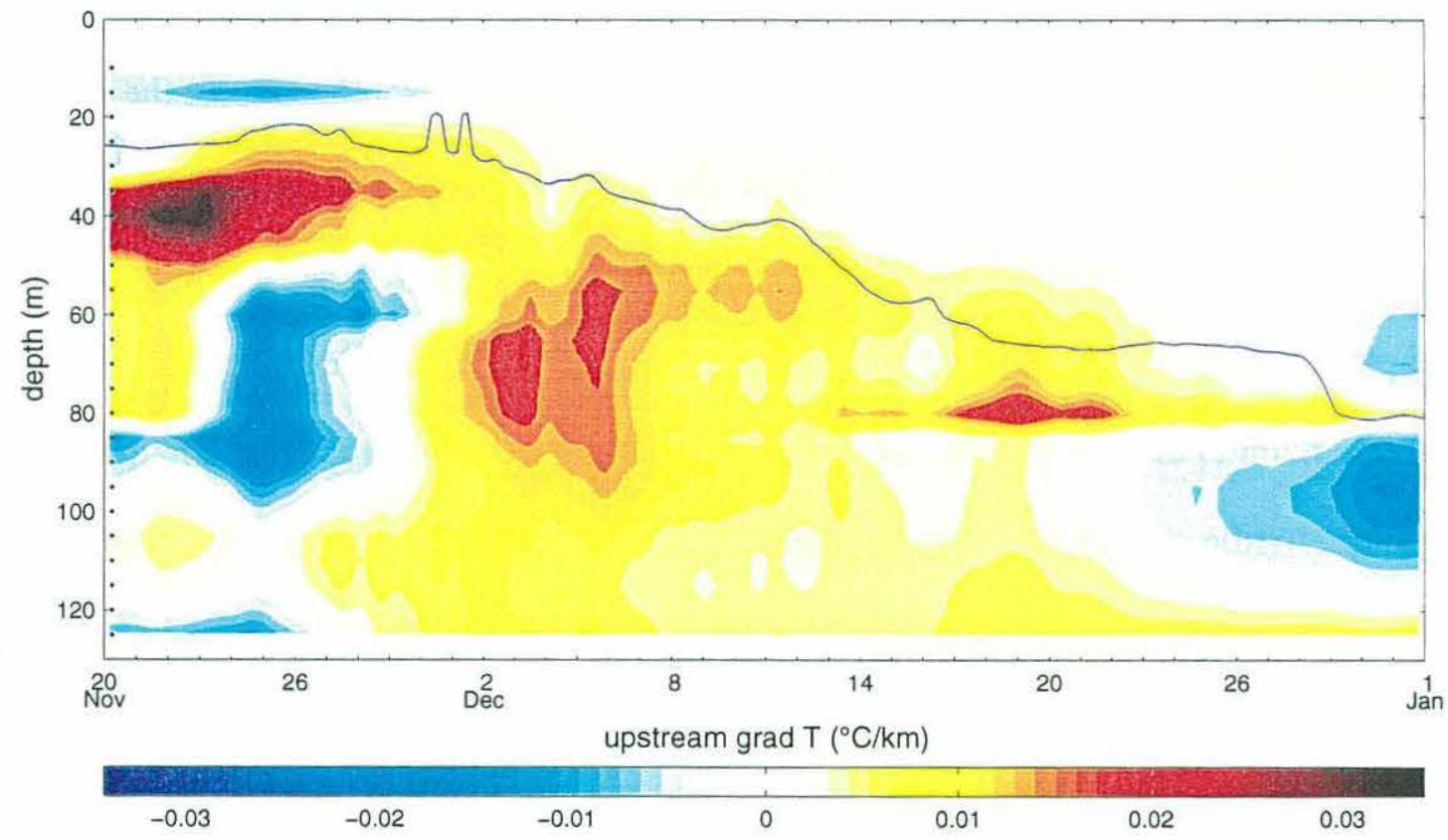

Figure 3.1 The upstream gradient in temperature based on the mooring array data. A positive gradient indicates warming. Mixed layer depth (blue) based on lowpass filtered temperature data. The upstream direction below $80 \mathrm{~m}$ is represented only by the two SIO moorings. 
average temperature and temperature gradients for the array were estimated using a simple plane fit at each depth. The gradient was projected onto the upstream direction, with velocity taken as the array average in a similar manner to the temperature. The result (Fig. 3.1) shows small horizontal gradients within the mixed layer, but large gradients below, consistent with the homogeneous mixed layer but horizontally varying thermocline noted in earlier.
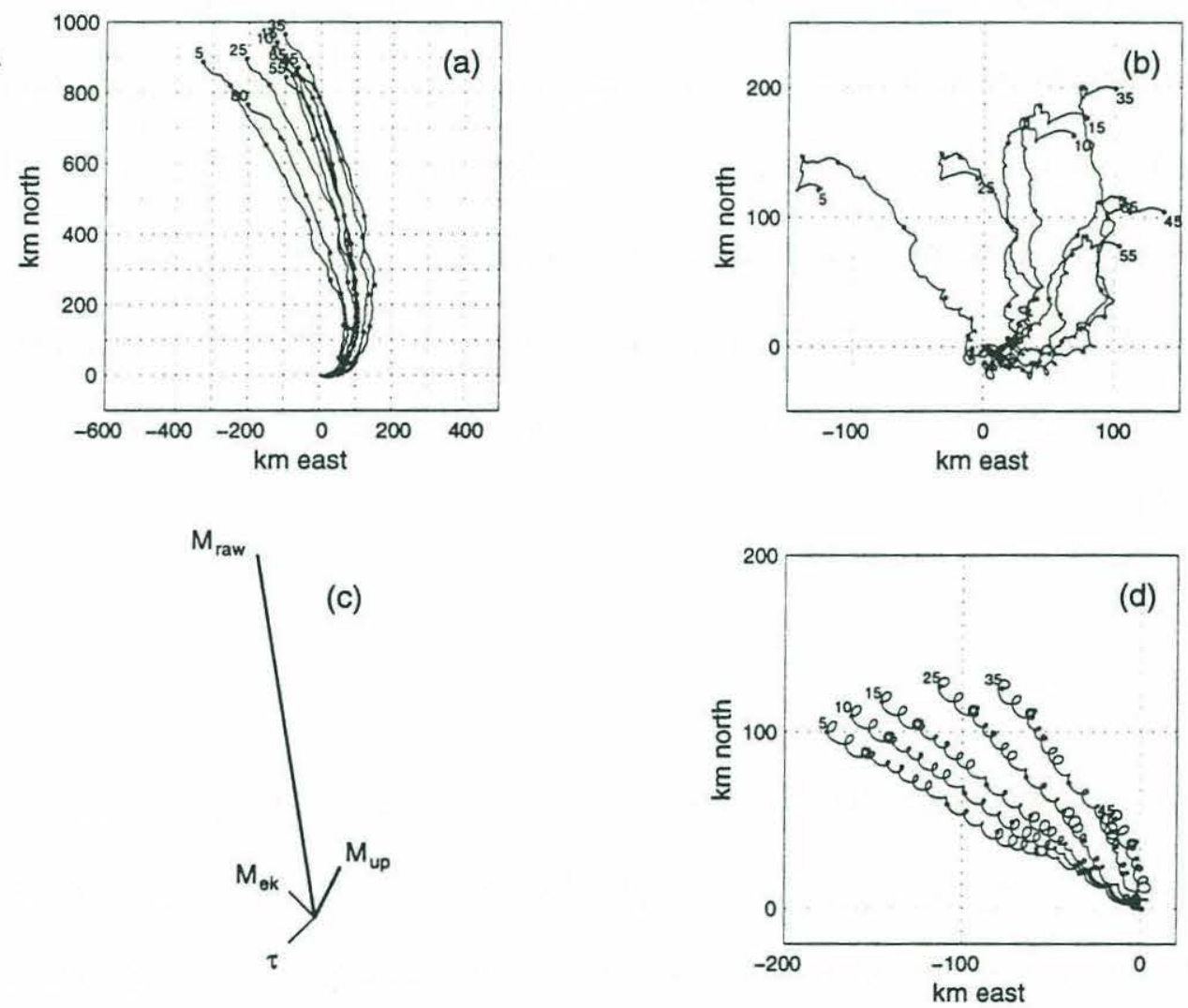

Figure 3.2 Progressive vector diagrams and the Ekman transport relation for the NE monsoon. Dots are separated by six days. (a) The raw velocities seen at the mooring, $(b)$ the same as $(a)$ with the $80 \mathrm{~m}$ velocity subtracted, $(d)$ velocities from a one-dimensional PWP model run, $(c)$ The observed transport integrated over the time period to a depth of $80 \mathrm{~m}\left(\mathrm{M}_{\text {raw }}\right)$, with the $80 \mathrm{~m}$ velocity removed ( $\left.\mathrm{M}_{\mathrm{up}}\right)$, and as expected from the mean wind stress $\left(\mathrm{M}_{\mathrm{Ek}}\right)$. The mean wind stress is $\tau$. 
The velocities recorded at the WHOI mooring during the NE monsoon are quite large, and represent far more than a local response to the wind forcing. A progressive vector diagram of the velocity, and the velocity with the deepest $(80 \mathrm{~m})$ upper ocean velocity removed (see Fig. 3.2), indicates that the local response is only a small fraction of the total measured response. The figure also shows the results of a one-dimensional model forced with the given surface conditions (see Section 3.5.3), the captured transport in the observations, and that expected from Ekman theory. They all show that the observed velocity in the upper ocean is very much larger than that expected from a local balance.

Since the velocity term is very large, one might expect the horizontal advection of properties to be important in the evolution of the mixed layer and the upper ocean. But since the horizontal gradient in temperature has been shown to be very small, a onedimensional evolution equation will still perform adequately in predicting the evolution of the mixed layer temperature, although it will miss important details in the mixed layer depth evolution.

\subsection{Surface Forcing}

The surface fluxes of momentum, freshwater, and heat are shown in Fig. 3.3. The wind stress is moderate but variable, with an average of 0.08 and standard deviation of 0.04 $\mathrm{N} \mathrm{m}^{-2}$. Reflecting the low relative humidity and moderately strong winds, evaporation is quite strong, with no precipitation to balance it. The mean evaporative rate is 6.6 mm day ${ }^{-1}$. The net heat flux changes sign daily as the incoming solar radiation dominates over surface heat losses, with a peak gain of $762 \mathrm{~W} \mathrm{~m}^{-2}$ and a maximum loss at night of $-489 \mathrm{~W} \mathrm{~m}^{-2}$. The losses dominate, however, and in the mean the net heat flux of $-52 \mathrm{~W} \mathrm{~m}^{-2}$ 


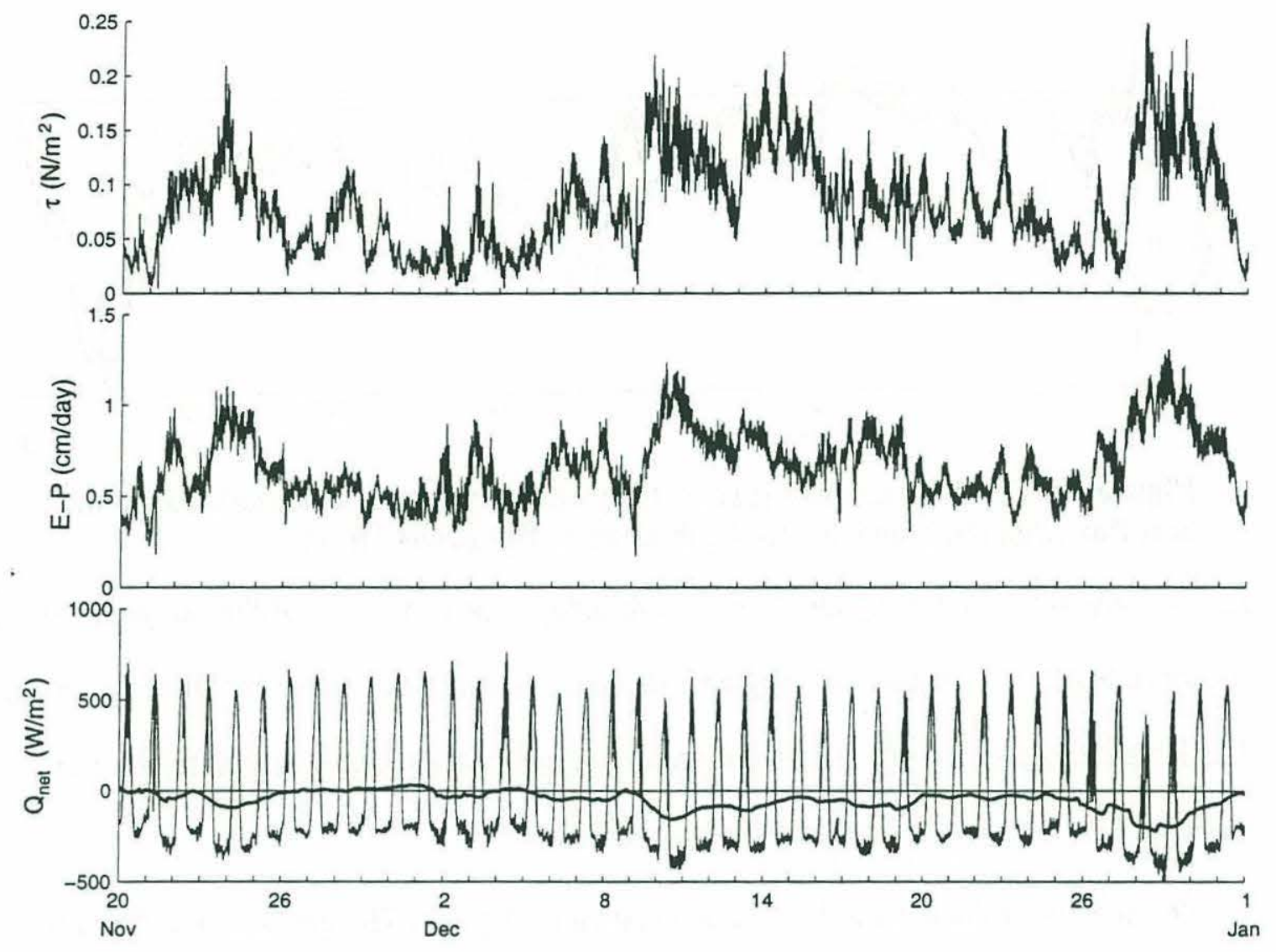

Figure 3.3 Timeseries of the surface forcing during the northeast monsoon. From top: the wind stress, the latent heat flux, the net heat flux, fully resolved and daily averaged.

represents an oceanic heat loss. A one-day running average shows that for the majority of the time during this six-week period the net heat flux is destabilizing.

The surface buoyancy flux is critical in terms of predicting the presence of penetrative convection and the ensuing entrainment at the base of the mixed layer. It is defined here, with units of $\mathrm{kg} \mathrm{sec}^{-1} \mathrm{~m}^{-2}$, as

$$
B=\rho_{0}\left[\alpha\left(\rho_{0} C_{p}\right)^{-1} Q_{\text {net }}-\beta S_{0}(E-P)\right]
$$

where $\alpha$ and $\beta$ are the respective coefficients of expansion due to temperature and salt, assumed constant, $S_{0}$ is an average surface salinity, and the average surface density $\rho_{0}$ and heat capacity $C_{p}$ were diagnosed from mean upper ocean values of the temperature 


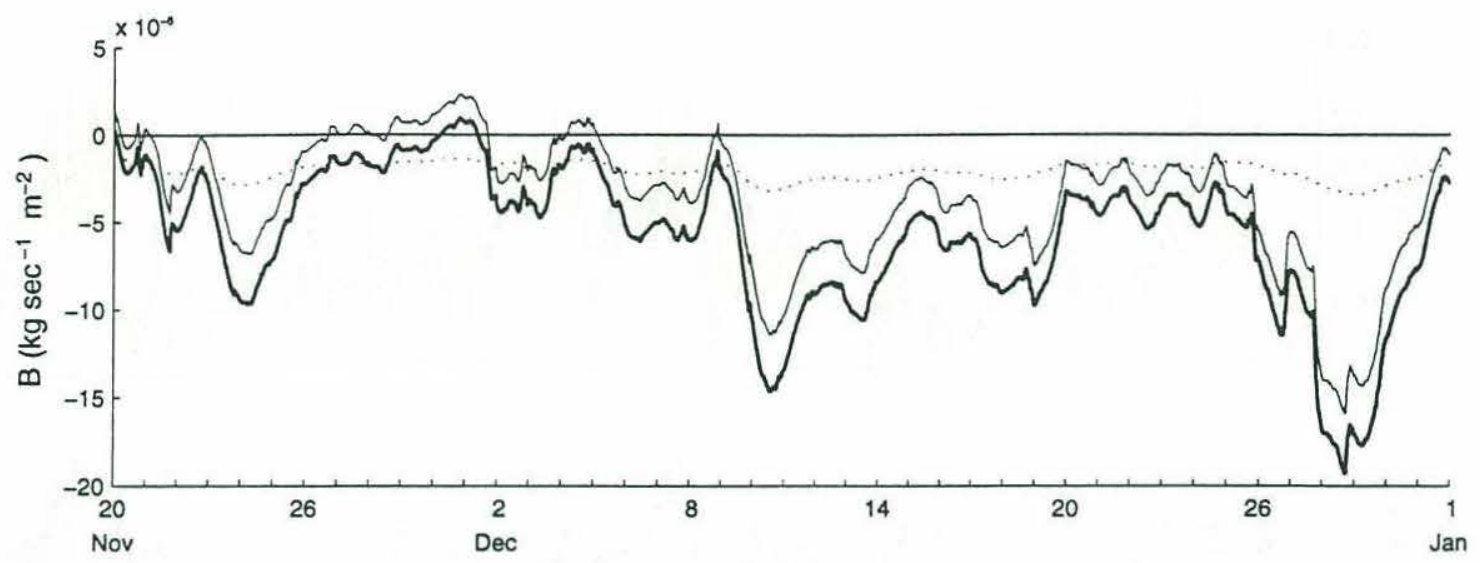

Figure 3.4 The daily average surface buoyancy flux, total (thick line), due to the heat flux (thin line), and due to the freshwater flux (dotted line).

and salinity. A positive buoyancy flux is stabilizing. The timeseries of the buoyancy flux is shown in Fig. 3.4. It is destabilizing on a diurnal timescale during nearly all of this record. The largest destabilizing flux occurs towards the end of the record, modulated by pulses in the wind speed which lead to large latent heat losses.

The spectra of the surface forcing are shown in Fig. 3.5. The net heat flux has a strong peak corresponding to a period of 24 hours, along with harmonics at shorter periods. The other fluxes are generally red, with a mild peak noted at the diurnal period in the clockwise-rotating component of the wind stress.

During this period, the primary local driving mechanism would appear to be the strong, steady, and destabilizing buoyancy flux. This should erode the stable stratification below the mixed layer, entraining cooler and fresher water and deepening the mixed layer. The strength of the wind stress and its ability to cause shear-driven instabilities and vertical mixing at the mixed layer base should not be discounted, however, as the forcing is moderate in strength. The dominant local forcing will be examined below. 

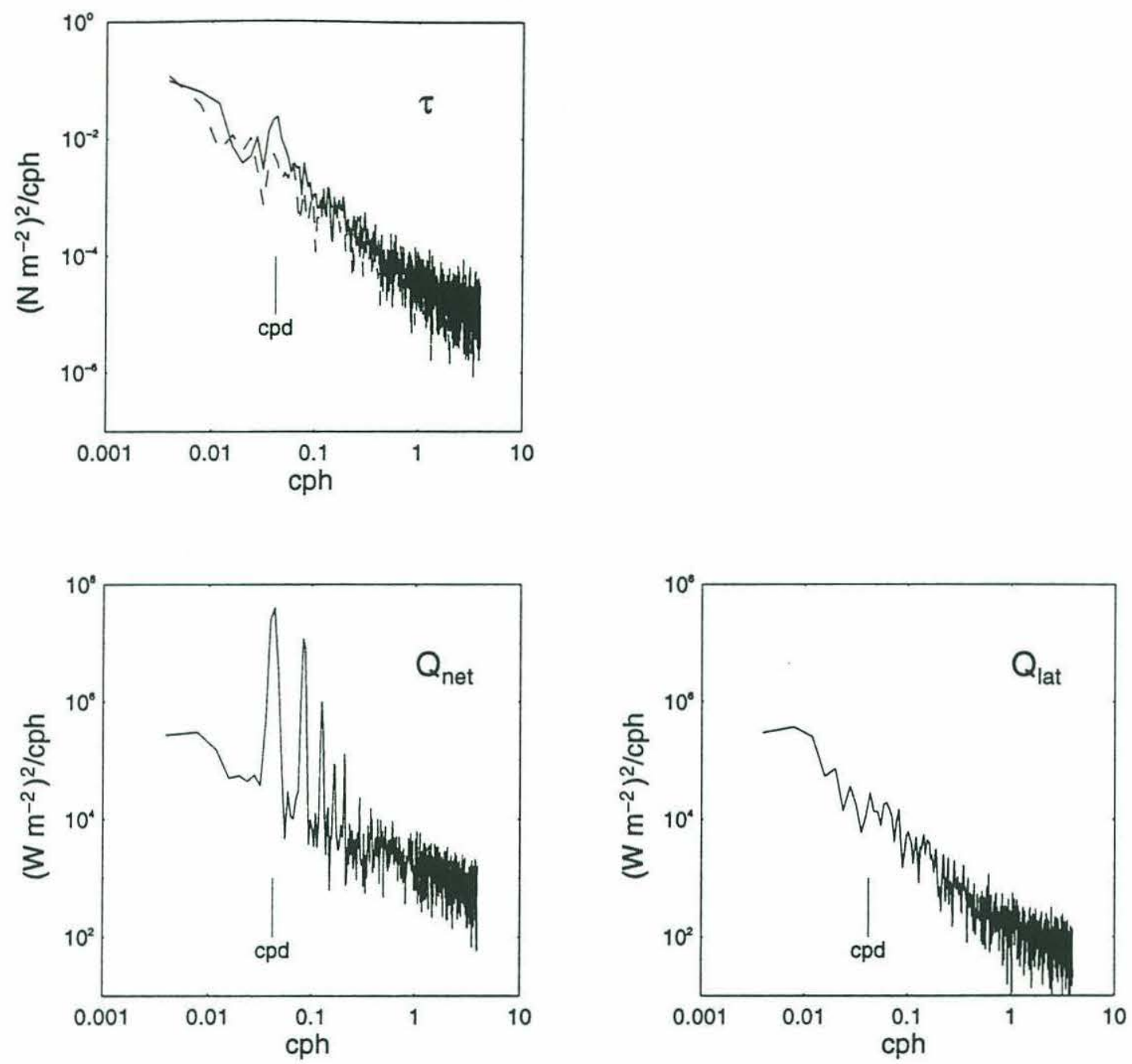

Figure 3.5 Autospectra of the surface forcing for the NE monsoon: wind stress $\tau$, net heat flux $Q_{\text {net }}$, and evaporative heat flux $Q_{\text {lat }}$. The rotary autospectra is shown for the wind stress, and a frequency of one cycle per day (cpd) is marked.

\subsection{Characterizing the upper ocean response}

The upper ocean response during this six-week period of characteristic northeast monsoon forcing is not immediately inconsistent with a local response to the local forcing: the mixed layer deepens and cools and the sea surface salinity slowly increases. But we shall see that nonlocal processes will have to be called into play to explain the extreme depth of the mixed layer penetration. 

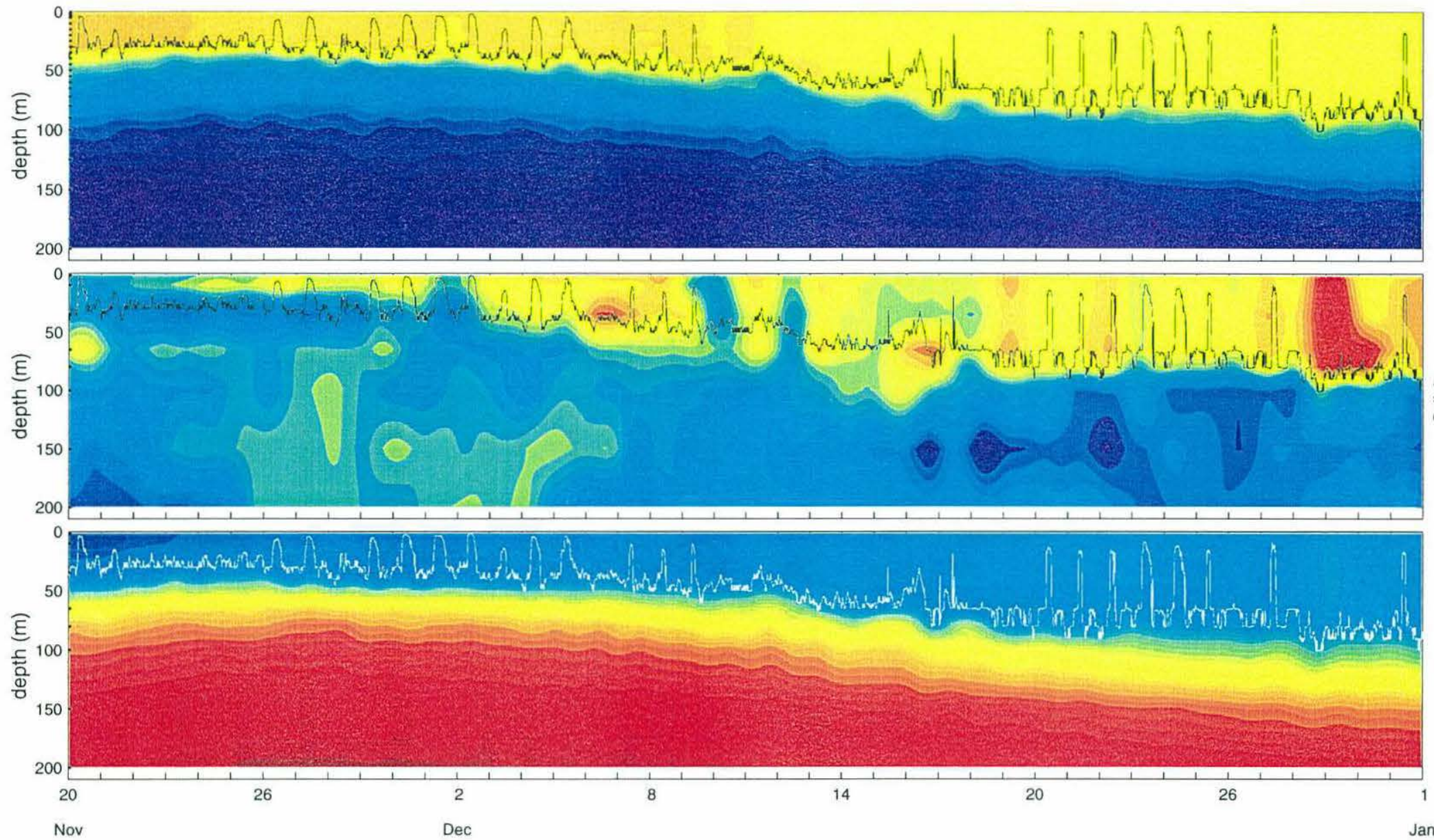

Figure 3.6 The lowpass-filtered subsurface temperature, salinity, and density. Dots at the left margin show the heights of the measurements. The mixed layer (displayed as a line, unfiltered) deepens and cools during this period. Salinity shows marked signs of variability. 
The subsurface evolution of the temperature, salinity, and density fields are shown in Fig. 3.6, lowpass filtered using the PL64 filter, which effectively filters out the tidal frequencies but leaves the inertial band behind, with a half power at 38 hours (Rosenfeld, 1983). Density was calculated with the full equation of state at a reference pressure of zero. Temperature makes a sharp transition below the mixed layer into the oceanic interior, creating a sharp thermocline. The salinity gradient is of the opposite sense, with saltier water in the mixed layer overlying the fresher water of the oceanic interior. This is reflective of the mean evaporative conditions found over the Arabian Sea, and serves to destabilize the water column. The mixed layer deepens from its initial depth of about $30 \mathrm{~m}$ to a full depth of about $90 \mathrm{~m}$ over the six week period. During periods of reduced wind stress, the surface layer restratifies and the mixed layer depth jumps to within a few meters of the surface. The buoyancy loss at night is enough to remix the water column to the depth of the previous night, and sometimes further. The salinity record shows strong variability, not only within the mixed layer, but in the thermocline as well. The surface salinity evolves from a mean of 35.94 in the first week to 36.16 in the last week of the period, but has a high standard deviation of 0.11 . But the temperature signal largely dominates the density record, and the stratification reflects the strong temperature gradient at the base of the mixed layer.

The subsurface velocity is presented in Fig. 3.7. The dominant response is modulated by oscillations of inertial period. While there is a transition across the mixed layer base, the velocity is mainly barotropic. The mean velocity is strongly northwards, and is significantly nonzero below the mixed layer, suggesting it is a nonlocal oceanic response.

The spectra of the temperature and velocity signals at depth is shown in Fig. 3.8. The inertial frequency $(f)$ as well as the main diurnal tide $\left(\mathrm{K}_{1}\right)$ and semi-diurnal tide $\left(\mathrm{M}_{2}\right)$ are marked. The surface temperature has a strong peak at a diurnal frequency, not tidally 

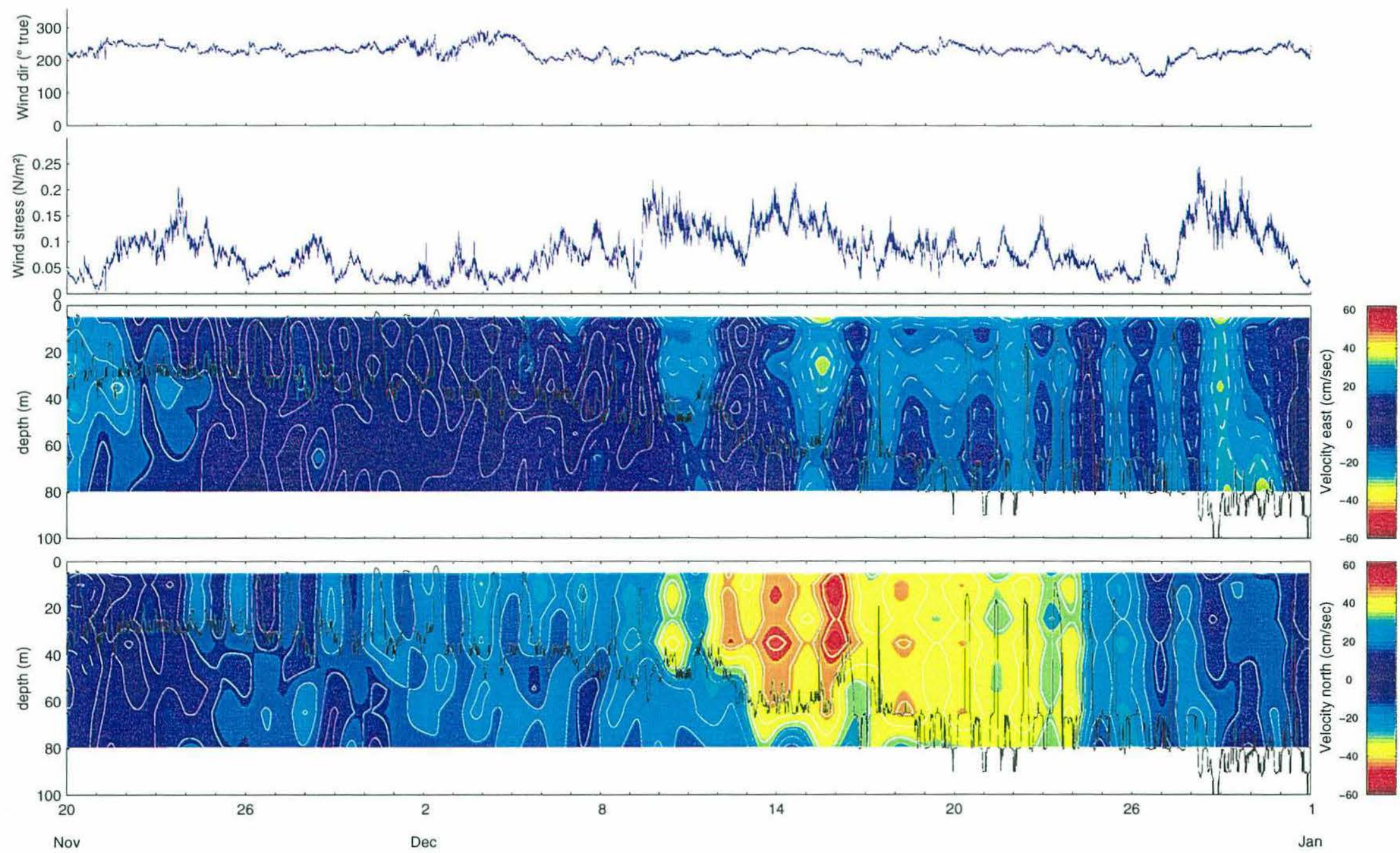

Figure 3.7 The wind stress and contour images of the subsurface velocity in the upper 80 meters. Positive contours are solid, negative are dotted. An inertial signal of 44 hours is apparent. 

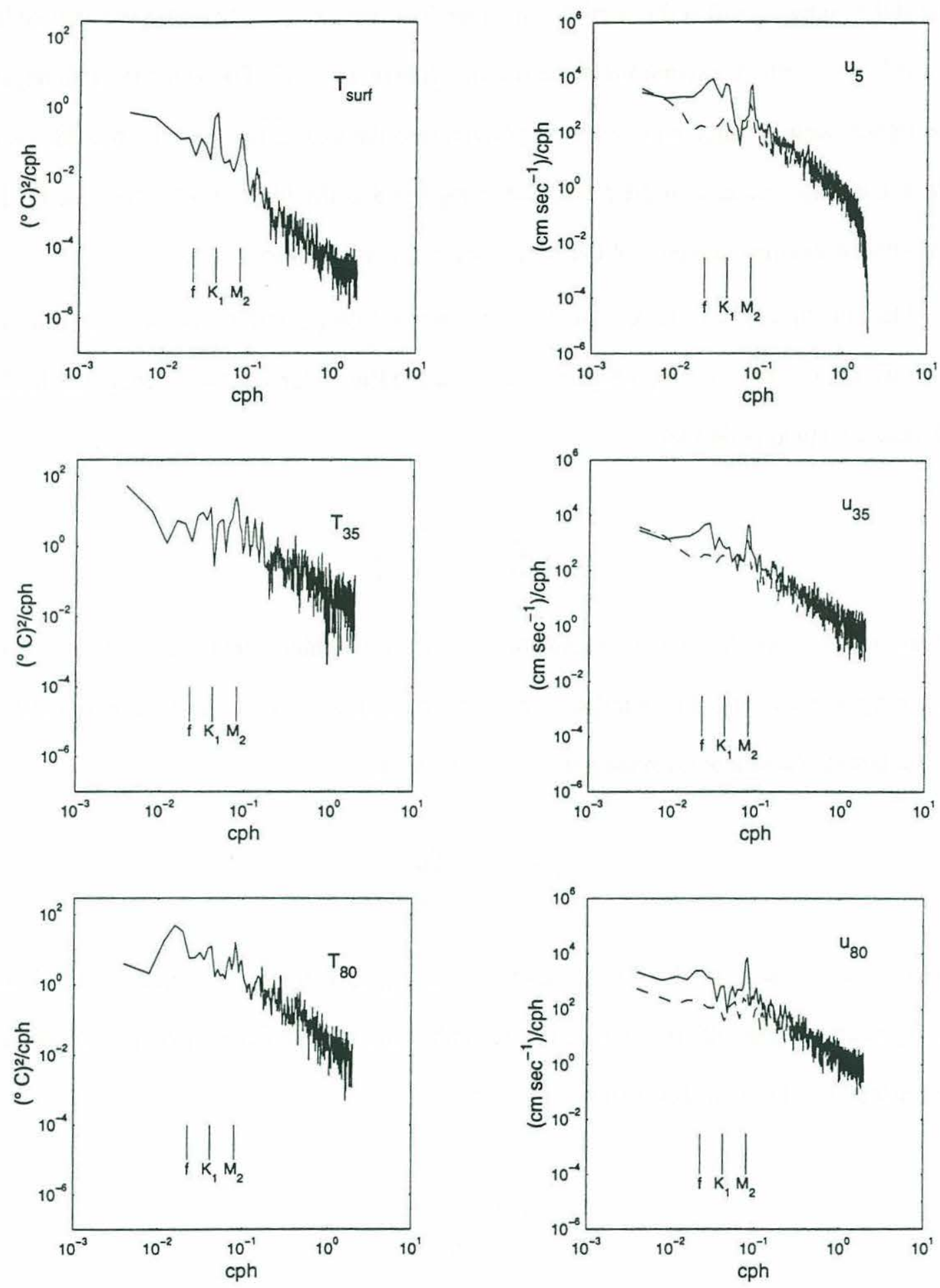

Figure 3.8 Autospectra of the velocity and temperature at selected depths. The rotary autospectra of the velocity is shown, with the clockwise component solid and counterclockwise dashed. Frequencies marked are the inertial (f), and the principal diurnal $\left(\mathrm{K}_{1}\right)$ and semi-diurnal $\left(\mathrm{M}_{2}\right)$ tides. 
driven but driven by solar heating. Subsurface temperature shows stronger response at the inertial frequency and at the semi-diurnal tide. The semi-diurnal tide was very active in the record, with vertical excursions in the thermocline up to $35 \mathrm{~m}$. The velocity at all depths in the upper ocean (which were all incorporated into the mixed layer by the records end) all show a strong response in the clockwise component at the inertial frequency, as well as a non-discriminatory response at the frequency of the semi-diurnal tide.

The subsurface data is used to calculate several diagnostic quantities: the horizontal velocity shear, the buoyancy frequency, and the gradient Richardson number. The horizontal velocity shear is defined

$$
\mathbf{u}_{z}=\left[\left(\frac{\partial u}{\partial z}\right)^{2}+\left(\frac{\partial v}{\partial z}\right)^{2}\right]^{1 / 2}
$$

where $u$ and $v$ are the east and north components of velocity. The horizontal shear should help diagnose the effect of wind-driven shear instabilities. The stratification is measured by the Brunt-Väisälä or buoyancy frequency $N$, with

$$
N^{2}=-\frac{g}{\rho_{0}} \frac{\partial \rho}{\partial z}
$$

where $g$ is the acceleration due to gravity, and $\rho_{0}$ is a reference value of the density. Strong stratification will act as a barrier to both wind or convectively-driven mixed layer deepening. The gradient Richardson number,

$$
\mathrm{Ri}=\frac{N^{2}}{\mathbf{u}_{z}^{2}}
$$

gives an idea of the stability of the sheared flow, where values less than 0.25 are generally considered to be unstable and prone to mixing through a shear instability process. These 

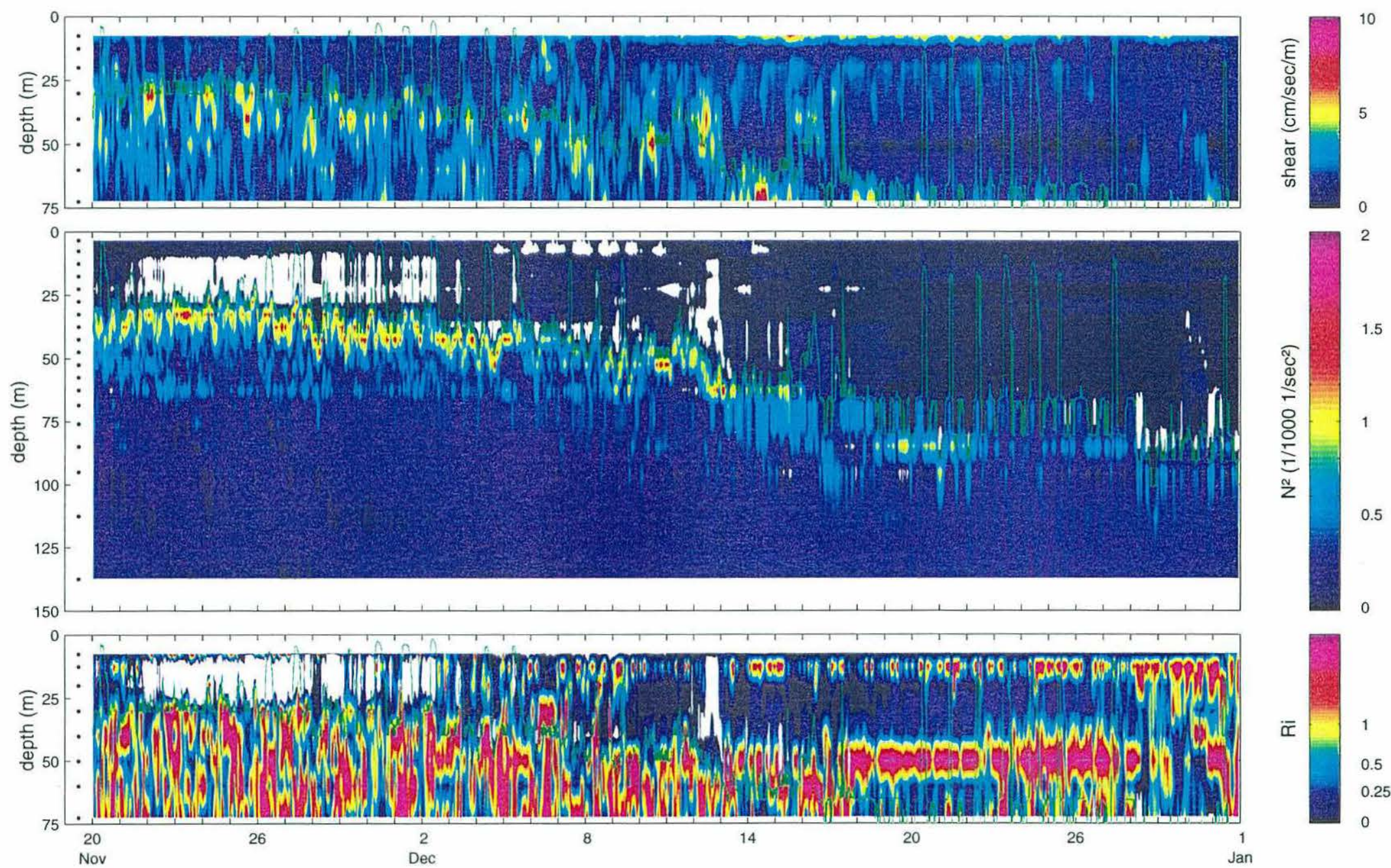

Figure 3.9 The subsurface velocity shear, stratification $\left(\mathrm{N}^{2}\right)$, and Richardson number shown at the 15 minute sample rate. Unstable stratification is marked by white. Mixed layer depth is marked in green. 
quantities are shown in Fig. 3.9. The largest signals in the shear record are below the mixed layer, and generally located near its base. If wind-driven shear instability was the primary mechanism of mixed layer entrainment and deepening, the shear would likely be more tightly trapped to the mixed layer base. The stratification profiles show large periods of near-zero and even negative stratification in the mixed layer. The negative profiles in stratification suggest the presence of convection forced from the surface. The subsurface

peak in $N^{2}$ is somewhat poorly resolved, because of the coarse resolution in the salinity, but appears to migrate downwards over the six weeks. Following the pattern of low $N^{2}$, the gradient Richardson number within the mixed layer is low for large parts of the record. Occasionally there are cases of low Richardson number at the base of the mixed layer, which is a possible sign of wind-driven deepening, but the relationship is by no means clear.

The spectra of the shear signal at depth (Fig. 3.10) reveal discernible responses at the diurnal frequency in the top two measurements $(7.5$ and $12 \mathrm{~m})$. There are generally broad peaks around the inertial frequency at depths that span the mixed layer base $(50,60$, and $72.5 \mathrm{~m}$ ), but they are not distinct. This suggests that inertially modulated shear does not play a dominant role in the deepening of the mixed layer.

\subsection{The dominant physical mechanism for deepening}

The surface forcing and the subsurface response so far suggest that the primary local dynamic in the deepening and cooling of the mixed layer is the destabilizing buoyancy flux. Here, the dominance of this mechanism over wind-driven mixing and deepening is further examined through arguments on the energetics of the mixed layer. 

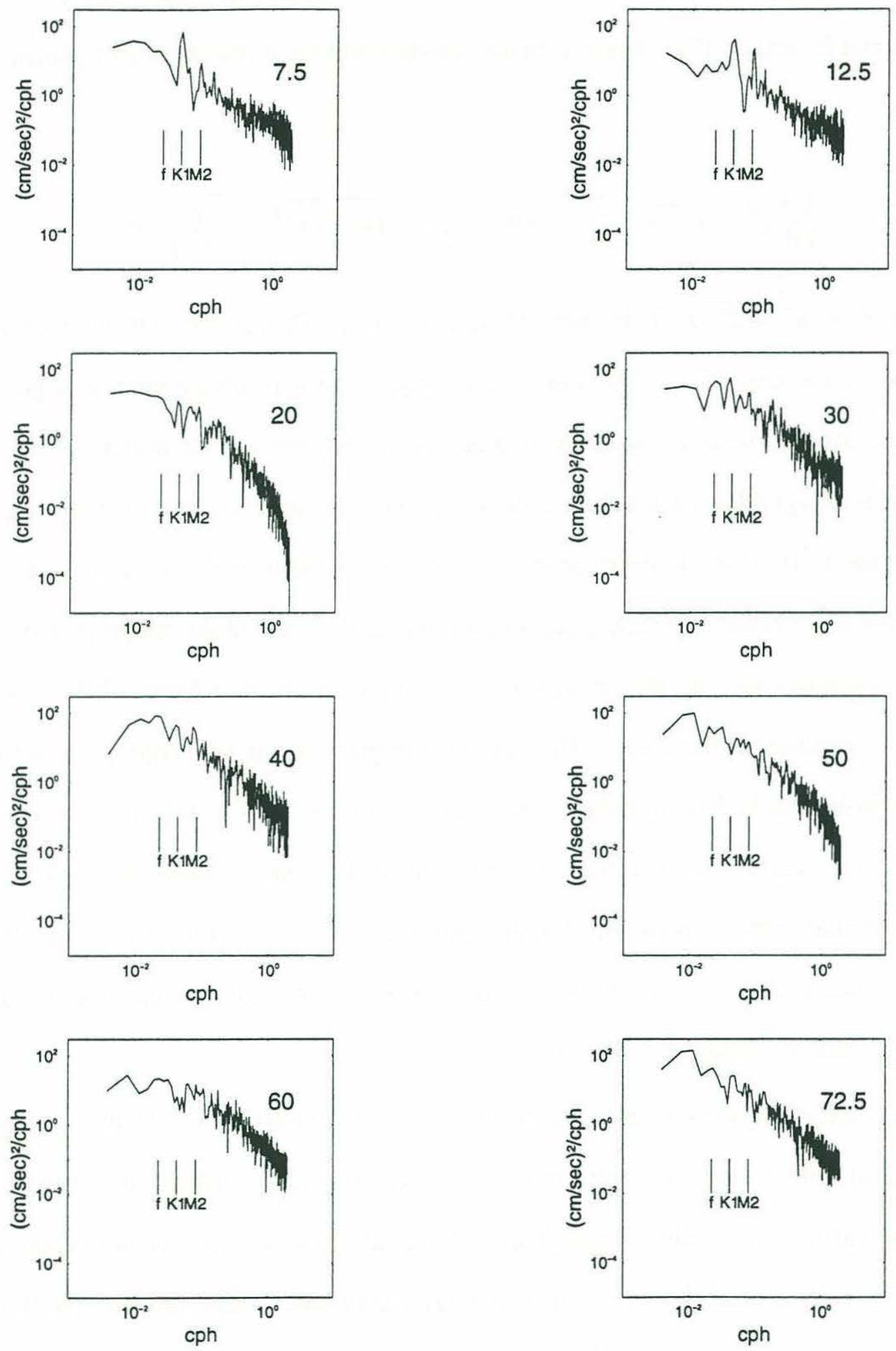

Figure 3.10 The autospectra of the shear at the depths indicated. 


\subsubsection{Energetics of mixed layer entrainment}

Bulk mixed layer models which rely on energetic arguments (Niiler and Kraus, 1977; Kraus and Businger, 1994) begin with the one-dimensional turbulent kinetic energy equation,

$$
\frac{1}{2} \frac{\partial}{\partial t} q^{2}=-\overline{w^{\prime} \mathbf{u}^{\prime}} \cdot \frac{\partial}{\partial z} \overline{\mathbf{u}}+\overline{w^{\prime} b^{\prime}}-\frac{1}{2} \frac{\partial}{\partial z}\left[\overline{w^{\prime}\left(\overline{\left.w^{\prime 2}+\mathbf{u}^{\prime 2}\right)}+\overline{w^{\prime} p^{\prime}}\right.}\right]-\varepsilon
$$

where $q^{2}=\overline{w^{\prime 2}}+\overline{\mathbf{u}^{\prime} \cdot \mathbf{u}^{\prime}}$ is the turbulent kinetic energy. Primes indicate turbulent deviations from the mean, and overbars indicate averages. Terms involving horizontal gradients of quantities have been ignored, implying that the forcing has a broad horizontal scale and that there is negligible wave radiation of energy. The first term on the right hand side represents the work of the momentum stress on the mean shear; if the shear is eroded, this releases energy to the turbulence. The second term is the work of the buoyancy force, if it acts to decrease the potential energy in the column by moving lighter fluid upwards, energy is released to turbulence. The third term represents the convergence of turbulent energy, which can be held in turbulent velocity fluctuations or in turbulent pressure fluctuations. This term is parameterized as a function of the wind stress at the surface. And finally, the last term, $\varepsilon$, represents the dissipation of TKE. In the mixed layer model, the left hand side is often assumed to be zero, and the production and dissipation terms on the right hand side are assumed to balance.

These turbulent erosion models of the mixed layer then assume that the mean temperature, salinity, and velocity are uniform in the mixed layer, so that their conservation equations can easily be vertically integrated over its extent. Parameterizations of the boundary conditions at the top and bottom of the mixed layer are made. A discontinuous interface is presumed to exist at the bottom of the mixed layer. Finally, the TKE equation can be verti- 
cally integrated, and with the assumption that the three different production processes (surface shear generation by the wind, buoyancy input from above, and entrainment shear input from below) dissipate in proportion to their generation rates, an equation for the entrainment velocity is expressed

$$
w_{e}=-2 \frac{m_{1} u_{*}^{3}+m_{2} w_{*}^{3}}{c_{1}^{2}+q^{2}-m_{3}(\Delta U)^{2}},
$$

where $c_{1}$ is the velocity of internal waves along the density discontinuity at the base of the Iayer, $\Delta U$ is the velocity jump across the interface, and $m_{1}, m_{2}$ and $m_{3}$ represent the fraction of energy available for the generation of TKE after dissipation, and are empirically derived constants. Kraus and Businger (1994) give the full details of this derivation, and cite values of $m_{1}$ between 0.4 and 0.5 , and values of $m_{2}$ around 0.2 . The friction velocity $u_{*}$ is parameterized from the wind stress with

$$
\tau=\rho_{0} u_{*}^{2}
$$

The convective velocity scale $w_{*}$ is defined as

$$
w_{*}^{3}=-\frac{h}{2}\left[B_{\mathrm{L}}+S_{\mathrm{b}}(0)\right]+\int_{-h}^{0} S_{\mathrm{b}} d z
$$

with a mixed layer depth of $h$. The buoyancy loss $B_{\mathrm{L}}$ due to the surface heat loss and evaporation, and the buoyancy gain due to penetrating solar radiation $S_{\mathrm{b}}$ are defined as

$$
\begin{gathered}
B_{\mathrm{L}}=g\left[\frac{\alpha}{\rho_{0} C_{p}}\left(Q_{\mathrm{LW}}+Q_{\text {lat }}+Q_{\text {sens }}\right)-\beta S_{0}(E-P)\right] \\
S_{\mathrm{b}}(z)=\frac{g \alpha}{\rho_{0} C_{p}} I(z)
\end{gathered}
$$


where $I(z)$ is the penetrating solar radiation as defined in (3.25).

The entrainment velocity, while not the only equation in the bulk energetic mixed layer model, is most important in this case because the expectation is that during a period of deepening the entrainment velocity will always be active. We see that it is dependent on both $u_{*}$, a measure of the strength of the wind stress, and $w_{*}$, a measure of the strength of the buoyancy forcing. These are each plotted as a timeseries, along with the mixed layer depth for reference, in Fig. 3.11. This is best viewed in contrast with Fig. 4.11, the equiva-

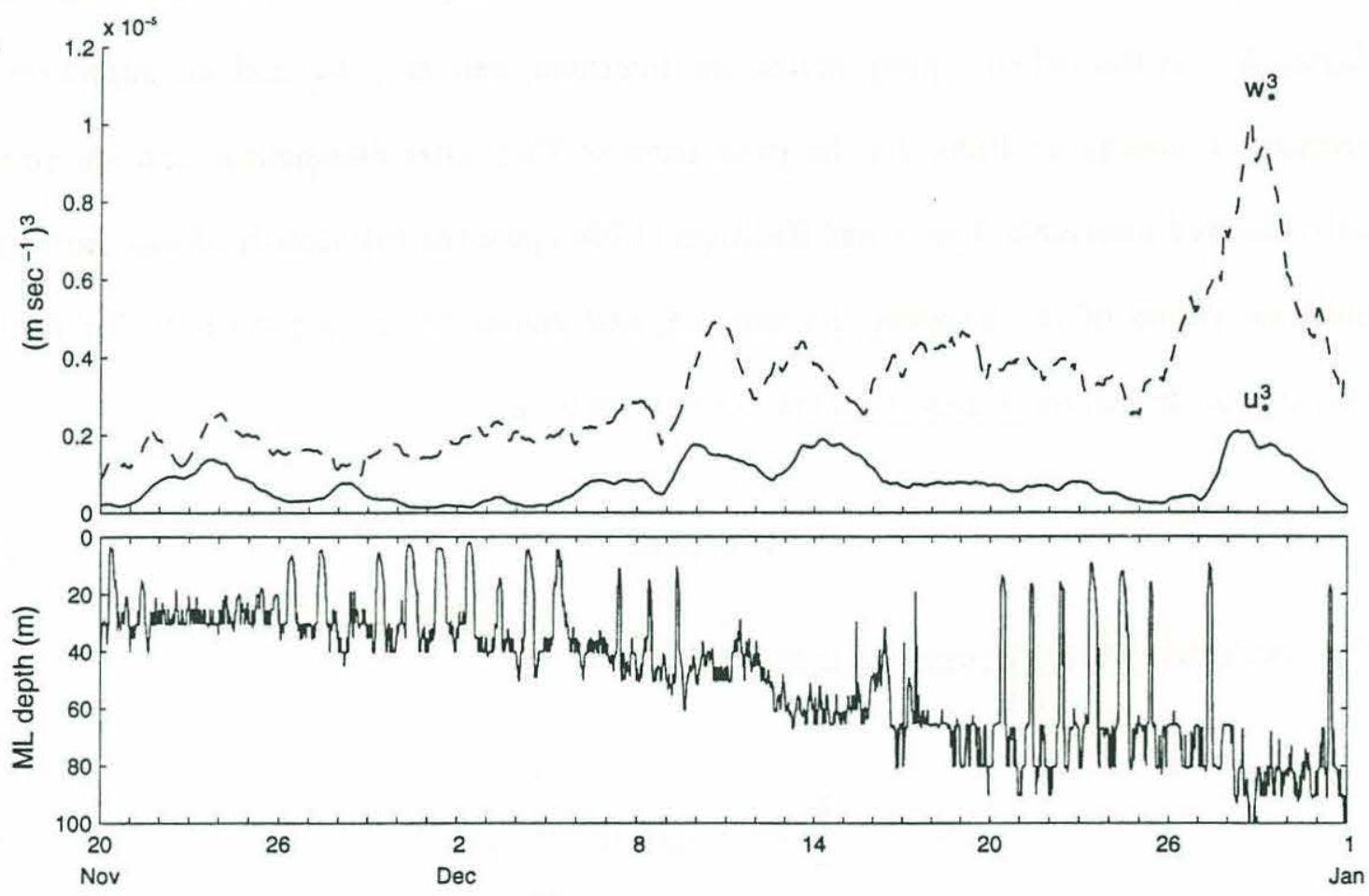

Figure 3.11 Timeseries of the friction velocity scale $u_{*}$ and convective velocity scale $w_{*}$ with the observed mixed layer depth during the NE monsoon. Periods of large $w_{*}$ are roughly correlated with deepening in the mixed layer.

lent for the southwest monsoon. The convective velocity scale dominates over the friction velocity scale, and periods of high $w_{*}$ seem to correlate roughly with deepening of the 
mixed layer. This is further implication that penetrative convection is a dominant mechanism over wind-deepening during the NE monsoon.

\subsubsection{Monin-Obukhov scaling}

To quantify this further, I turn to Monin-Obukhov similarity theory, and a scaling for the relative importance of convective forcing versus wind forcing. Monin-Obukhov similarity theory assumes that all fluxes are uniform throughout the surface layer. This is not entirely correct in the ocean, since penetrative solar heating will change the profile of the buoyancy flux within the mixed layer. But it is a reasonable approximation especially when the mixed layer is deep relative to the extinction coefficient of the penetrating radiation, and correct at night. Under this assumption, the TKE equation can be nondimensionalized. In neutral conditions it has been shown that the shear production term in the steady-state TKE equation generally balances the dissipation, so

$$
\varepsilon=-\overline{w^{\prime} \mathbf{u}^{\prime}} \cdot \frac{\partial}{\partial z} \overline{\mathbf{u}}
$$

In a constant flux layer, the shear is that of the logarithmic wind profile

$$
\frac{\partial}{\partial z} \overline{\mathbf{u}}=\frac{u_{*}}{\kappa z}
$$

where $\kappa=0.42$ is the empirically derived von Karmann constant. Combined with the fact that $\overline{-w^{\prime} \mathbf{u}^{\prime}}=\tau / \rho_{0}=u_{*}^{2}$, the dissipation term in neutral conditions can be written as

$$
\varepsilon=\frac{u_{*}^{3}}{\kappa z} .
$$

Obukhov equated this neutral form of the shear production term with the buoyancy term and derived a length scaling 


$$
L=\frac{u_{*}^{3}}{\kappa \overline{w^{\prime} b^{\prime}}} .
$$

where the shear production and buoyancy production terms were equal. As mentioned earlier, Monin-Obukhov similarity theory assumes that fluxes are constant in the surface layer, and an important parameter emerges (from Niiler and Kraus, 1977)

$$
\frac{L}{h}=-\frac{2 u_{*}^{3}}{B_{0} h}
$$

where $L$ is now a generalized Obukhov length (since $\kappa$ is taken to be $1 / 2$ ) and

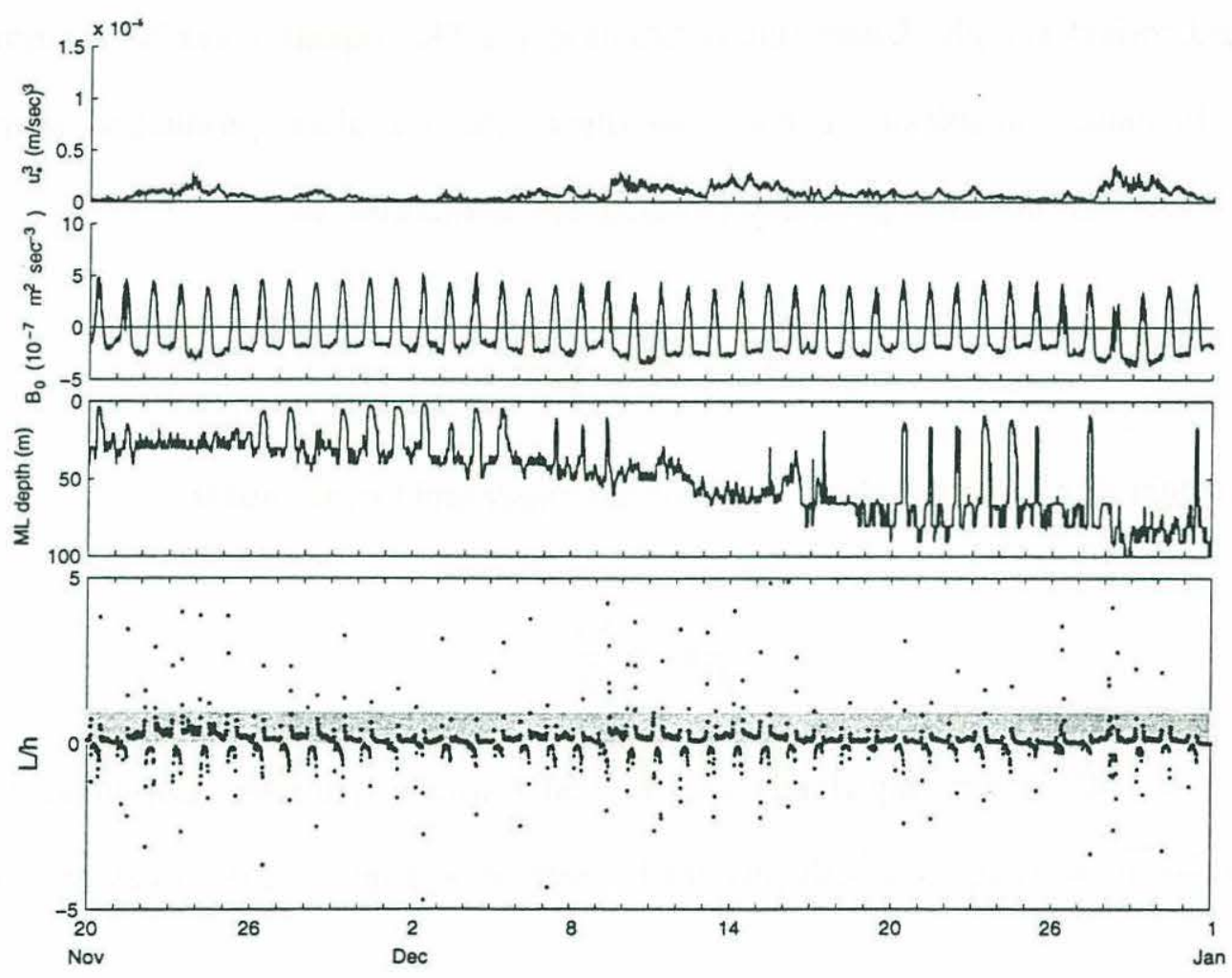

Figure 3.12 The ratio of the generalized Obukhov length to the mixed layer depth. The first three panels show the elements of the Obukhov length: the wind-driven friction velocity, the net buoyancy flux, and the boundary layer depth. The last shows the ratio, which spends the majority of the time in the region indicating convection is dominant. 
$B_{0}=\left(g / \rho_{0}\right) B$ is the surface buoyancy flux (see (3.1)). In the oceanic case, the Obukhov length represents the height below the surface at which the buoyant production term becomes larger than the shear production term in the TKE equation. When the ratio of the Obukhov length to the mixed layer depth $L / h$ is small and positive, convection is dominant, while if the ratio is large (of either sign), wind stirring dominates.

This ratio is shown as a timeseries in Fig. 3.12. It is apparent that for large periods of the NE monsoon, the buoyancy forcing is strong and destabilizing, the friction velocity moderate, and the ratio $L / h$ is small and positive. The buoyancy flux changes sign each day, changing the sign of the ratio. Some part of each day is spent in a regime where convection doesn't exists. But the magnitude of the ratio remains small. During times when the ratio is positive, it is generally very small, and spends virtually none of its time in a regime where wind stresses clearly dominate.

\subsection{Local forcing of upper ocean response}

The primary local forcing mechanism during the NE monsoon is now clear. I now return to the subsurface evolution, to determine how well the upper ocean response can be understood as a direct response to the local forcing.

\subsubsection{One dimensional heat budget}

The budget of heat in the upper ocean is

$$
\rho_{0} C_{p}\left(\frac{\partial T}{\partial t}+\mathbf{u} \cdot \nabla T+w \frac{\partial T}{\partial z}\right)=\frac{\partial}{\partial z}(q-r)
$$

where $q$ represents the penetrative solar flux, and $r$ represents turbulent mixing. A onedimensional heat budget will quantify the expectation of the upper ocean evolution in 
response to the local surface heat flux. In the one-dimensional budget, one ignores the horizontal and vertical advective terms, leaving simply a temperature trend term on the left hand side, and the solar and turbulent fluxes on the right. The surface boundary condition is that the turbulent flux goes to zero, and that the solar flux is simply the net heat flux through the surface. If one integrates to a reference depth below which one think the effects of turbulent fluxes are important, the heat budget simply becomes

$$
\int_{-H}^{0} \rho_{0} C_{p} \frac{\partial T}{\partial t} d z+R^{*}=Q_{\text {net }},
$$

a simple balance between the water-column integrated temperature trend and the surface heat flux. The residual term $R^{*}$ represents the processes I have chosen to eliminate, horizontal and vertical advection. This can be integrated in time,

$$
\rho_{0} C_{p} \int_{-H}^{0} T d z+R=\int Q_{\text {net }} d t
$$

and this is the balance shown in Fig. 3.13, integrated to various reference depths. This last integral assumes that the temperature at depth $-H$ never changes, another way of stating that the depth to which I have integrated is deep enough that the (assumedly) surfacedriven turbulent fluxes do not penetrate, although this could also be changed by the forgotten processes embodied in $R$. The arbitrary constant is set so that both sides of the budget start at zero. Obviously, none of the values of the reference level are appropriate. The closest match is with a reference level of $40 \mathrm{~m}$, which clearly violates the assumption that the turbulent fluxes are negligible at that level, since it is within the mixed layer for much of the time period. The heat content of the upper ocean first drops slightly, then increases dramatically during this period, despite the persistently negative heat flux at the surface. The 


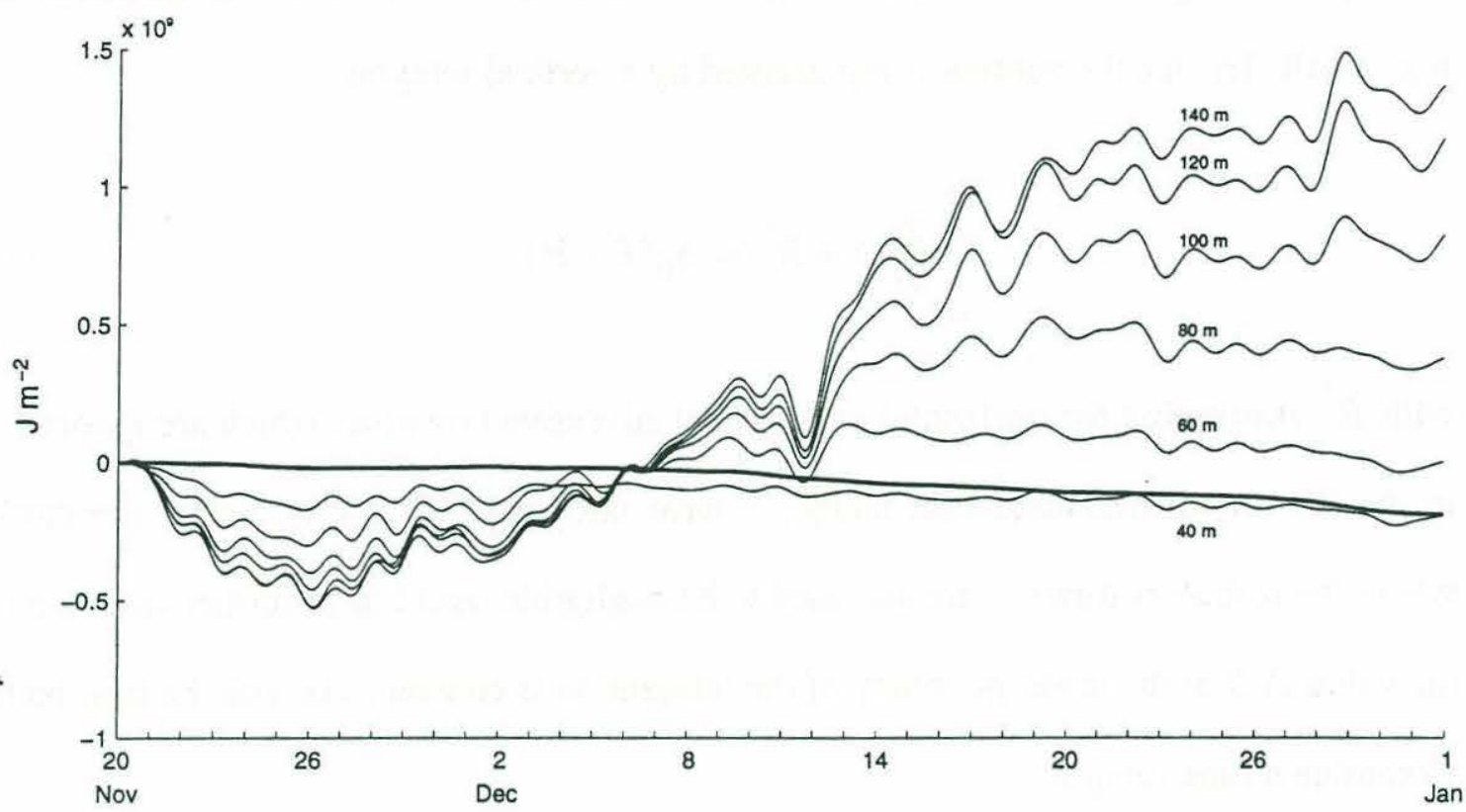

Figure 3.13 The one-dimensional heat budget, integrated down to various reference depths. The solid line is the surface flux term, while lighter lines correspond to the heat content term, integrated to the depths indicated. The heat content term suggests the strong influence of nonlocal effects.

mismatch becomes worse as the point of integration becomes deeper, indicating that the process that is causing this mismatch continues deep beneath the mixed layer. This is certainly not a response to the local surface forcing, and this serves the first hint of the importance of nonlocal processes on the evolution of the upper ocean during the NE monsoon.

\subsubsection{One dimensional salt budget}

A one-dimensional salt budget provides another independent assessment of the upper ocean response to the local surface forcing. The evolution of salt in the upper ocean is given by

$$
\frac{\partial S}{\partial t}+\mathbf{u} \cdot \nabla S+w \frac{\partial S}{\partial z}=\frac{\partial}{\partial z}(q-r),
$$

where the left hand side is the full advective derivative of salt, $q$ represents the flux of salt 
with $q(0)=S_{0}(E-P)$, the surface freshwater flux, and $r$ represents the turbulent mixing of salt. The local evolution is represented by a vertical integral

$$
\int_{-H}^{0} \frac{\partial S}{\partial t} d z+R^{*}=S_{0}(E-P),
$$

with $R^{*}$ subsuming the horizontal and vertical advective processes which are ignored. As in the the one-dimensional heat budget, I have integrated to a depth below the surface where the turbulent fluxes $r$ are assumed to be negligible, and I have further assumed that the value of $S$ at the lower boundary of the integration is constant. As with the heat budget I examine a time integral

$$
\int_{-H}^{0} S d z+R=S_{0} \int(E-P) d t,
$$

which has an arbitrary constant of integration.

This time-integrated one-dimensional salt budget for the northeast monsoon is shown in Fig. 3.14. While no one reference depth matches the prediction of the surface flux alone, the general trend is matched. There is strong evidence of variability on several day timescales. The residual term in the salt budget is a smaller fraction of the whole than the residual in the heat budget, suggesting that the gradients in salinity are less sharp than those in temperature, in terms of their effect on a local budget. But it remains of primary importance in closing the budget, implying that horizontal or vertical advection is playing an important role in the upper ocean salt evolution. 


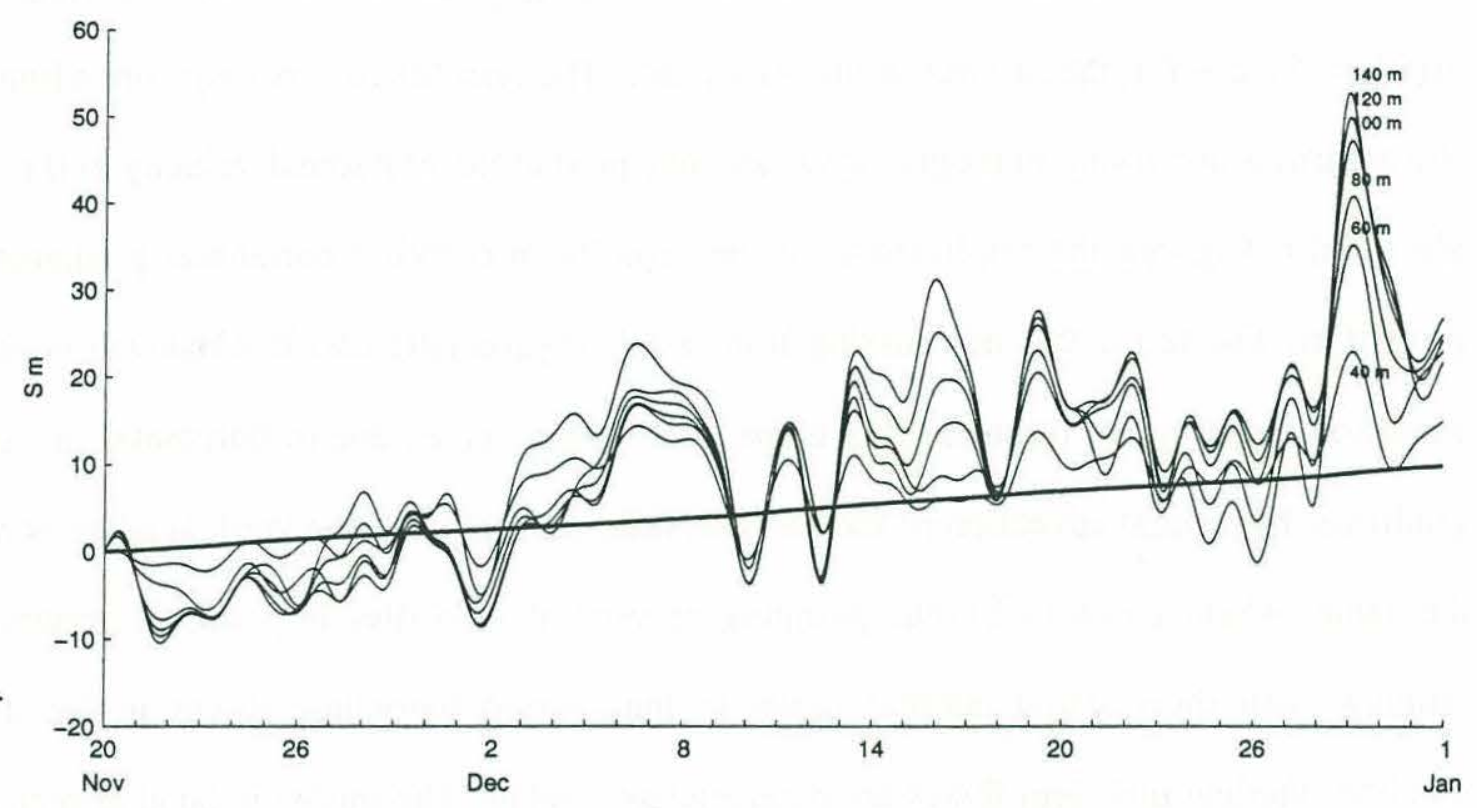

Figure 3.14 The one-dimensional salt budget, integrated to various reference depths. The solid line is the surface (E-P) term, while the lighter lines indicate the salt content term, integrated to the depths indicated. There are signals of nonlocal effects, although the match is better than the heat budget, indicating that salinity is more vertically uniform than temperature.

\subsubsection{Model experiment}

To further asses the role of the local response to local surface forcing in the evolution of the mixed layer, a one-dimensional mixed layer model is employed. The one used here is a version of the model in Price et al. (1986), and is defined as follows. The conservation equations for momentum, heat, and salt are their usual one-dimensional forms,

$$
\begin{gathered}
\frac{\partial}{\partial t} \mathbf{u}+f \hat{\mathbf{k}} \times \mathbf{u}=-\frac{1}{\rho_{0}} \frac{\partial}{\partial z} \mathbf{G} \\
\frac{\partial T}{\partial t}=-\frac{1}{\rho_{0} C_{p}} \frac{\partial F}{\partial z} \\
\frac{\partial S}{\partial t}=\frac{\partial E}{\partial z},
\end{gathered}
$$


where $\mathbf{G}(0)=\tau$, the surface wind stress, $F(0)=Q_{\text {net }}$ the net surface heat flux, and $E(0)=S_{0}(E-P)$, the salt flux at the sea surface. The one-dimensional equations implicitly assume a horizontal homogeneity, since they predict the horizontal velocity at the single point but ignore the implications of the velocity in carrying horizontal gradients of properties. The terms that are missing from a full (hydrostatic and Boussinesq) oceanic evolution equation are turbulent flux terms, momentum forces due to horizontal pressure gradients, horizontal advection of momentum, heat, and salt, and the vertical advection of the same, whether due to Ekman pumping or vertical velocities imposed by processes ranging from short-period internal waves to long-period baroclinic waves in the thermocline. Vertical turbulent fluxes are parameterized below. The model is good at predicting local response to local surface forcing over short and long timescales. Observed deviations from the model prediction should give us an indication of nonlocal processes influencing the oceanic evolution, and these will be pursued further.

The only non-turbulent subsurface flux that the model accounts for is the penetrative solar flux, which is modeled as a two-component exponential decay

$$
I(z)=I(0)\left[I_{1} e^{z / \lambda_{1}}+I_{2} e^{z / \lambda_{2}}\right]
$$

where the constants for clear midocean water used here are (Paulson and Simpson, 1977; Jerlov, 1968)

$$
\begin{array}{ll}
I_{1}=0.62 & \lambda_{1}=0.6 \mathrm{~m} \\
I_{2}=1-I_{1} & \lambda_{2}=20 \mathrm{~m}
\end{array} .
$$

The Arabian Sea is known as a place of especially high primary productivity, and so selecting constants for clear midoceanic water may not be truly representative. But as the primary concern is with periods of deepening, where the mixed layer is generally deep enough to neglect a solar heating flux through its base, this is not a major concern. It may 
become important in examining periods of restratification with shallow mixed layers.

The 'artful' part of this model comes in the parameterization of vertical mixing due to turbulent fluxes. At each timestep, the momentum, heat, and salt fluxes are imposed. Then the density is diagnosed from the temperature and salinity fields using a linear equation of state

$$
\rho=\rho_{0}\left[1-\alpha\left(T-T_{0}\right)+\beta\left(S-S_{0}\right)\right] .
$$

Vertical mixing is then carried out until three stability conditions are satisfied.

$$
\begin{gathered}
\frac{\partial \rho}{\partial z} \leq 0 \\
\mathrm{Ri}_{b}=\frac{g \Delta \rho h}{\rho_{0}(\Delta \mathbf{u})^{2}} \geq 0.65 \\
\mathrm{Ri}=\frac{N^{2}}{\mathbf{u}_{z}^{2}} \geq \frac{1}{4} .
\end{gathered}
$$

The first one, a condition for static stability that models convection, and the second, a condition for mixed layer stability, are meant to emulate the entrainment process. These two conditions create a slab-like mixed layer with a sharp discontinuity at its base. The last condition is for shear-flow stability, and the resulting jump at the base of the mixed layer is gradually partially mixed until this condition is satisfied. This creates a transition layer beneath the mixed layer connecting it to the oceanic interior.

The model was run on a vertical grid with $0.5 \mathrm{~m}$ resolution in the upper $100 \mathrm{~m}$ and one meter resolution in the remaining $200 \mathrm{~m}$ for a full depth of $300 \mathrm{~m}$, and with a timestep of 900 seconds. The model was initialized with a linear interpolation of the observed profiles 
(from mooring data) of temperature and salinity, and with zero velocity. It was forced with the observed fluxes of momentum, heat, and salt.

The resulting upper ocean evolution predicted by the model is quite limited in its vertical penetration (Fig. 3.15). The strict mixed layer in the model (based on the first two stability criteria) shoals each day as the surface layer restratifies from a net positive heat flux. A different diagnostic of mixed layer depth, using the same definition used on the data of a $0.1{ }^{\circ} \mathrm{C}$ difference from SST, only shoals in limited circumstances, like the observed mixed layer depth. Driven by the surface forcing, the mixed layer depth gradually deepens through convection, and the sea surface temperature drops. The surface salinity increases, reflecting the mean evaporative conditions, as well as entrainment erosion into a preexisting fairly salty layer. The main thermocline and pycnocline, not affected by the surface forcing, remain unperturbed during the model run.

A comparison with the observations is shown in Fig. 3.16. The mixed layer depth prediction is quite poor. The model under purely local surface forcing predicts a deepening of the mixed layer to just less than $50 \mathrm{~m}$, while the data shows the mixed layer depth has reached nearly $100 \mathrm{~m}$ by the end of the season. The model predictions of sea surface temperature and salinity fare better. Although there are obvious differences due to advectioninduced variability, the general trends and magnitudes of change are well-predicted.

The comparison of the one-dimensional model prediction and the observations reveals that local forcing cannot account for the extreme depth of the observed mixed layer during the NE monsoon. There is some nonlocal process at work, and the remainder of this chapter is devoted to investigating what processes are responsible. 


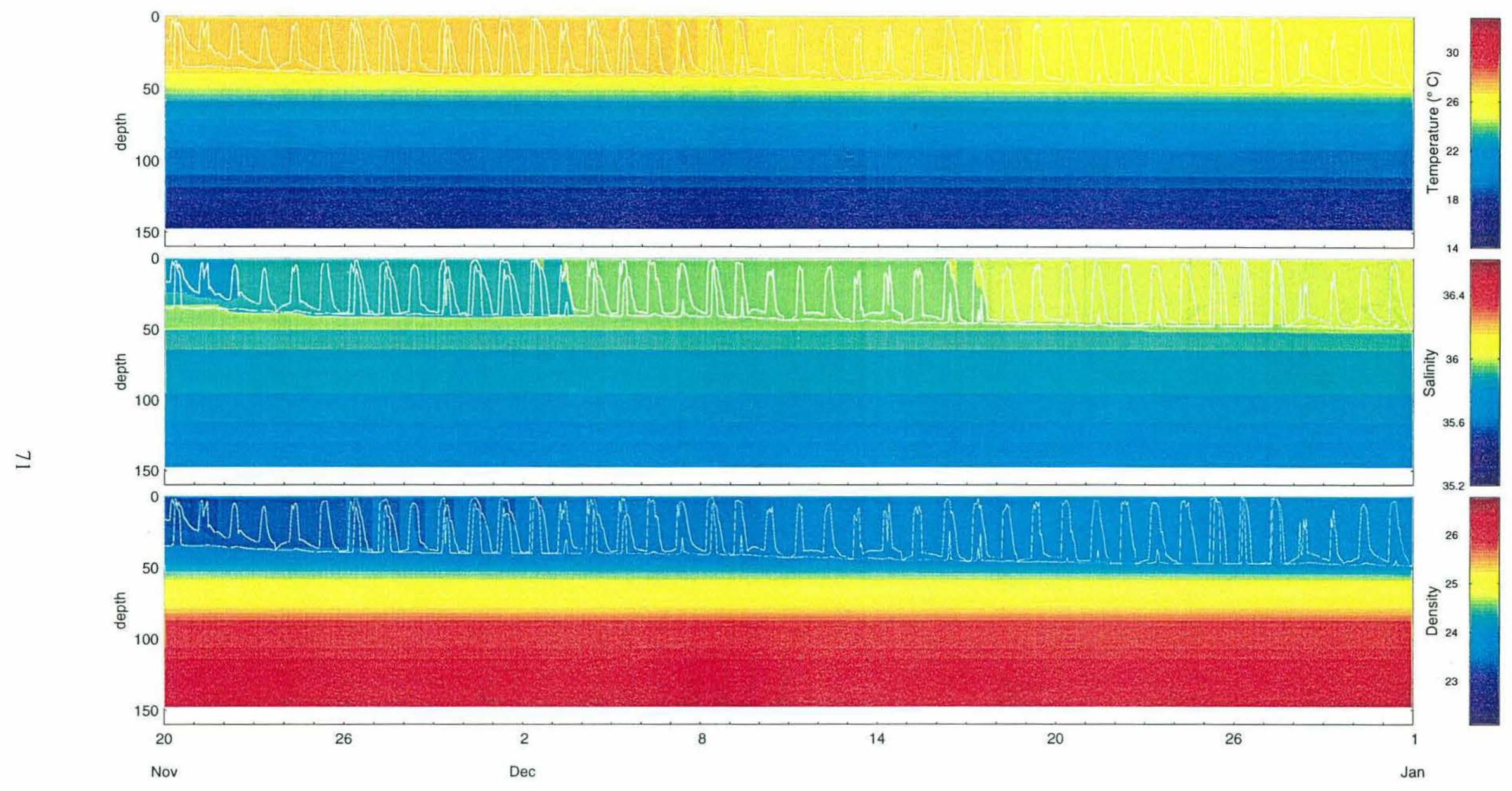

Figure 3.15 The temperature, salinity, and density in the upper ocean from the first PWP model run. The two solid lines are the strict model definition of the mixed layer, and the looser criterion used on the data. The most glaring difference in the model calculation from the observations is the relative lack of deepening of the mixed layer. 


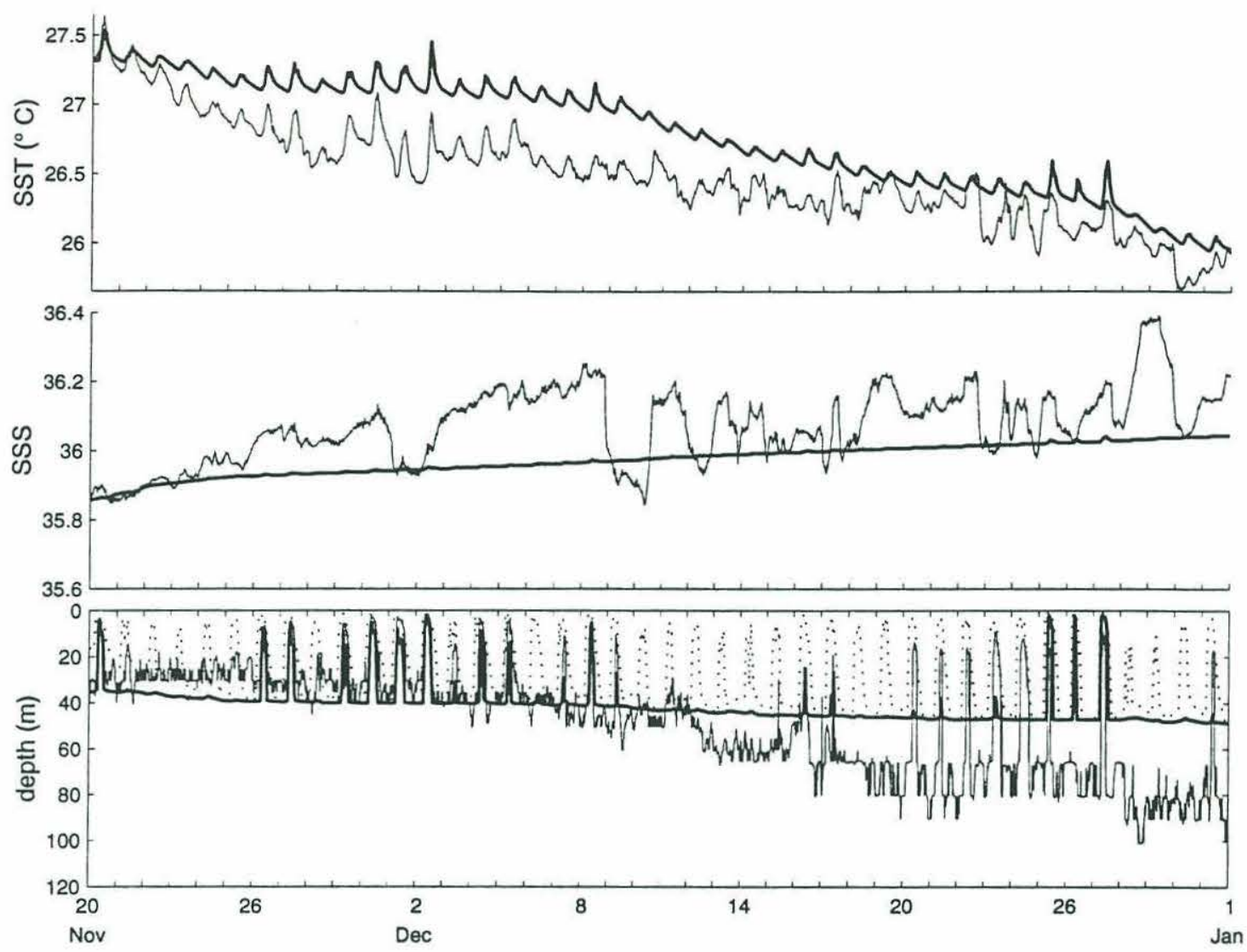

Figure 3.16 A comparison of modeled and observed mixed layer depth, sea surface temperature, and sea surface salinity. The solid lines are the model results, the light lines the observations. The dotted line in the bottom panel is the PWP model definition of the area of active mixing, while the solid line uses the same criterion as was used in selecting the observed mixed layer depth. The mixed layer depth is the least successfully predicted. The model prediction of the temperature and salinity do not demonstrate the observed variability, but generally predict the trends.

\subsection{Investigating nonlocal upper ocean forcing}

The nonlocal processes that are considered here as possible processes that account for the observed upper ocean evolution during the northeast monsoon are vertical velocities due to Ekman pumping, other vertically advective processes, and horizontal advective fluxes. This section will address these processes through a series of investigations based on data analysis and modeling. One finds, through a process of elimination, that horizontal advec- 
tion of warmer water in the thermocline, or what can be thought of as a horizontal advection of a deeper thermocline, is needed to account for the observed upper ocean evolution.

\subsubsection{The thermocline as a diagnostic for vertical displacement}

We saw in the previous section that a one-dimensional mixed layer model forced by surface fluxes alone does not evolve the upper ocean below a shallow $50 \mathrm{~m}$ mixed layer depth. But observations (see Fig. 3.7) show that the temperature evolves below the mixed layer, that the thermocline appears to subside steadily over the six week NE monsoon period. To quantify this vertical movement, the depth of the $21^{\circ} \mathrm{C}$ isotherm is traced. This

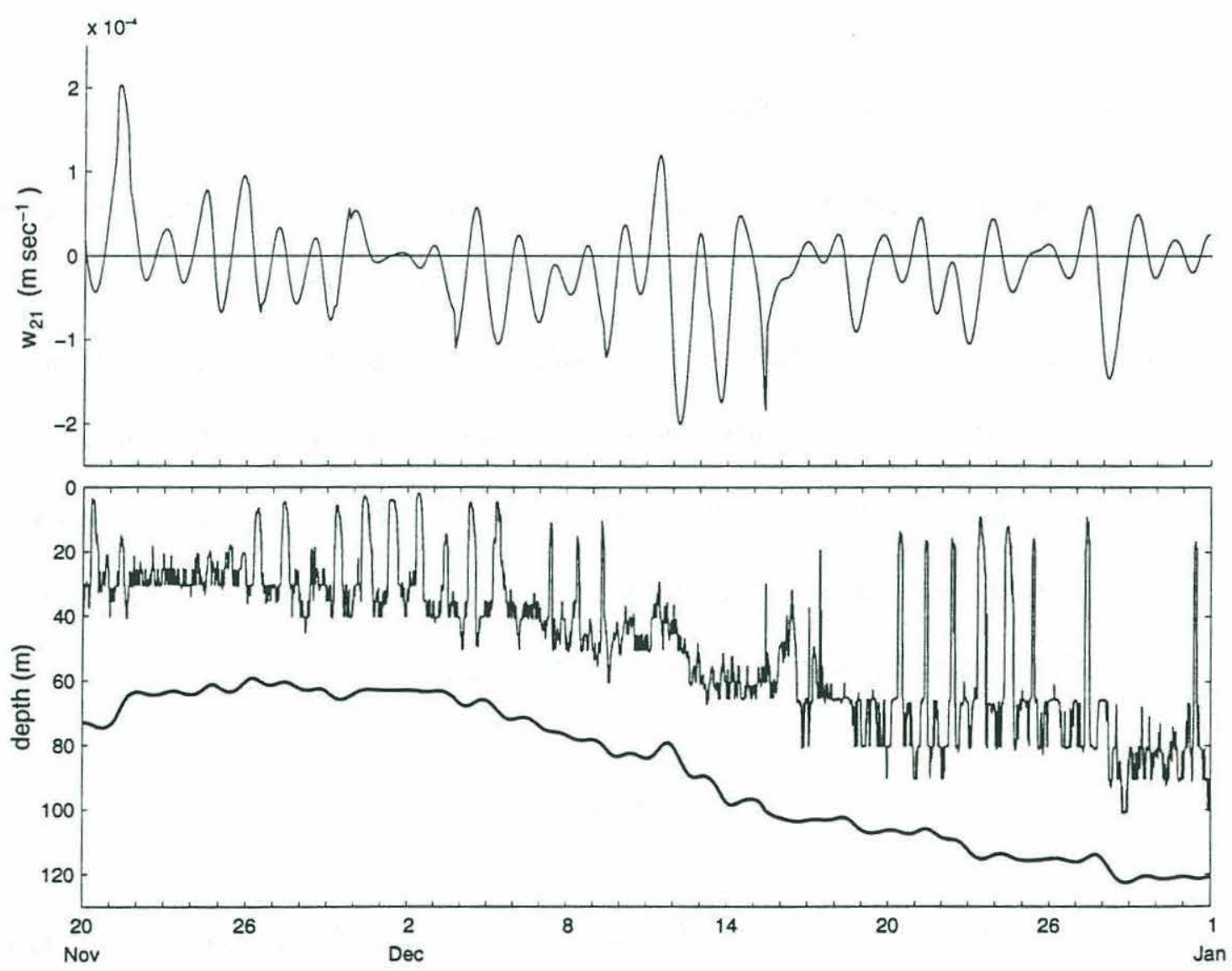

Figure 3.17 The derived vertical velocity (top) of the $21^{\circ} \mathrm{C}$ isotherm (bottom, along with the mixed layer depth). The isotherm depth tracks the mixed layer depth well, suggesting the importance of thermocline movement in the evolution of the upper ocean. 
isotherm was chosen because it remains below the reach of the mixed layer at all times during this period, but is close enough to the mixed layer base (within $40 \mathrm{~m}$ ) to be a reasonable predictor of the vertical velocity there.

The thermocline depth (as diagnosed by the $21^{\circ} \mathrm{C}$ isotherm depth) reflects the evolution of the mixed layer to a tremendous degree (Fig. 3.17) at lower frequencies. The vertical velocities derived from the movement of this isotherm are significant, and generally negative. At this point it is not clear whether this diagnosed vertical displacement is due to a true vertical velocity, or if it is the result of a one-dimensional view of horizontal advection. We will soon see (and already know from looking at the moored array temperature gradient data) that it is the latter.

\subsubsection{Ekman pumping velocity as diagnosed by ECMWF winds}

Certainly a leading candidate for a source of vertical velocity is Ekman pumping. Based on the large scale and steadiness of the winds, previous studies (Bauer et al., 1991; Brock et al., 1992) have indicated the importance of wind-induced vertical velocities in the upper ocean dynamics in this basin. Here I use a global wind product, the surface analysis winds of the ECMWF as an independent assessor of the Ekman pumping velocity.

Ekman pumping vertical velocities are the result of divergences and convergences in the surface Ekman layer mass transport. The induced vertical velocity is then

$$
w_{\mathrm{Ek}}=\nabla \times\left(\frac{\vec{\tau}}{\rho_{0} f}\right)
$$

where the Coriolis parameter $f$ is generally taken to be constant. But $f$ varies with latitude, and most rapidly in equatorial regions. If the variation of the Coriolis parameter is taken into account, the Ekman pumping velocity has two terms 


$$
w_{\mathrm{Ek}}=\frac{1}{\rho_{0} f_{0}}\left(\nabla \times \vec{\tau}+\frac{\beta_{f}}{f_{0}} \tau^{x}\right)
$$

where $f_{0}$ is the constant value of the Coriolis parameter at the latitude in question, $\beta_{f}=\partial_{y} f$ is the north-south derivative of $f$, and $\tau^{x}$ is the east component of the wind stress. The first term indicates convergence and divergence in Ekman transport due to the curl of the wind stress. The second term indicates convergence or divergence in latitudinal Ekman transports, due to the change in magnitude of the Coriolis parameter. The second term is shown to have an primary effect on the net displacement predicted by the Ekman pumping velocity, since the wind direction is so steady over such a long period of time. This is especially true in the southwest monsoon (see Fig. 4.19).

The ECMWF analysis has a grid resolution of about 1.2 degrees in both latitude and longitude. The closest gridpoint to the site of the buoy is at $61.88^{\circ} \mathrm{E}, 15.14{ }^{\circ} \mathrm{N}, 57 \mathrm{~km}$ away. The Ekman pumping velocity was calculated, with estimates for the curl of the wind stress at the point being calculated from its four closest neighbors in each direction. The results of this calculation are in Fig. 3.18. The time resolution of the ECMWF analysis is six hours. The expected downwelling due to Ekman pumping is predicted by ECMWF to be only on the order of five meters over the six-week period under examination. Ekman pumping can only contribute a small part to the diagnosed vertical displacement. ECMWF winds only capture the broadest scales, but the winds matched those observed at the mooring site well, and since the scales of the wind in the Arabian Sea are known to be broad, my confidence in this estimate of the Ekman pumping velocity is quite high. Work to confirm this independently from the array winds and from satellite wind scatterometer data is ongoing. 


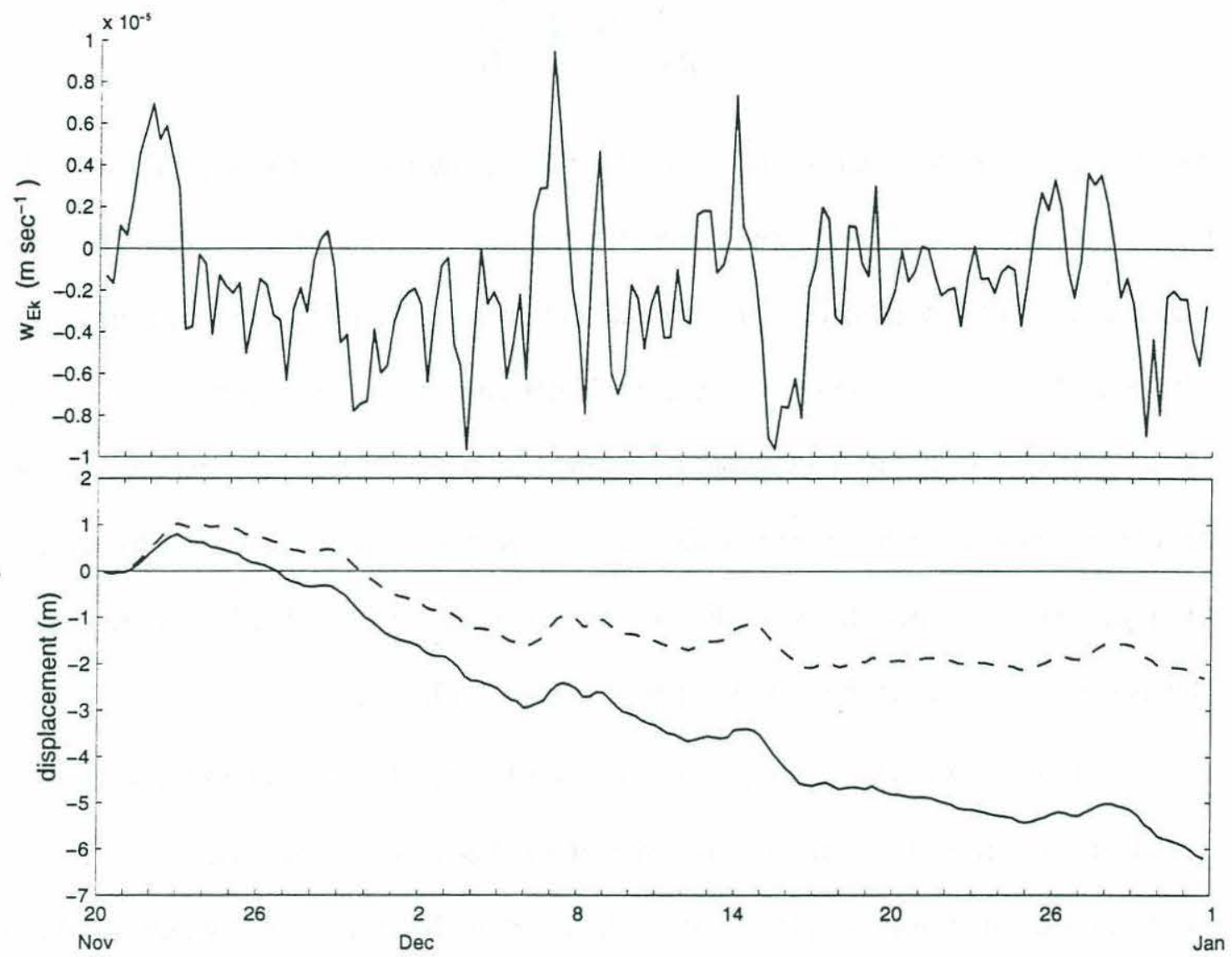

Figure 3.18 ECMWF analysis-derived estimates of the vertical Ekman velocity induced by the divergence of the Ekman transport. The first panel is the vertical velocity, the second panel shows the expected displacement over time. The vertical velocity here is one order of magnitude smaller than that found in Fig. 3.17. The dotted line in the second panel shows the displacement when only the variation in the wind stress is used in the calculation; the variation in the coriolis parameter is ignored. During periods of sustained directional winds, the variation in latitude of the coriolis parameter is important, especially in low latitudes where $\beta_{f}$ is large.

\subsubsection{Modified heat budget}

Earlier I used a one-dimensional heat budget to diagnose whether the upper ocean response can be understood as a local response to local forcing. The effect of the horizontal advection of temperature gradients in the thermocline can now be added with the diagnosed vertical velocity found in Section 3.6.1. A crucial assumption must be made: that the slope of all isotherms is uniform. Another way of stating this is that the profile of strat- 
ification remains uniform in space, but is only displaced vertically. Then a vertical advection term with the vertical velocity diagnosed from the vertical displacement of an isotherm can take the place of a horizontal advection term. Within the mixed layer, we know the horizontal gradients of properties are small, so horizontal advection is small. The vertical advection terms mimics this as well, since the vertical gradient in the mixed layer is by definition nonexistent.

The temperature evolution equation now becomes

$$
\rho_{0} C_{p}\left(\frac{\partial T}{\partial t}+w \frac{\partial T}{\partial z}\right)+R=\frac{\partial}{\partial z}(q-r)
$$

There is a diagnosed vertical velocity at the level of the isotherm from which it is taken. But to integrate down to a deep reference level, the full vertical profile of the vertical velocity is needed. I here assume that the profile decays linearly to zero at the surface (Price et al., 1978),

$$
w=w_{\mathrm{H}}(-z / H)
$$

where $w_{\mathrm{H}}$ is the vertical velocity at the reference depth of integration. This velocity is taken from the diagnosis for the $21^{\circ} \mathrm{C}$ isotherm, interpolated to the reference depth of 100 $\mathrm{m}$. The slope in vertical velocity is then a constant

$$
\frac{\partial w}{\partial z}=-\frac{w_{\mathrm{H}}}{H} .
$$

The vertical integral of the vertical advection term now takes the form, after some manipulations and integration by parts,

$$
\int_{-H}^{0} w \frac{\partial T}{\partial z} d z=\left.w T\right|_{-H} ^{0}-\int_{-H}^{0} \frac{\partial w}{\partial z} T d z=-\left.w_{\mathrm{H}} T\right|_{-H}+\frac{w_{\mathrm{H}}}{H} \int_{-H}^{0} T d z=w_{\mathrm{H}}\left(\bar{T}^{z}-\left.T\right|_{-H}\right)
$$


The symbol $\bar{T}^{z}$ refers to the vertical average of the temperature in the layer bounded by the surface and the reference depth. The full heat budget equation then becomes

$$
\rho_{0} C_{p}\left[\int_{-H}^{0} \frac{\partial T}{\partial t} d z+w_{\mathrm{H}}\left(\bar{T}^{z}-\left.T\right|_{-H}\right)\right]+R=Q_{\text {net }}
$$

where the first term is the vertical integral of the temperature trend, the second term accounts for the vertical displacement at the base of the reference layer, and these plus a residual are balanced by the surface heat flux. Again the depth of the reference level is

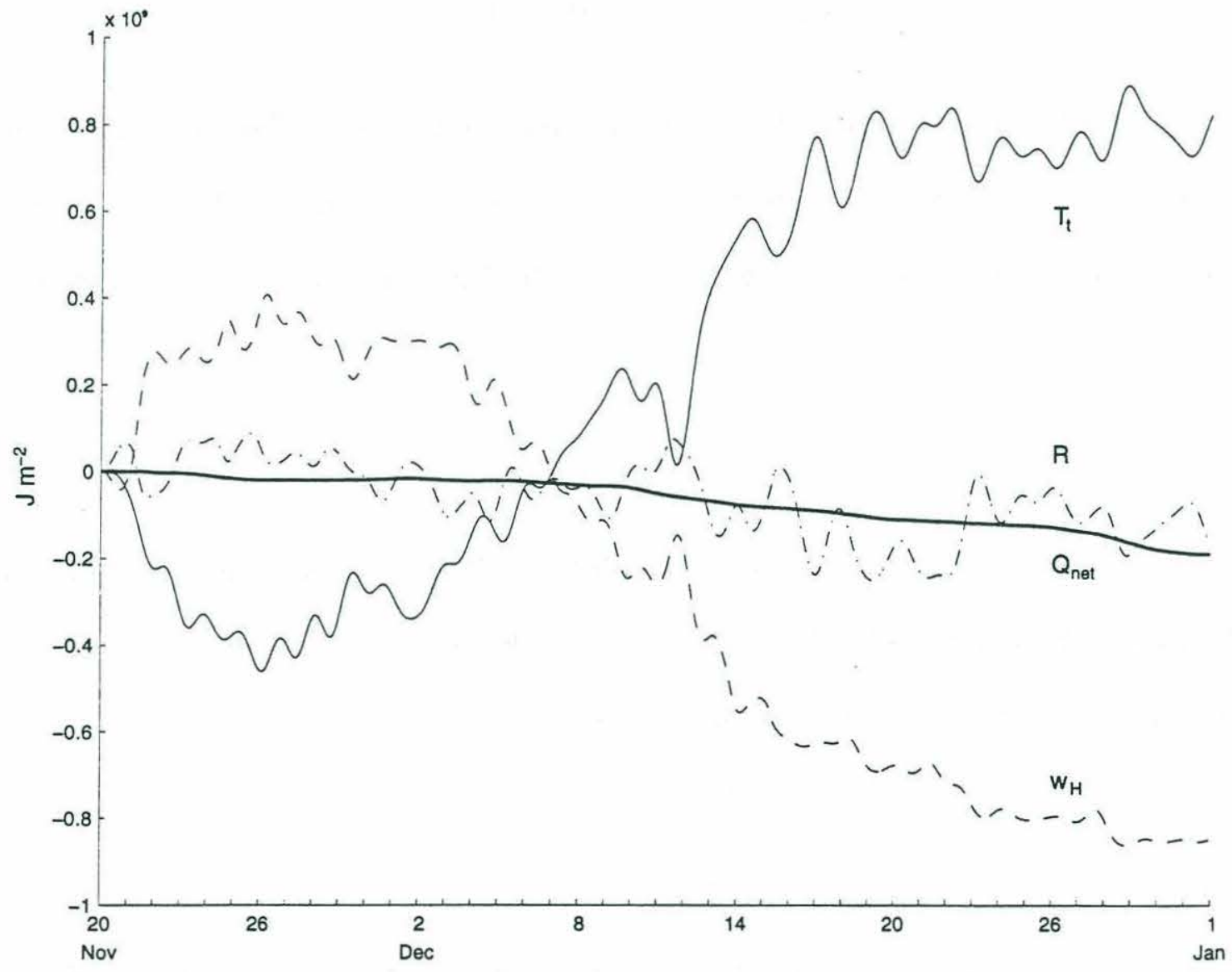

Figure 3.19 The heat budget accounting for the effect of vertical displacement of the thermocline. The terms from (3.36) are the temperature trend $\left(T_{t}\right)$, the effect of vertical displacement $\left(w_{H}\right)$, the residual $(R)$ and on the RHS the net heat flux $\left(Q_{\text {net }}\right)$. The primary balance appears to be between the heat content term and the vertical displacement term. 
assumed to be below that where turbulent fluxes are active, but now changes in the temperature at the reference depth are accounted for.

The result of this calculation is shown in Fig. 3.19 as a time integral of (3.36), with constants of integration set to zero. It shows a remarkable balance between the temperature content and the change in heat accounted for by vertical displacement. The values of $\bar{T}^{z}$ and $\left.T\right|_{-H}$ are diagnosed from data. This imposed vertical displacement nearly closes the heat budget.

\subsubsection{Modified salt budget}

The salt budget is extended in a similar way to include vertical displacement of vertical gradients. The salt evolution equation is

$$
\frac{\partial S}{\partial t}+w \frac{\partial S}{\partial z}+R=\frac{\partial}{\partial z}(q-r)
$$

Assuming the same profile in vertical velocity as before, diagnosed from the velocity of the displacement of the $21^{\circ} \mathrm{C}$ isotherm, one finds that the full salt budget equation is

$$
\int_{-H}^{0} \frac{\partial S}{\partial t} d z+w_{\mathrm{H}}\left(\bar{S}^{z}-\left.S\right|_{-H}\right)+R=S_{0}(E-P)
$$

where $\bar{S}^{z}$ is the vertical average of the salinity between 0 and $-H$, and $R$ represents the residual.

This balance is shown in Fig. 3.20 as a time integral, with a reference depth of $100 \mathrm{~m}$. Values of $\bar{S}^{z}$ and $\left.S\right|_{-H}$ are diagnosed from the data. Vertical displacement serves the freshen the upper layer, on balance, making the residual smaller, but not capturing the variability displayed in the salinity data. 


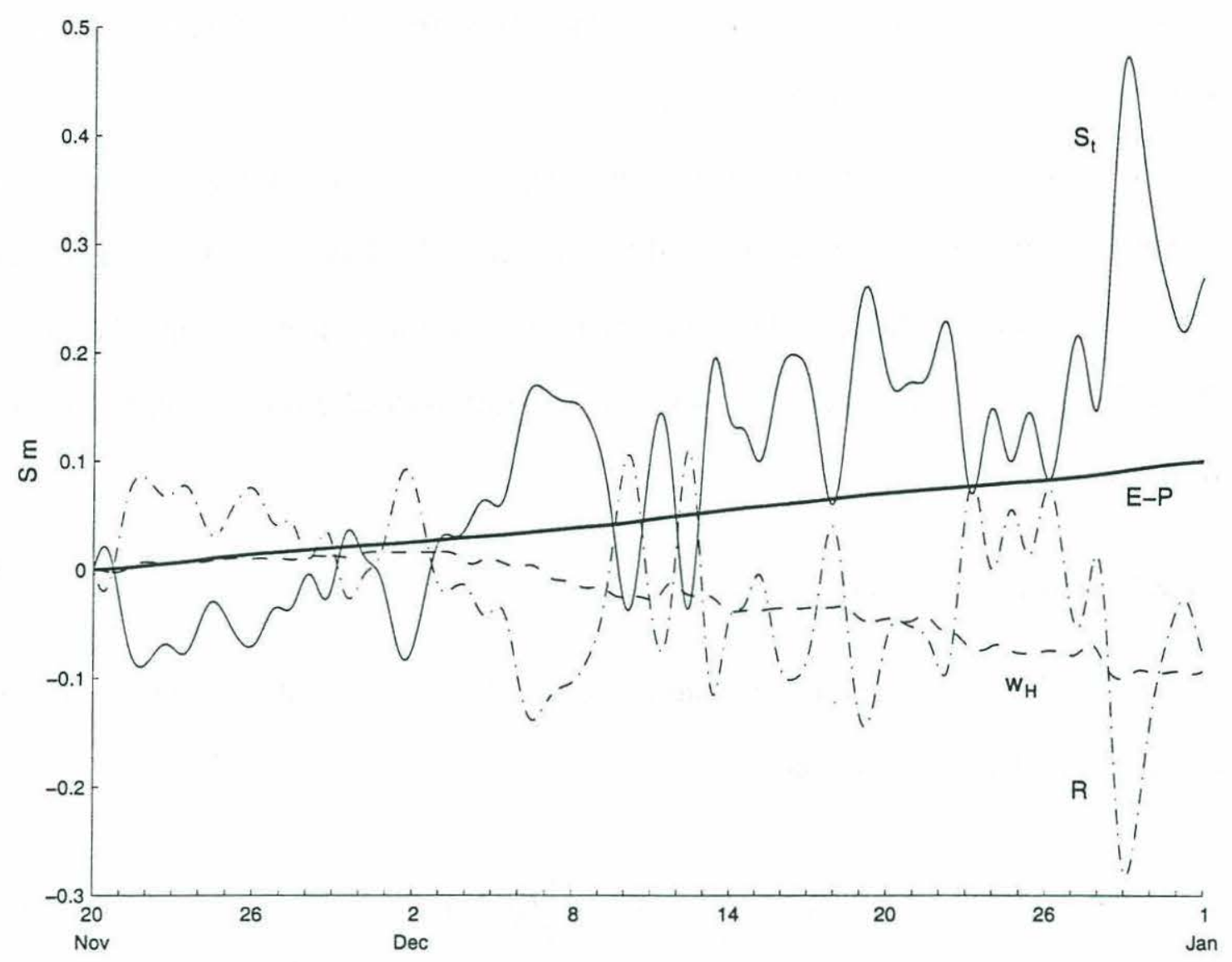

Figure 3.20 The salt budget accounting for the imposed vertical velocity. The terms from (3.38) are the salt trend term $\left(\mathrm{S}_{\mathrm{t}}\right)$, the vertical displacement term $\left(\mathrm{w}_{\mathrm{H}}\right)$, the residual, and the surface forcing term (E-P).

\subsubsection{Model experiment}

To further help evaluate the diagnosed vertical displacment of the thermocline and its effect on the upper ocean, an addition is developed to the previously presented one-dimensional mixed layer model, adding an imposed vertical velocity to the equations for the conservation of momentum, heat and salt. This is similar to the model used by Schudlich and Price (1992), although instead of applying a true dynamical vertical velocity, I use it as a handle to apply a horizontal advection of temperature below the mixed layer. I will here use the example of temperature, but this imposed vertical displacement is applied to 
the velocity and salinity as well. The conservation equation for heat (3.23) is modified by the addition of a vertical displacement term

$$
\frac{\partial T}{\partial t}=-w \frac{\partial T}{\partial z}-\frac{1}{\rho_{0} C_{p}} \frac{\partial F}{\partial z}
$$

In the model, the vertical velocity is imposed by the diagnosed velocity from the depth of the $21^{\circ} \mathrm{C}$ isotherm. The imposed profile of vertical velocity is of a sawtooth shape, with values of zero at the upper and lower boundary of the model $\left(z=0\right.$ and $\left.z=z_{\mathrm{B}}\right)$, and the isotherm value $w_{\mathrm{I}}$ at the isotherm depth $\left(z=z_{\mathrm{I}}\right)$

$$
w=\left\{\begin{array}{cc}
w_{\mathrm{I}}\left(z / z_{\mathrm{I}}\right) & z_{\mathrm{I}} \leq z \leq 0 \\
w_{\mathrm{I}}\left(\frac{z-z_{\mathrm{B}}}{z_{\mathrm{I}}-z_{\mathrm{B}}}\right) & z_{\mathrm{B}} \leq z<z_{\mathrm{I}}
\end{array} .\right.
$$

The surface-driven mixing in the model never reaches the depth $z_{\mathrm{I}}$, so the return in the vertical velocity to zero at the base of the model is not meant to be physically realistic, but is a numerical convenience with no effect on the physics of the model.

Numerically the vertical advection term was implemented at each timestep using a centered-differencing scheme for calculating local gradients. Using the example of temperature again, the actual forward integration is a simple Euler timestep,

$$
T_{i+1, z}=T_{i, z}+\Delta T_{i, z}-\left[w_{i} \frac{\left(T_{i, z+1}-T_{i, z-1}\right)}{\Delta z}\right] \Delta t
$$

where the index $i$ refers to the timestep and the index $z$ the vertical gridpoint in the model. The quantity $\Delta T_{i, z}$ is the indicated change in temperature due to the previously noted heat flux and turbulent mixing parameterizations, the other model physics. Since $w$ is set to 0 on the boundaries, there is no numerical difficulty with vertical boundary condi- 
tions of gradients in velocity, temperature, or salt.

The model was again initialized with the linearly interpolated observed profiles of salinity and temperature at the beginning of the integration period, and forced with the observed surface fluxes of momentum, heat, and salt. An additional input of the imposed vertical velocity diagnosed from isotherm displacement, and depth at which this should be applied, were fed to the model. The predicted time evolution of the model now involves a much larger vertical fraction of the water column (Fig. 3.21). As the thermocline moves downwards vertically through the imposed velocity, the mixed layer base follows, as the strongest barrier to mixing displaces downwards. The predicted values of the surface temperature and salinity do not appear to be markedly different from the previous model, but the overall structure of the upper ocean is closer to the observations.

A comparison with the observed data (Fig. 3.22) shows a remarkable correspondence in the predicted and observed mixed layer depths. It seems that the combination of the surface forcing and the diagnosed vertical displacement below the mixed layer together account well for the upper ocean evolution. The temperature and salinity predictions are not much changed, although they are slightly worse than before. The temperature prediction is warmer than before due to the larger volume of warm upper water present as the thermocline sinks. There is then relatively more buoyant water that must be changed before penetrative convection can work to erode at the mixed layer base.

This diagnosed vertical displacement is an important variable, and the upper ocean evolution is only understood with its addition. Now we can answer the question: what is dynamical root of this vertical displacement? ECMWF winds suggest that it is not Ekman pumping. This leaves two choices, that it is a vertical velocity of another type, or that it is truly horizontal advection that has been aliased into an apparent vertical displacement by our blindered one-dimensional view of the upper ocean evolution. In fact, the discrepan- 

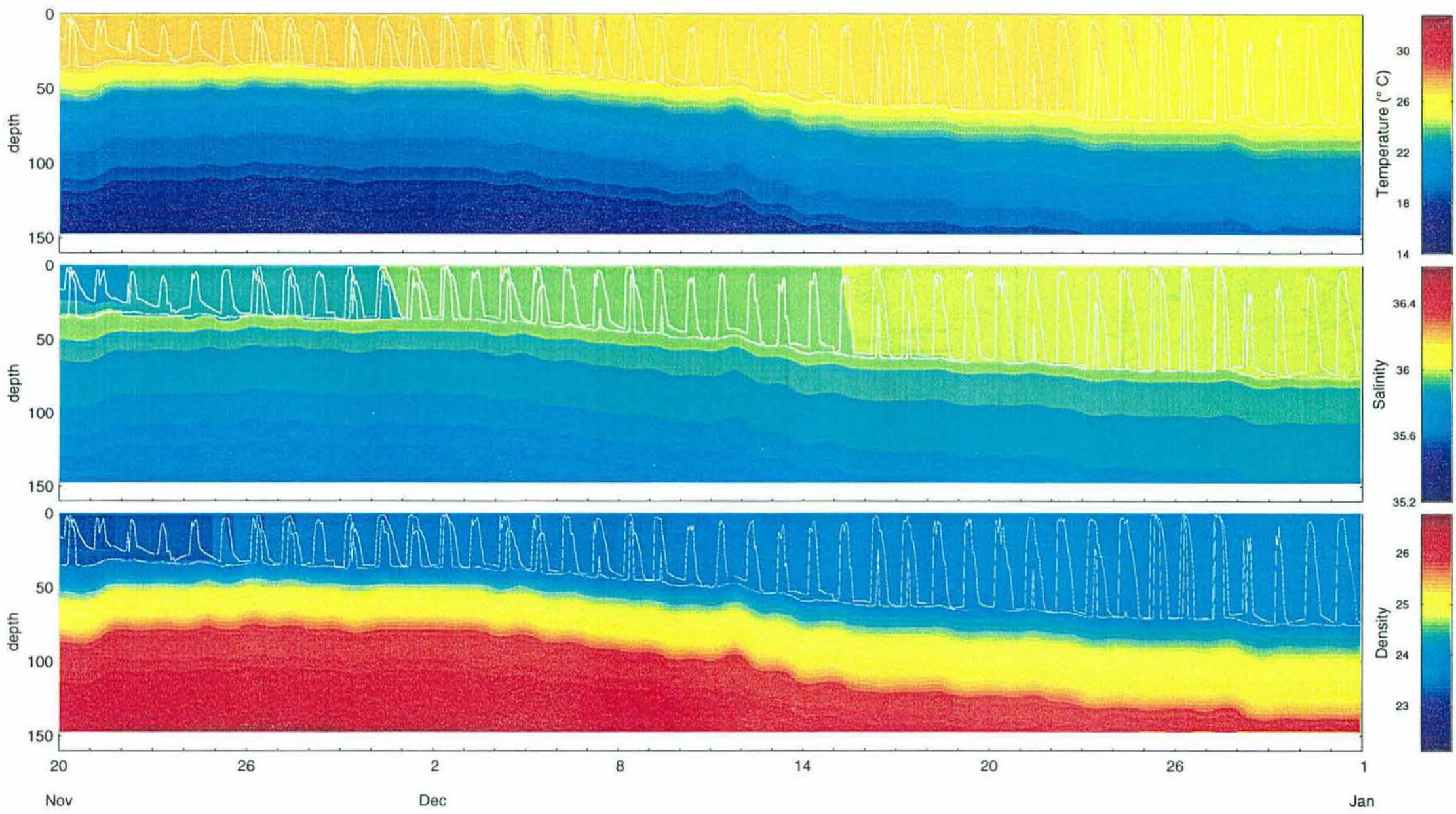

Figure 3.21 Modeled temperature, salinity, and density from the PWP model run with an imposed vertical velocity. The mixed layer depth prediction closely follows the changing thermocline. Otherwise it is quite similar to the first run. 


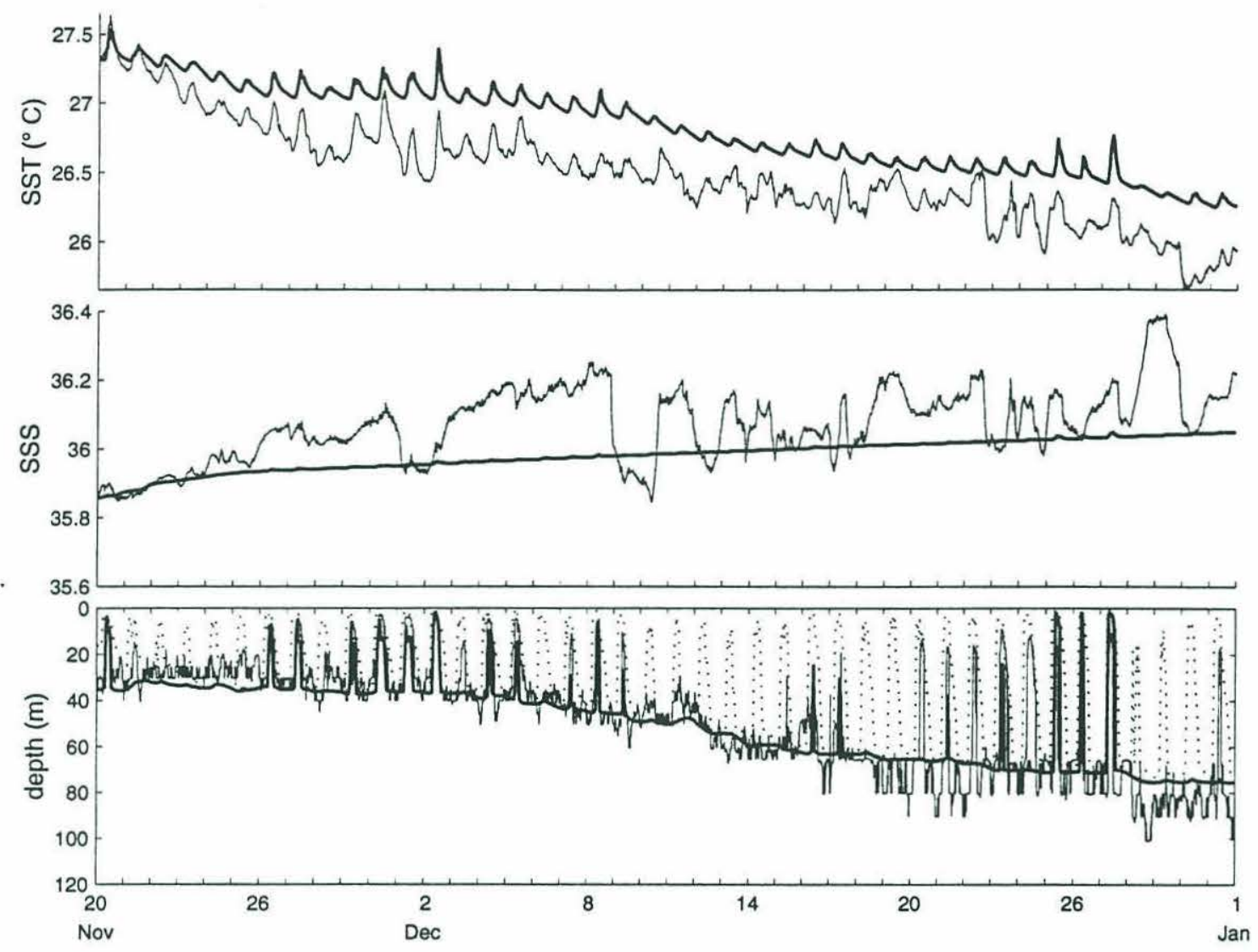

Figure 3.22 Comparison of the observed and modeled mixed layer depth, temperature, and salinity using the imposed vertical velocity version of the model. Thick lines are modeled, thin are observed, dotted is the PWP model strict definition of the region that is vertically mixed.

cies between the observed and modeled velocity fields (see Fig. 3.2) have already suggested that this latter explanation. It is pursued further below.

\subsubsection{TS properties}

The temperature-salinity properties of a water mass are set through contact with the atmosphere, and are retained in the absence of mixing processes. Because of this, TS characteristics are a good label for various water masses, and looking at the evolution of this relationship can be instructive, especially in our current situation of trying to separate the effects of vertical and horizontal advection. The TS relationship of the water in the upper ocean during the NE monsoon period is shown in Fig. 3.23. There is large scatter even in 

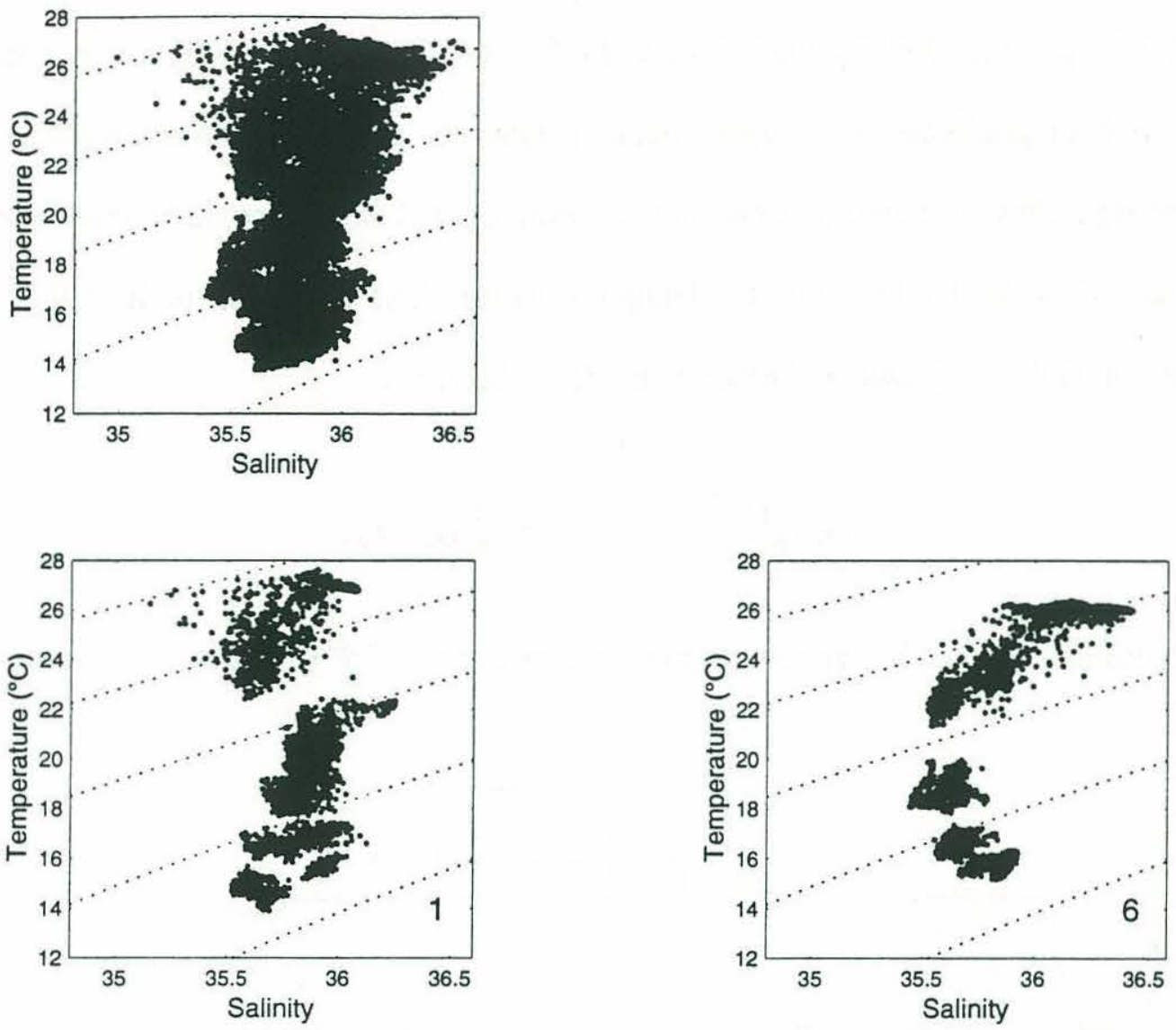

Figure 3.23 The changing TS relationship during the NE monsoon. The top panel encompasses all six weeks of the studied period, while the panels below contain the first (1) and last ( 6 ) weeks.

density classes well below the mixed layer, which is indicative of water mass changes at the mooring site. In fact, the first and last week TS relationships of the NE monsoon period at the mooring site are quite different within and more importantly beneath the mixed layer. There is evidence of a saltier and cooler water mass displacing the original water mass in the upper part of the data (which starts with $\mathrm{T}$ of $22-25.5^{\circ} \mathrm{C}$ and $\mathrm{S}$ of $35.4-$ 35.7 and ends up with $\mathrm{T}$ of $21-25^{\circ} \mathrm{C}$ and $\mathrm{S}$ of $\left.35.5-35.9\right)$, but below the mixed layer. This can only be accomplished through horizontal advection of different water masses past the mooring site, and cannot be accounted for through a vertical velocity alone. 


\subsubsection{Putting bounds on advective gradients}

So I argue that the important nonlocal effect that has been investigated is a horizontal advection of gradients in the upper ocean properties, gradients that are weak within the mixed layer, but particularly strong in the thermocline. I can put some bounds on what this gradient must be by looking at a budget equation. The evolution of heat if horizontal advection is the only nonlocal effect considered becomes

$$
\rho_{0} C_{p}\left(\frac{\partial T}{\partial t}+\mathbf{u} \cdot \nabla T\right)=\frac{\partial}{\partial z}(q-r) .
$$

I now assume that the horizontal gradient in temperature $\nabla T$ is independent of the depth $z$

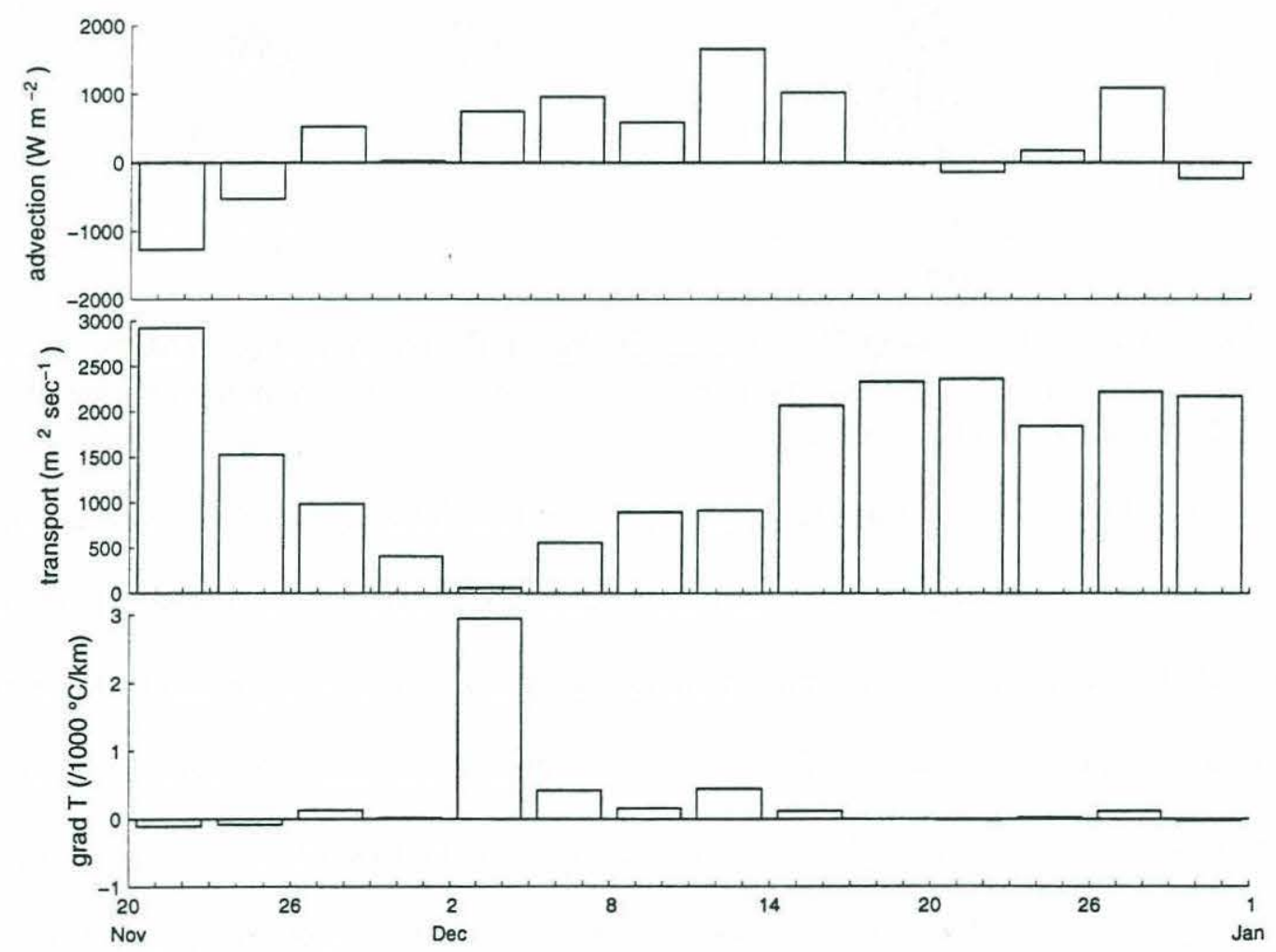

Figure 3.24 The required gradients in temperature if horizontal advection is assumed to be the sole nonlocal process, binned into three-day periods. From top: the residual advection of heat in the local budget, the observed vertically integrated transport, and the gradient in temperature necessary to account for the residual and close the budget. 
in the upper ocean. This is not a particularly good assumption when one remembers the estimation of the gradients from the array data, and so the resulting gradient calculated must be thought of as a lower bound, or an average over the integration depth. A heat budget equation can then be formed in which the only unknown is the horizontal gradient in temperature. This is

$$
\rho_{0} C_{p}\left(\int_{-H}^{0} \frac{\partial T}{\partial t} d z+\int_{-H}^{0} \mathrm{u} d z \cdot \nabla T\right)=Q_{\text {net }} .
$$

where I take the depth of integration $-H$ to be a fixed $100 \mathrm{~m}$. The estimates of what the horizontal gradient in temperature must be to account for the residual in the one-dimensional heat budget are extremely small (Fig. 3.24). In the array data, it was not unusual to

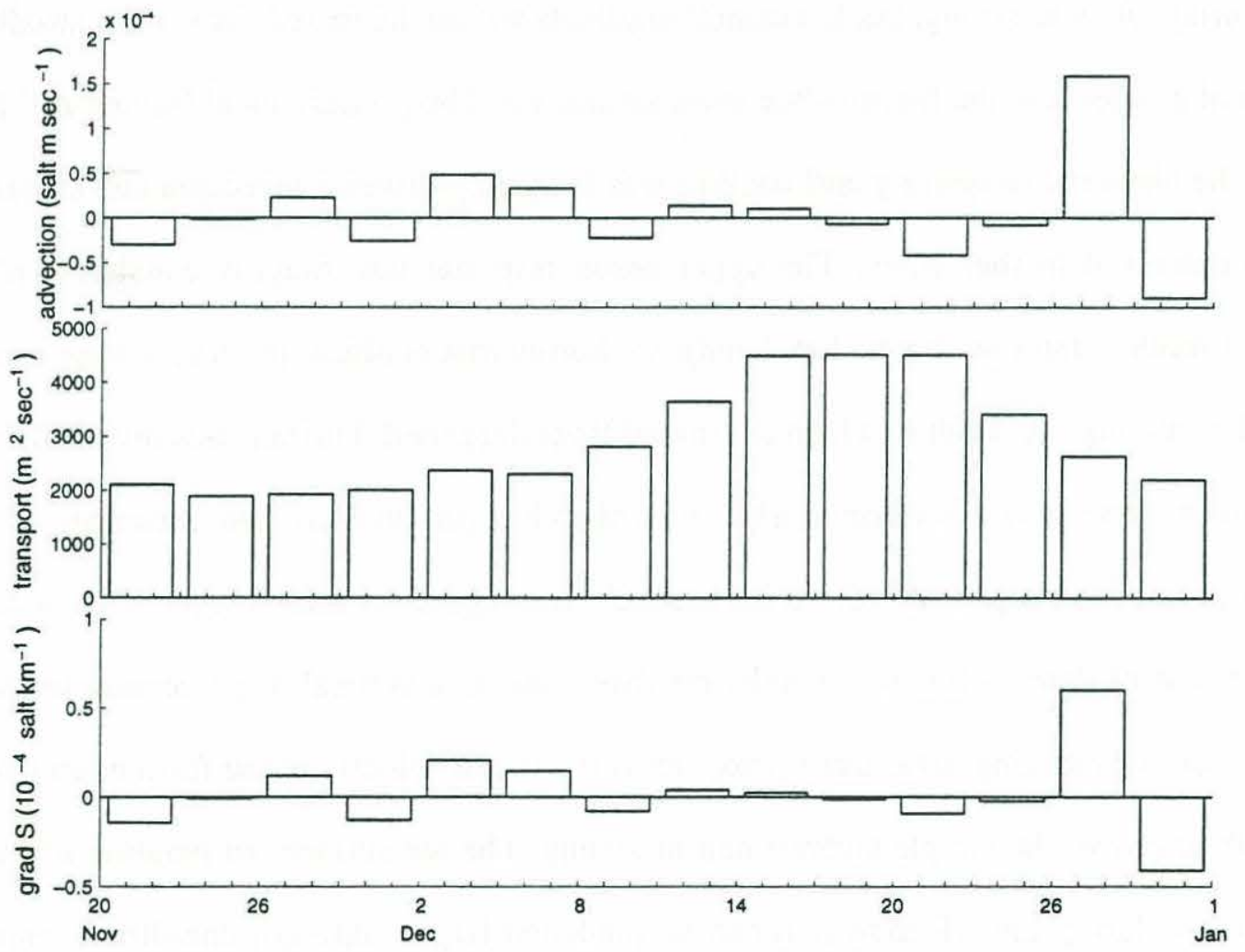

Figure 3.25 The required gradient in salinity if horizontal advection is assumed to be the sole nonlocal process, three-day binned. From top: residual to local budget, observed transport, and required horizontal salinity gradient. 
find gradients an order of magnitude larger (see Fig. 3.1). But when one recalls that this is the average gradient over the $100 \mathrm{~m}$ of integration, then these estimates are consistent with the gradients observed in the array data, which are largely confined to the top of the thermocline.

A similar calculation is made with the salt budget (Fig. 3.25). The gradients necessary to close the salt budget are similarly small, but again should be regarded as a lower bound, since they are assumed to be uniform over the depth of integration.

\subsection{Summary}

The northeast monsoon forces the upper ocean on a broad spatial scale with a moderately strong wind stress and a destabilizing buoyancy flux. The nonlocal velocity response at the mooring site was strong, but horizontal gradients within the mixed layer were small. Horizontal gradients in the thermocline were significant. The primary local forcing mechanism for the observed deepening and cooling was buoyancy-driven convection and entrainment of cooler and fresher water. The upper ocean response was roughly consistent with the local forcing, but one-dimensional budgets showed that nonlocal processes were crucial in understanding the depth to which the mixed layer deepened. Further tests revealed that this nonlocal process is a horizontal advection of a changing thermocline, remnants of eddies that have been capped off with a horizontally homogeneous mixed layer. This horizontal advection of thermocline topography resolves itself as a vertical displacement in the onedimensional mooring data, and a proxy for this vertical velocity in the form of an isotherm depth improves the simple budgets and modeling. The sea surface temperature of the Arabian Sea during the NE monsoon can be predicted largely through one-dimensional balances heat processes driven by convection, without appealing to higher order dynamics. 


\section{Chapter 4}

\section{Southwest Monsoon}

The southwest, or summer monsoon, over the Arabian Sea has some of the strongest and steadiest winds observed (Knox, 1987). The general pattern of atmospheric flow at the surface brings winds across the equator, and with them hot, humid air. The winds resolve themselves in the time mean into a jet which flows steadily from the southwest in a largescale pattern over the Arabian Sea and onto the Indian subcontinent. Despite the strength

of the winds, the evaporative heat loss from the ocean is limited by the extreme humidity of the air. This atmospheric moisture also limits the amount of longwave radiative heat loss from the surface. The net result is that the heat flux is generally, and sometimes overwhelmingly in the sense of an oceanic gain during the southwest monsoon. Yet the mixed layer is observed to deepen and cool.

The aim of this chapter is to examine the deepening and cooling of the mixed layer during the southwest monsoon, and to make a determination of what balance of processes in the upper ocean are responsible. The methods, and therefore the structure of this chapter, are very similar to those applied to the northeast monsoon. The first section puts the observations of the upper ocean in the context of the general oceanographic background. 
Then the next two sections examine the surface fluxes and the upper ocean response during the selected period. The primary driving mechanism for the deepening is found to be wind-driven shear instabilities at the base of the mixed layer. The local and nonlocal processes that force the mixed layer are then examined. The last section is a brief summary. While the primary deepening mechanism is local, in order to close the budgets of heat and salt a moderate horizontal advection of cooler and fresher water in the mixed layer is needed.

Defining the southwest monsoon by the steadiness in the direction of the winds, it extends in earnest from early June through mid-September. There is an earlier false start in May, in which the winds tend to be moderately strong and southwesterly, the relative humidity is very high, and the longwave heat loss is limited (see Fig. 2.5). The mixed layer deepens to about $30 \mathrm{~m}$ and diurnal cycling in sea surface temperature is curtailed. Intermonsoon conditions return by the latter third of May, the mixed layer restratifies, and sea surface temperatures reach their deployment peak of $32.3^{\circ} \mathrm{C}$ on June 1 . I will restrict my analysis to the period of observed mixed layer cooling and deepening, which ranges from the beginning of June with the sustained onset of the southwest monsoon, and lasts through mid-July. At the beginning of June, the mixed layer depth reaches minima during the daylight hours of less than one half meter, and is between 15 and 20 meters at night. By mid-July, the sea surface temperature has dropped to $27.5^{\circ} \mathrm{C}$, and the mixed layer depth (defined by a $0.1{ }^{\circ} \mathrm{C}$ difference from the SST) has reached nearly 80 meters, with no diurnal restratification. After this time, the SST continues to drop, but the mixed layer shoals. To examine the primary period of cooling and deepening, I extracted the record from May 30 through July 11. 


\subsection{Oceanographic setting}

The southwest monsoon is a period of strong mesoscale and fine scale activity in the Arabian Sea. The wind-driven Somali current is very energetic, and as is separates from the coast and becomes the more eastward Southwest Monsoon Current, it sheds eddies (Kantha, pers. comm.). The broad southwesterly winds also promote significant coastal upwelling and drive a current along the Omani coast, which has been observed to become unstable and shed filaments and eddies of cold and fresh water which extend far into the Arabian Sea (Arnone, Brink, Lee, pers. comm.).

Array data return during the strong southwest monsoon was lower than that during the NE monsoon, and so estimates of the horizontal gradients in temperature are limited to the lower mixed layer and thermocline. But these estimates generally support the idea that horizontal gradients in the mixed layer can be significant. The data return on the SIO-N mooring was poor, and so the estimate in this case is based on the central WHOI mooring, the SIO-S mooring, and the UW-S profiling current meter (PCM) mooring (see Fig. 2.1), which reached a minimum depth of $30 \mathrm{~m}$ below the surface. The estimate was computed in the same fashion as for the NE monsoon: a 48-hour lowpass filter, EOF decomposition and truncation, vertical splining and plane fitting to estimate horizontal gradients. The first 4 modes in temperature were retained, representing $97 \%$ of the variability in the lowpass filtered fields. In velocity the first 3 modes representing $93 \%$ of the variability were retained. The gradient was then projected onto the upstream direction, determined from a similar procedure yielding the average velocity for the array. The resulting upstream gradient (see Fig. 4.1) is smaller in the mixed layer than elsewhere, but still significant. Gradients in the thermocline are not as strong as they were during the NE monsoon. 


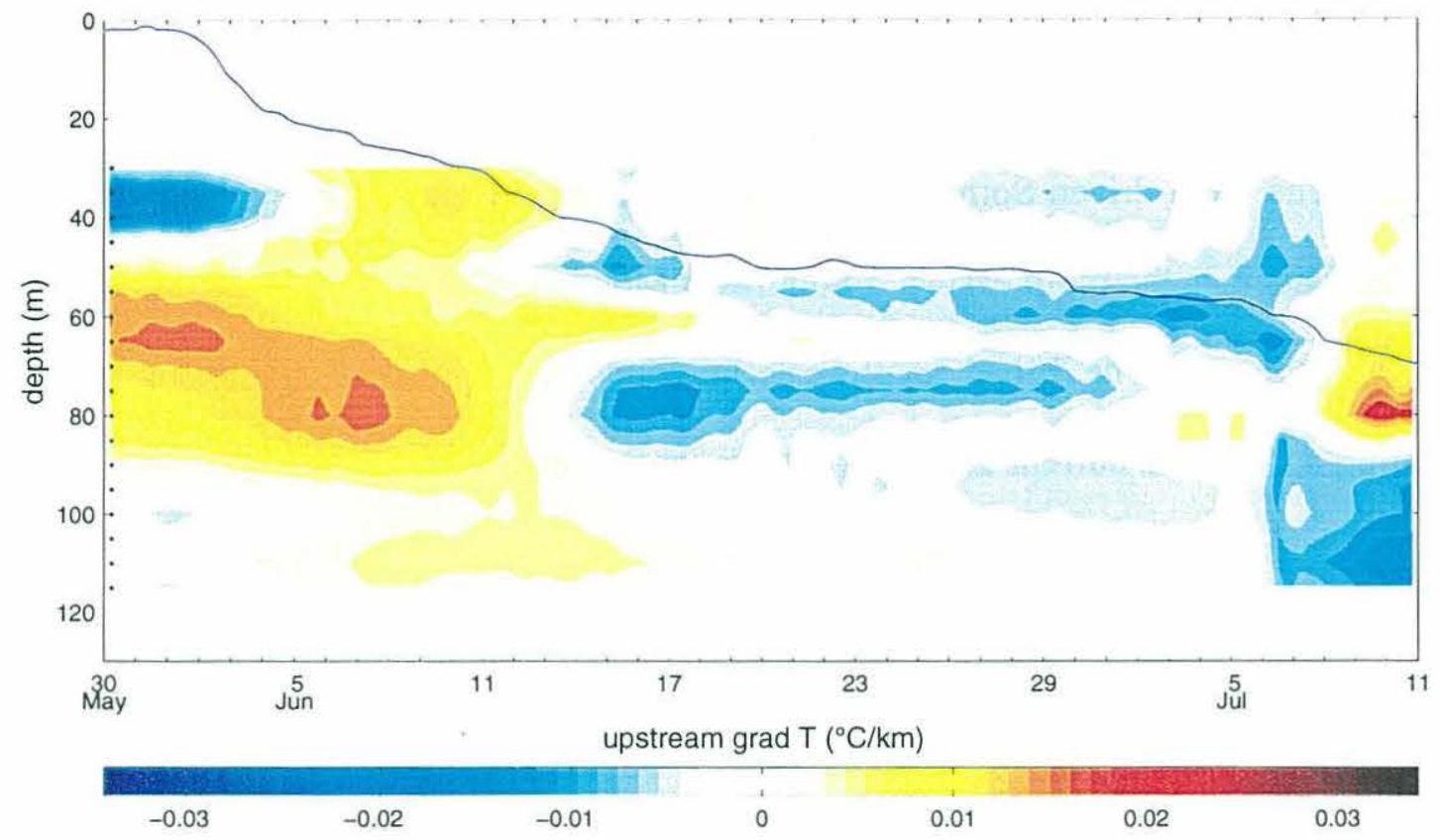

Figure 4.1 The upstream gradient in temperature based on the moored array data. A positive gradient indicates warming. Grey areas mark areas where insufficient data existed to compute a horizontal gradient. Mixed layer depth (blue line) based on lowpass filtered temperature data. The upstream direction below $80 \mathrm{~m}$ is represented only by the SIO-S and UW-S moorings.

Velocities recorded at the central WHOI mooring during the first part of the SW monsoon season were much less than those seen in the NE monsoon, averaging $20 \mathrm{~cm} \mathrm{sec}^{-1}$ at the surface. Progressive vector diagrams of the raw velocity, as well as the velocity with the deep 80 m velocity subtracted (Fig. 4.2) show that the velocity response is close to being the local response to the wind. The transport in the upper ocean (minus the deep velocity) is within $15 \%$ of the magnitude and $15^{\circ}$ in direction of the theoretical Ekman transport. The overall transport is of the same magnitude. A progressive vector diagram of the output of a one-dimensional model forced with the observed surface fluxes is similar in structure and direction to the upper ocean velocities.

The gradient in temperature within the mixed layer is fairly large. The observed velocities are largely understood as a local response to the wind forcing. But we shall find that 

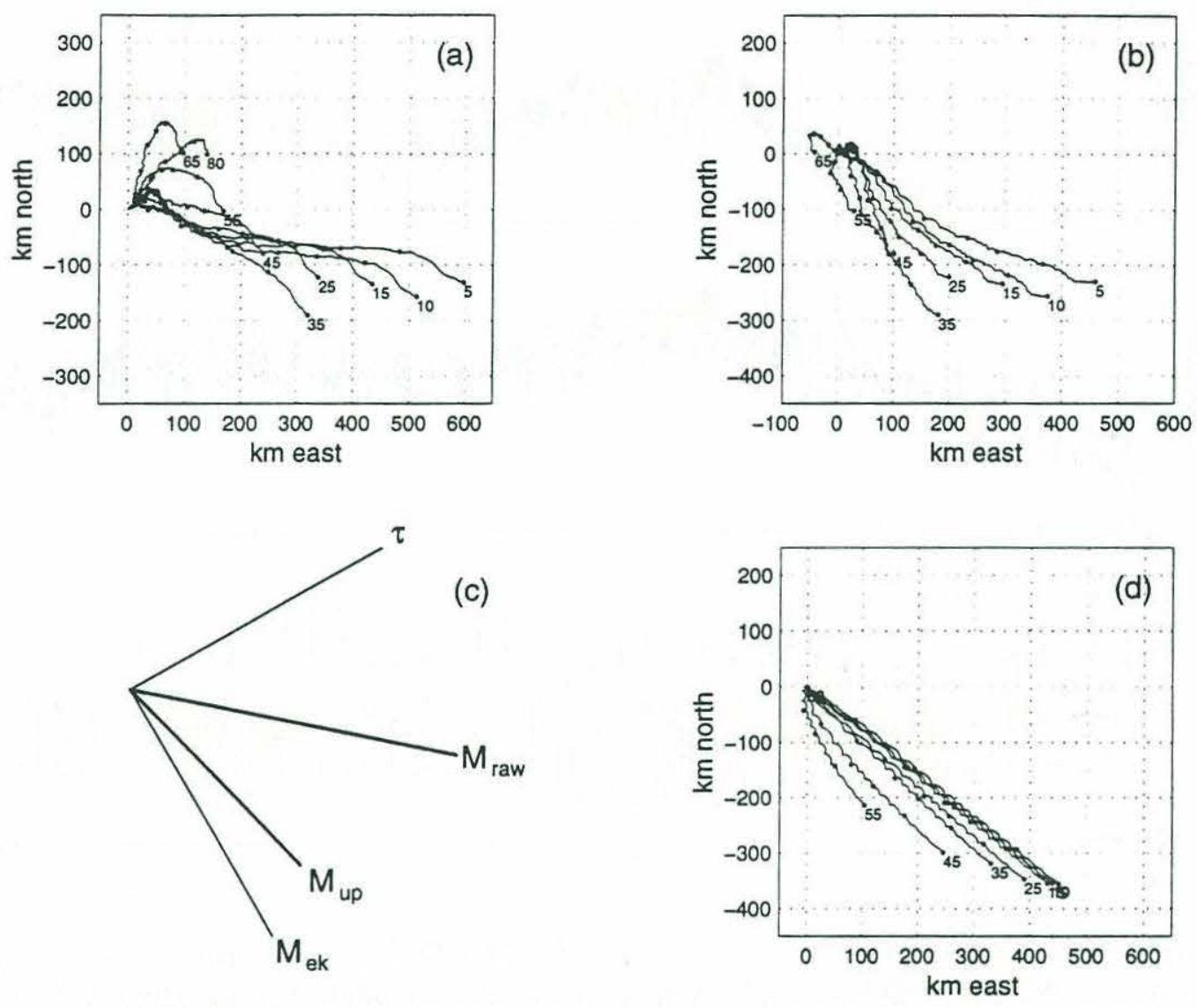

Figure 4.2 Progressive vector diagrams and the Ekman transport relation for the $\mathrm{SW}$ monsoon. Dots are separated by six days. (a) The raw velocities as seen at the mooring, and (b), the same with the $80 \mathrm{~m}$ velocity subtracted. (d) Velocities from a one-dimensional PWP model run, and (c), the observed transport integrated over the time period to a depth of $80 \mathrm{~m}\left(\mathrm{M}_{\text {raw }}\right)$, with the $80 \mathrm{~m}$ velocity removed $\left(\mathrm{M}_{\mathrm{up}}\right)$, and as expected from the mean wind stress $\left(\mathrm{M}_{\mathrm{Ek}}\right)$. The mean wind stress is $\tau$.

they are large enough to significantly advect these gradients in mixed layer temperature, and this advective heat flux will be needed to close a local heat budget.

\subsection{Surface Forcing}

The surface forcing during this period is dominated by an extremely strong wind stress (see Fig. 4.3). The average wind stress once the monsoon has set in (arbitrarily defined as 


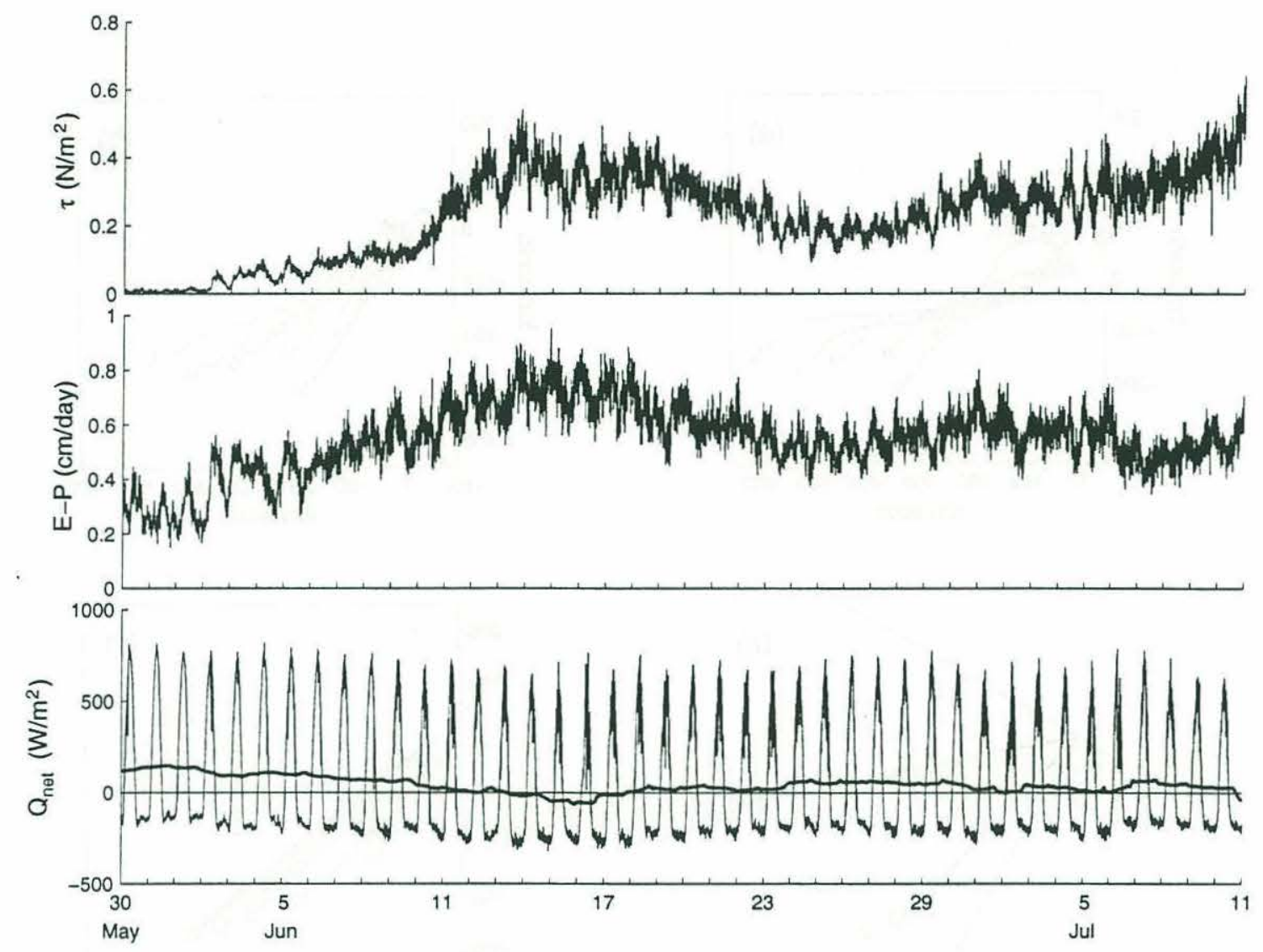

Figure 4.3 The surface forcing at the mooring site during the southwest monsoon period. From top: wind stress, freshwater flux, and the net heat flux, along with a daily average. The strength of the wind forcing is very strong, but despite this the evaporative flux is less than that observed during the NE monsoon. The net heat flux is generally positive

June 10) is $0.29 \mathrm{~N} \mathrm{~m}^{-2}$, and is quite steady, with a standard deviation of $0.08 \mathrm{~N} \mathrm{~m}^{-2}$. The peak value in this period is the tremendously large $0.63 \mathrm{~N} \mathrm{~m}^{-2}$. There are two broad pulses, with a local maximum around June 17 and another at the end of the record. Despite the high wind speeds, the freshwater flux, driven solely by the evaporative flux since there is no precipitation, is only moderately strong compared to the NE monsoon, limited by the extreme humidity of the air. The mean over the six weeks of this period is $5.5 \mathrm{~mm} \mathrm{day}^{-1}$, less than that observed during the NE monsoon. The net heat flux changes sign daily with the rhythm of the sun, and has a peak of $819 \mathrm{~W} \mathrm{~m}^{-2}$ and a minimum of $-321 \mathrm{~W} \mathrm{~m}^{-2}$. In this case the heat gain generally dominates, and the daily averaged net heat flux is positive for 
the entire six-week period excepting four days (June 13-17). The mean for the period is a moderate warming of $44 \mathrm{~W} \mathrm{~m}^{-2}$.

While the net heat flux generally stabilizes the water column, the buoyancy flux is less clearly one-sided. The timeseries is shown in Fig. 4.4. The salt contribution to the buoy-

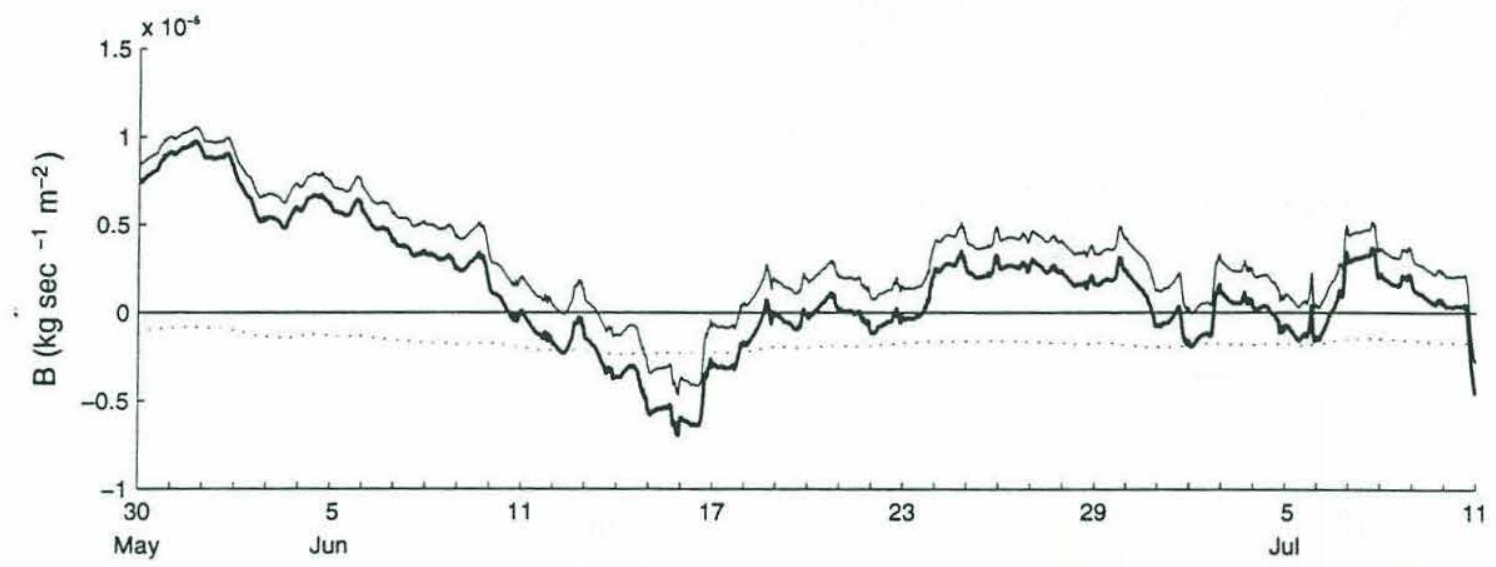

Figure 4.4 The net buoyancy flux, in a 24-hour running average. The buoyancy flux due to heat (thin line) is generally stabilizing, but the buoyancy flux of salt (dotted line) is always destabilizing. The net result (thick line) is a stronger and longer destabilizing period between Jun 11-20.

ancy flux is always destabilizing, and tips the balance to some extent. The period of destabilization extends from June 11-18, with shorter one to two-day periods of destabilizing flux scattered through the rest of the period. However, the overall net buoyancy flux during this period remains positive, and the maximum daily buoyancy loss is about a third of the maximum observed in the NE monsoon.

The spectra of the surface forcing shows a strong diurnal period variability (Fig. 4.5). This variability is of course strongest in the record of the net heat flux, dominated by the solar period, but also appears in the wind stress and thus in the latent heat flux record. The largest amount of energy remains in the lowest frequencies, but the peak at the diurnal fre- 

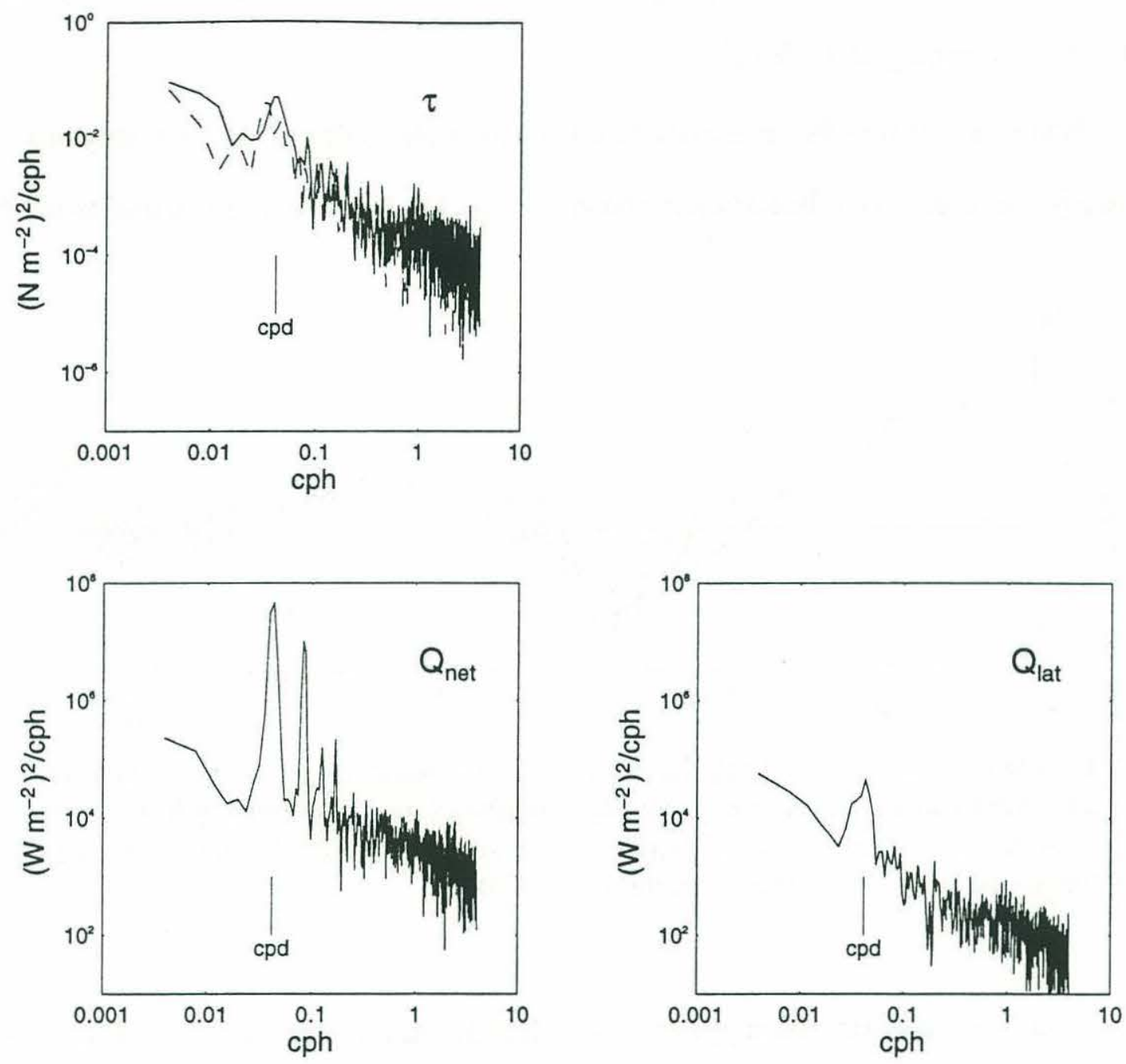

Figure 4.5 Autospectra of the surface forcing for the SW monsoon: the net heat flux $Q_{\text {net }}$, latent heat flux $Q_{\text {lat }}$, and rotary spectrum of the wind stress $\tau$. All the signals show a peak at the diurnal frequency (cpd).

quency in the momentum and freshwater fluxes is stronger than that seen in the NE monsoon.

The strong momentum input by the wind is the strongest forcing during this period. This momentum input into the mixed layer should create strong shears across the mixed layer base, leading to vertical mixing and subsequent deepening of the mixed layer and entrainment of the cooler water below. An alternate view is that the wind momentum input is an input of kinetic energy, which can be used to increase the potential energy of the 
water column by bringing colder and heavier water up from below. In either view the end result is the same: a deeper mixed layer and cooler mixed layer temperatures due to entrainment of the cooler water below.

\subsection{Upper ocean response}

The upper ocean response during this period is in many ways consistent with the onedimensional picture painted above. The mixed layer does deepen, entraining cooler water below, and the mixed layer temperature cools. But a full explanation of the response will require a small horizontal advection of heat and salt within the mixed layer.

The subsurface record of temperature, salinity, and density is shown in Fig. 4.6. The temperature record shows a remnant of the NE monsoon mixed layer as the preponderance of water of about $26^{\circ} \mathrm{C}$ above 100 meters. The permanent thermocline starts below this. Above the $26^{\circ} \mathrm{C}$ water, a temporary seasonal thermocline has been laid down during the intermonsoon season, with its weak winds and strong solar heating. This seasonal thermocline is slowly eroded as the mixed layer deepens through this period. Like the NE monsoon record, the salinity is quite variable not only within the mixed layer but in the thermocline. There are also persistent inversions. These reflect the complicated salinity structure of the area, and are indicative of some horizontal advection. Like earlier in the record, salty water overlies fresher water with a strong halocline around $130 \mathrm{~m}$, reflecting the mean evaporative conditions. The density is dominated by the temperature signal.

The subsurface velocity record is dominated by inertial-period oscillations (see Fig. 4.7). The strongest velocities are trapped in the mixed layer, though there is some surface trapping. There is also some evidence of negative phase propagation across the mixed 

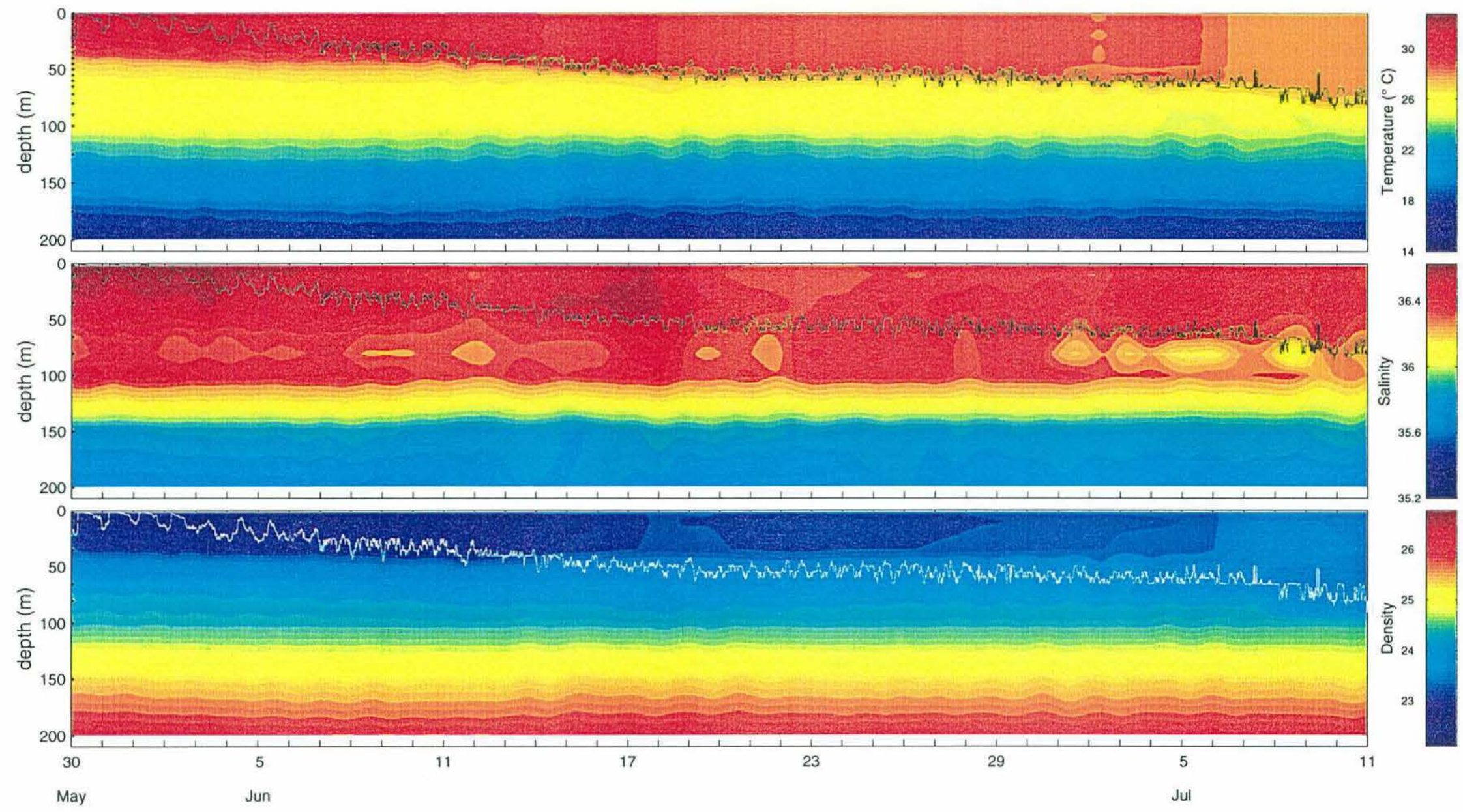

Figure 4.6 The lowpass-filtered subsurface temperature, salinity, and density record during the SW monsoon. The mixed layer (line, unfiltered) deepens, entraining cooler water below. The salinity record is variable, suggestive of horizontal advection. 


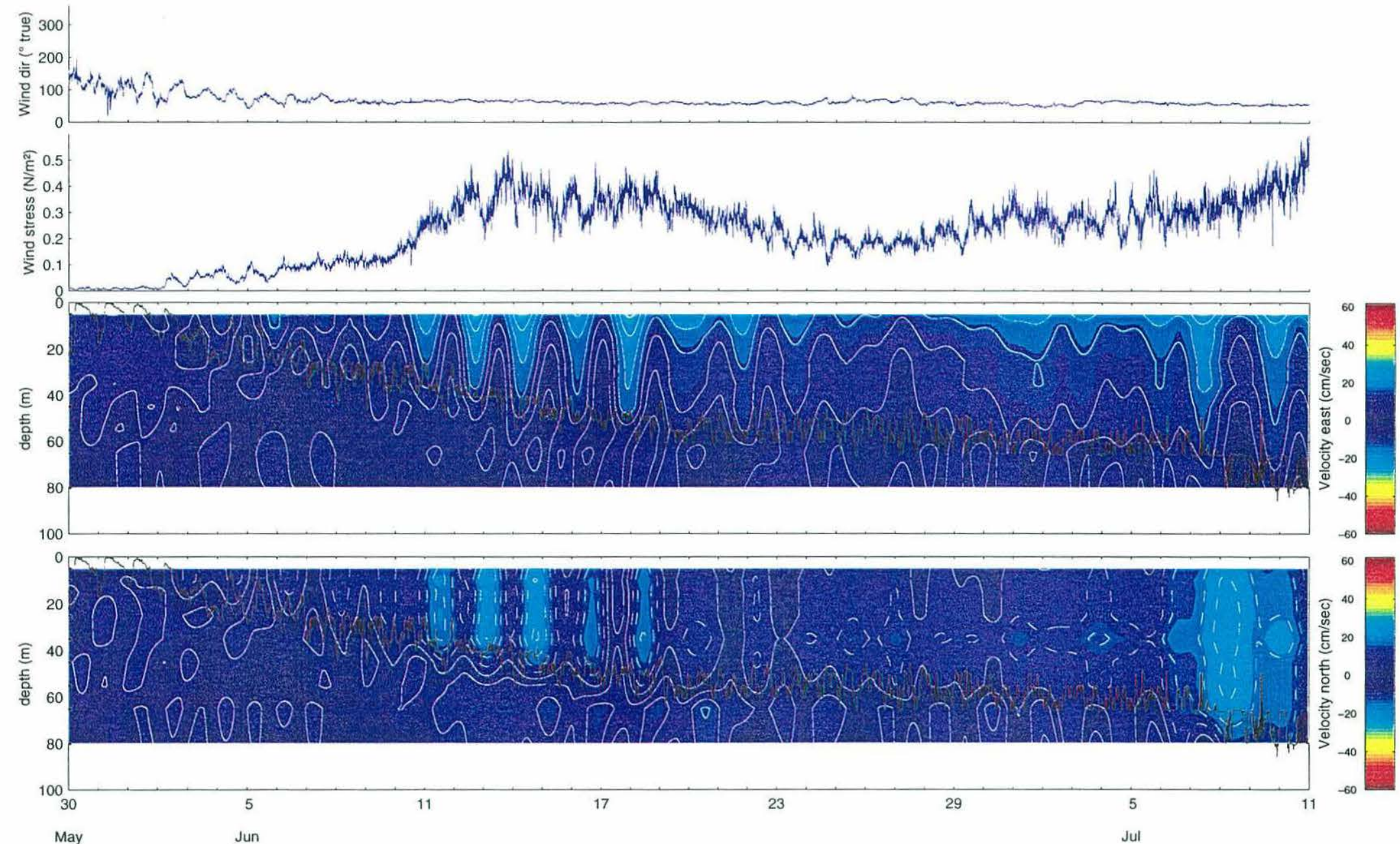

Figure 4.7 Contours of subsurface velocity and the wind stress record. Positive contours are solid, negative are dotted, every 5 $\mathrm{cm} / \mathrm{sec}$. Strong inertial oscillations are apparent, especially in response to the first wind maximum. There is a hint of negative phase propagation across the mixed layer base, indicative of downwards energy propagation by internal waves. 
layer base, indicating downwards energy radiation. It is largely the local response to the wind, as indicated in Fig. 4.2.

The spectra of the subsurface temperature and velocity (see Fig. 4.8) show a strong response at the frequency of the semi-diurnal tide $\left(\mathrm{M}_{2}\right)$. The velocity record also shows a strong response, somewhat broad, at the inertial frequency, but only in the clockwise rotating component. This is again indicative of downwards energy propagation.

The diagnostic quantities, the shear, the stratification, and the Richardson number are shown in Fig. 4.9. The shear is tightly trapped to the mixed layer base, and shows the inertial modulation seen first in the velocity record. It is strongest during the period of strongest mixed layer deepening, from about June 8-22. But it persists through the end of the end of the record, when it is barely resolved by the deepest current meter. The shear within the mixed layer is very low. The buoyancy frequency has an original maximum in the water column at about $50 \mathrm{~m}$ depth, above the permanent thermocline which has a peak around 130 depth. The mixed layer deepens fairly rapidly to this point, and then slows its rate of decline. The stratification then sharpens underneath the mixed layer, although this is poorly resolved. Reflecting the high shear at the mixed layer base, the Richardson number is low there. The picture that emerges is of momentum input at the surface driving the entire mixed layer through rapid vertical mixing, halted by the strong stratification at the layer base. This layer base is gradually eroded away through the continual action of shear instabilities, driven by yet more wind input of momentum.

The spectrum of the shear signal (Fig. 4.10) shows clear peaks at the inertial frequency in the depth bands (50 and $60 \mathrm{~m}$ ) that the mixed layer base frequents. From $20 \mathrm{~m}$ up through the surface, a strong diurnal peak resolves itself (at the frequency of the diurnal tide $\left.\mathrm{K}_{1}\right)$. In the shear record closest to the surface $(7.5 \mathrm{~m})$, there is also a distinct response at the inertial frequency, reflecting the slightly stronger velocities seen in the near-surface. 

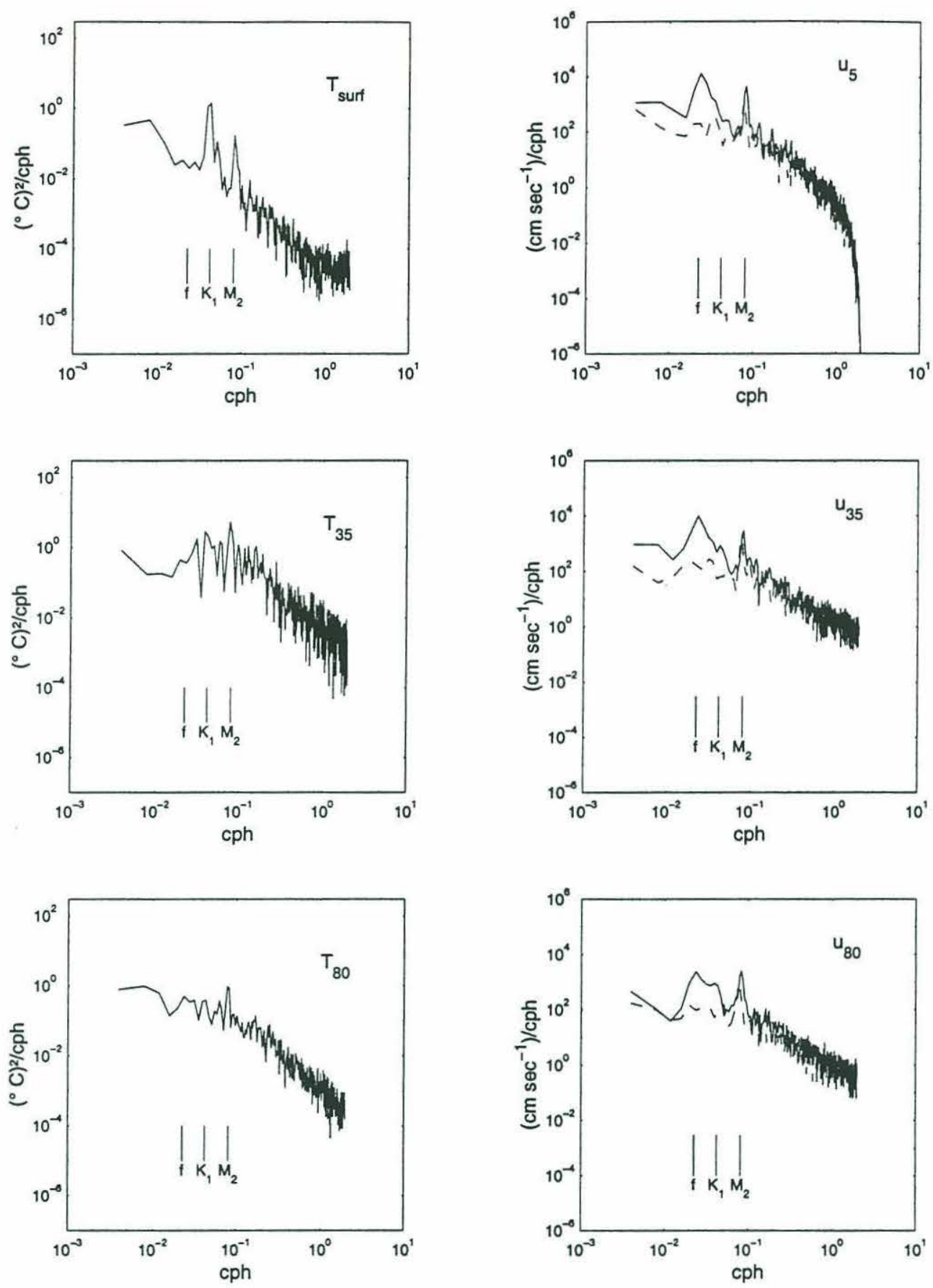

Figure 4.8 Autospectra of the subsurface temperature and velocity. Rotary spectra (clockwise solid, counterclockwise dashed) are shown for the velocity. The frequencies of the primary semi-diurnal tide $\left(\mathrm{M}_{2}\right)$, the diurnal tide $\left(\mathrm{K}_{1}\right)$ and the inertial frequency ( $\mathrm{f}$ ) are marked. Velocities show strong counterclockwise response at the inertial frequency, as well as a response to the semi-diurnal tide. 

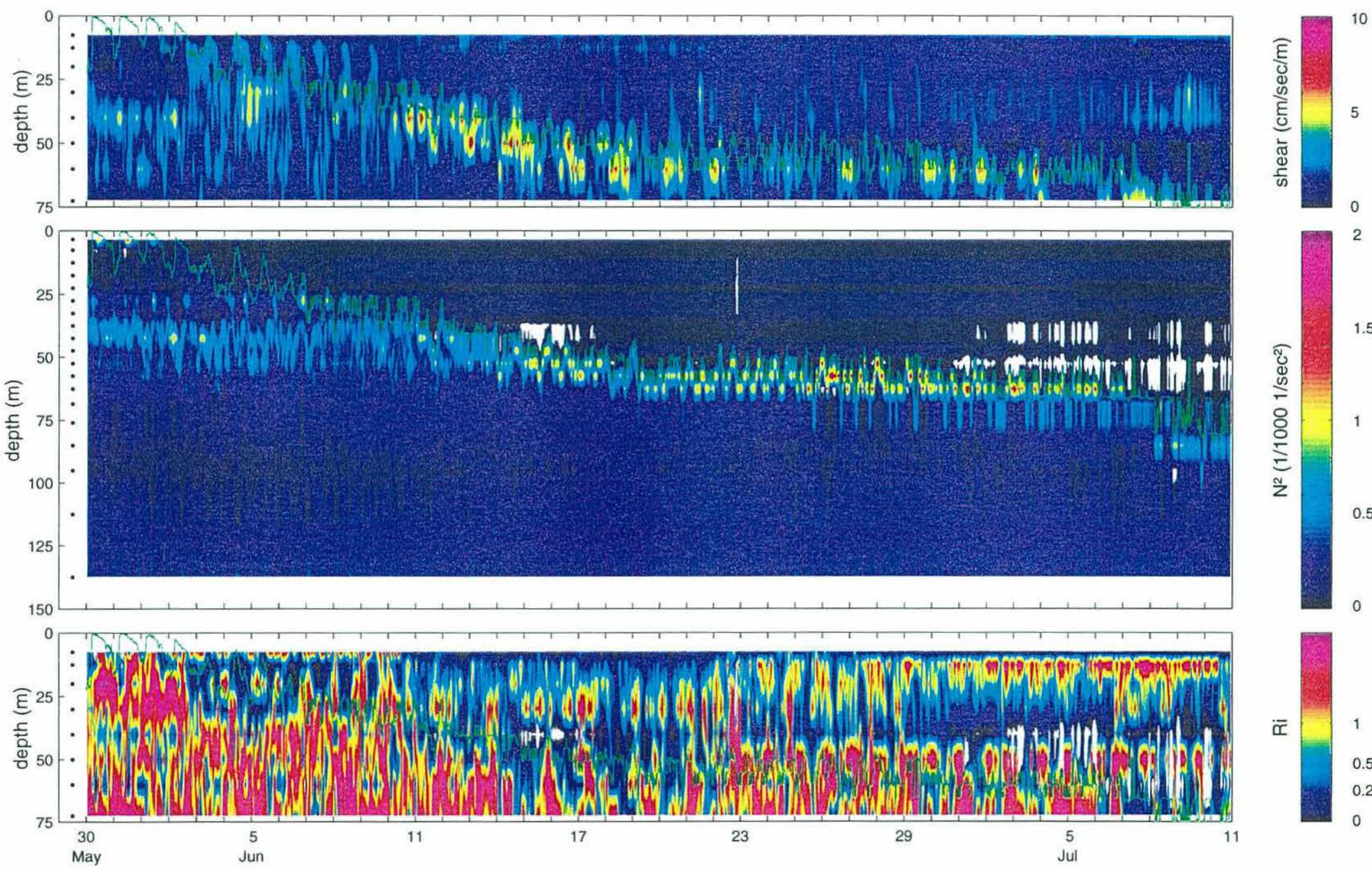

$\overline{\tilde{x}}$

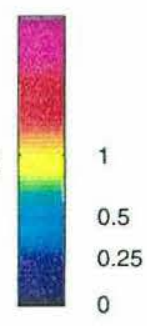

Figure 4.9 The subsurface shear, stratification, and Richardson number. The Richardson number has persistent low values at the mixed layer base, due to shear trapped there. 

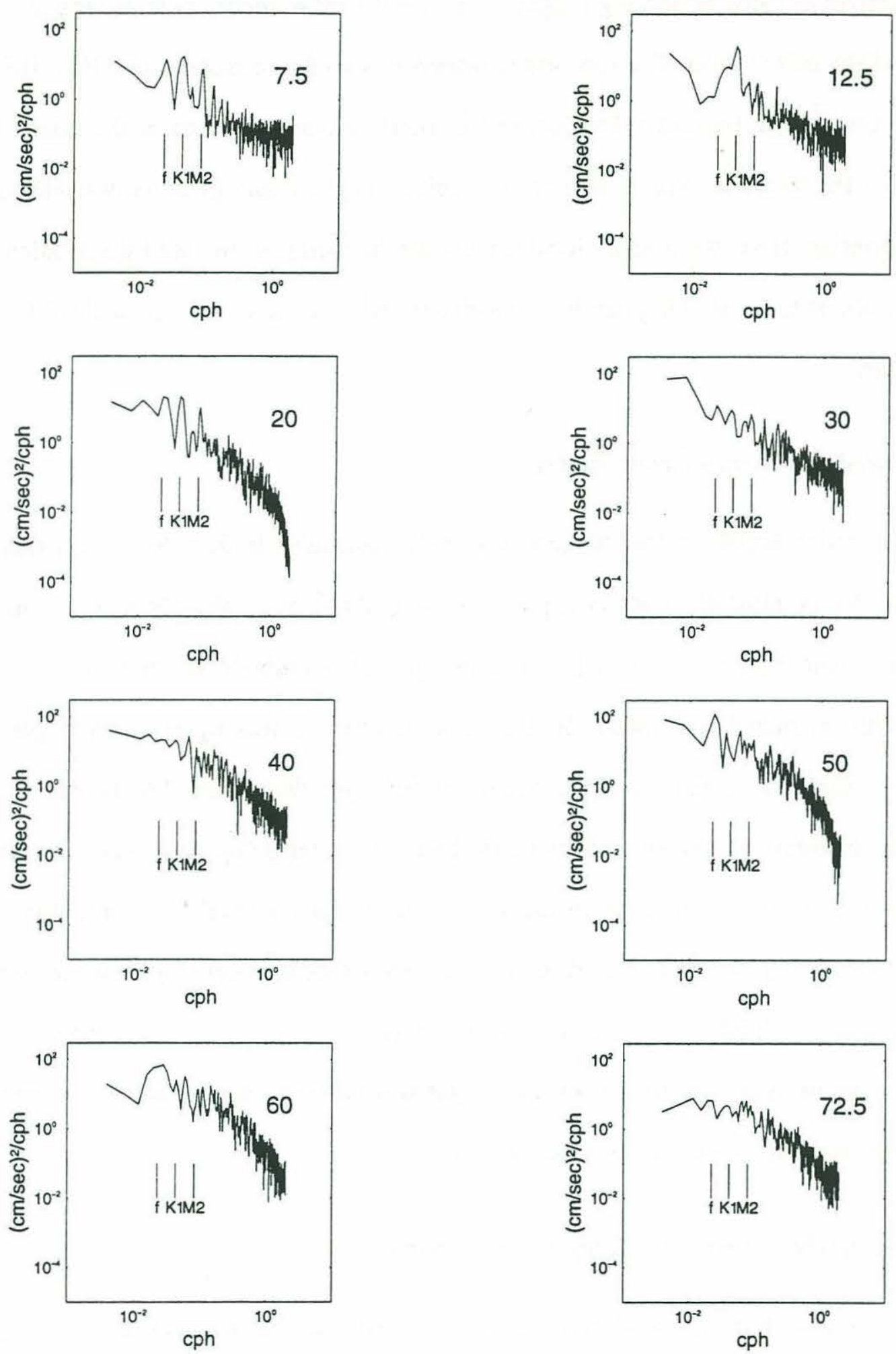

Figure 4.10 Spectra of shear. The large numbers indicate the depths at which the shear is resolved, in between velocity measurements. 


\subsection{The dominant physical mechanisms for deepening}

The strength of the wind forcing suggests that it is the most important in driving the deepening of the mixed layer. The subsurface response is so far consistent with this, showing strong mixed layer-trapped velocities, and inertially modulated shear at the mixed layer base. But the buoyancy flux is at times destabilizing, and could potentially contribute to this deepening. Here, the primary local driving mechanism is sorted out by a detailed look at energetic arguments. They are best understood when contrasted against the NE monsoon case.

\subsubsection{Energetics of entrainment mixing}

This section builds on the energetic arguments presented in Section 3.4.1, where the all-important entrainment velocity is proportional to the friction velocity scale $u_{*}$ and the convective velocity scale $w_{*}$ (see (3.6)). These quantities (cubed) are shown in Fig. 4.11, along with the mixed layer depth. In the NE monsoon, $w_{*}$ was significantly larger than $u_{*}$, and correlated roughly with periods of mixed layer deepening. The reverse is true here. The convective velocity scale as defined here has a term dependent on the radiative heating at depth (see (3.8)), which can contribute to the potential for convection. It is slightly positive on average, even when the buoyancy flux is stabilizing. But the friction velocity scale $u_{*}$ dominates, and tends to be large when the mixed layer is deepening most rapidly. This becomes yet further evidence that wind-driven entrainment is the primary deepening mechanism during this time period.

\subsubsection{Scaling the strength of the entrainment forcing}

Another energetically-based check of the dominant forcing mechanism is through a scaling argument, drawing on Monin-Obukhov similarity theory. The important parameter 

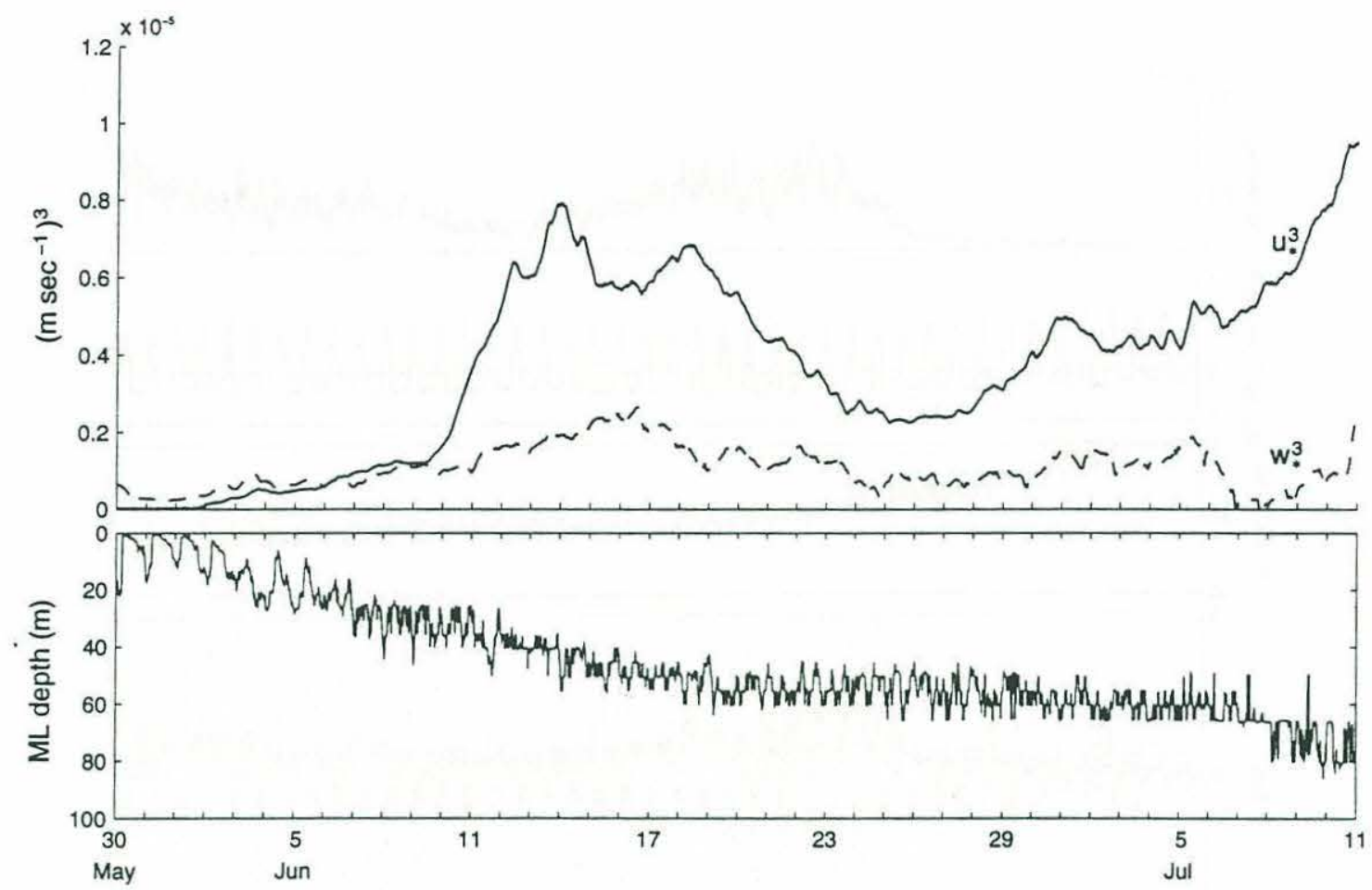

Figure 4.11 The friction velocity scale $u_{*}$ and the convective velocity scale $w_{*}$ with the mixed layer depth during the SW monsoon. Periods of high $u_{*}$ are roughly correlated with periods of mixed layer deepening. The friction velocity scale is generally much larger than the convective velocity scale.

here is the ratio $L / h$ defined in (3.15). A timeseries of this ratio reveals that when the wind is blowing strongly, the ratio is often large, of both signs as the buoyancy flux changes sign daily (see Fig. 4.12). During the day when the buoyancy flux is stabilizing, the ratio is large and negative, indicating that wind-driven turbulence is important at the layer base. At night, when the buoyancy flux turns destabilizing, the ratio is often large and positive, and never approaches close to zero. The effect of shear-generated turbulence dominates over convectively driven turbulence during the majority of the time that both operate. 


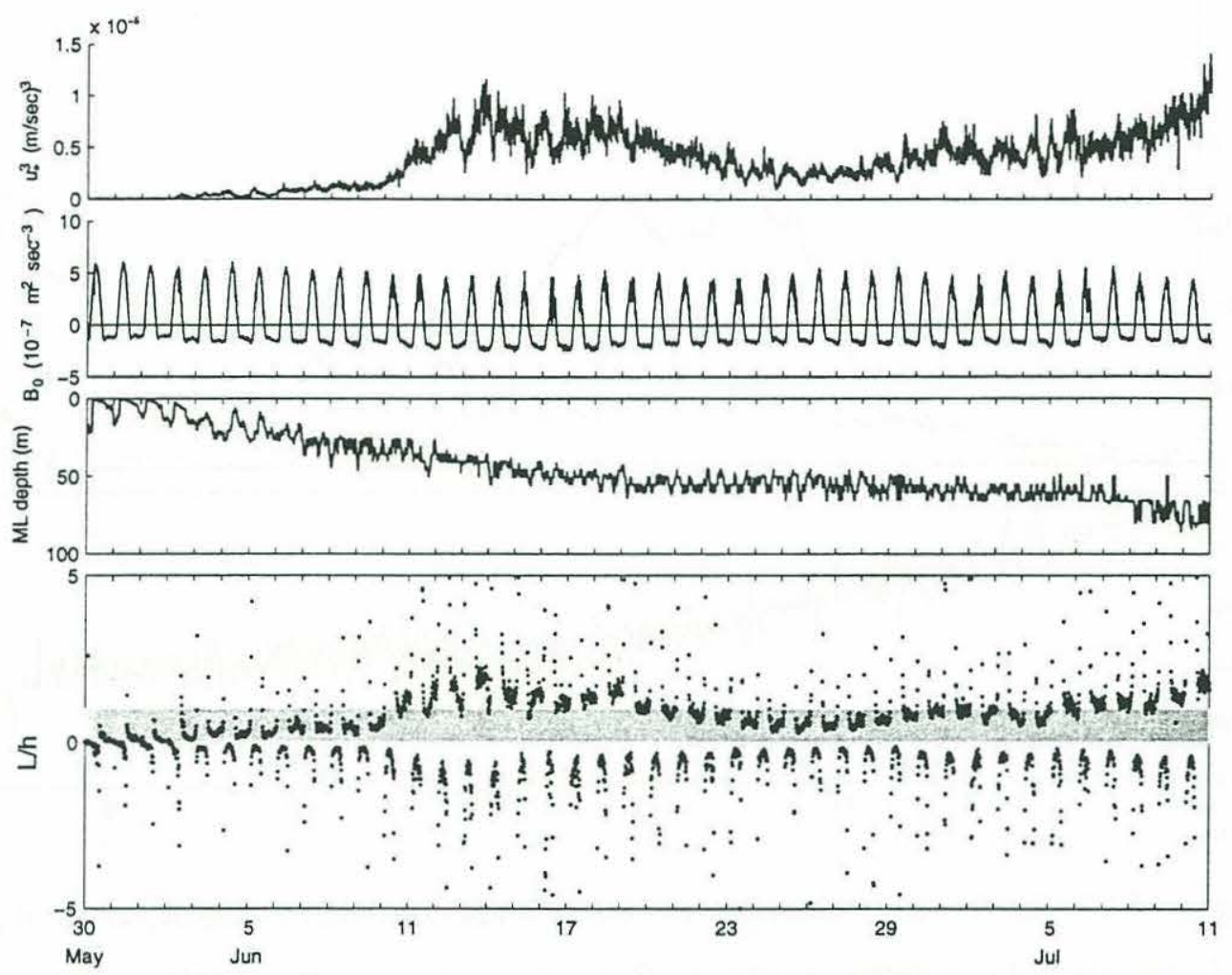

Figure 4.12 The ratio of the generalized Obukhov length to the mixed layer depth. The first three panels show the components of $\mathrm{L}$, the friction velocity scale, the surface buoyancy flux, and the surface layer depth. The last panel shows that the ratio $L / h$ is generally quite large, and of variable sign as the buoyancy flux changes sense. The shaded area which is entirely avoided shows a ratio $L / h$ between 0 and 1 , which is indicative of buoyancy flux deepening dominating over the wind-driven deepening.

\subsection{Local forcing of upper ocean response}

These lines of evidence all point to the conclusion that the primary local driving mechanism for the deepening and cooling of the SW monsoon mixed layer is wind-driven stirring and entrainment. Here I investigate how much of the oceanic response can be understood as a local response to local forcing. My tools are one-dimensional heat and salt budgets and a one-dimensional model of the mixed layer evolution. Finally in this section 
I investigate the generation of the inertial-period oscillations observed earlier with an even simpler slab model of the mixed layer.

\subsubsection{One dimensional heat budget}

In an upper ocean purely driven by local forcing, the time integrated one-dimensional heat budget (3.18) would close. The terms in this budget are shown in Fig. 4.13, integrated

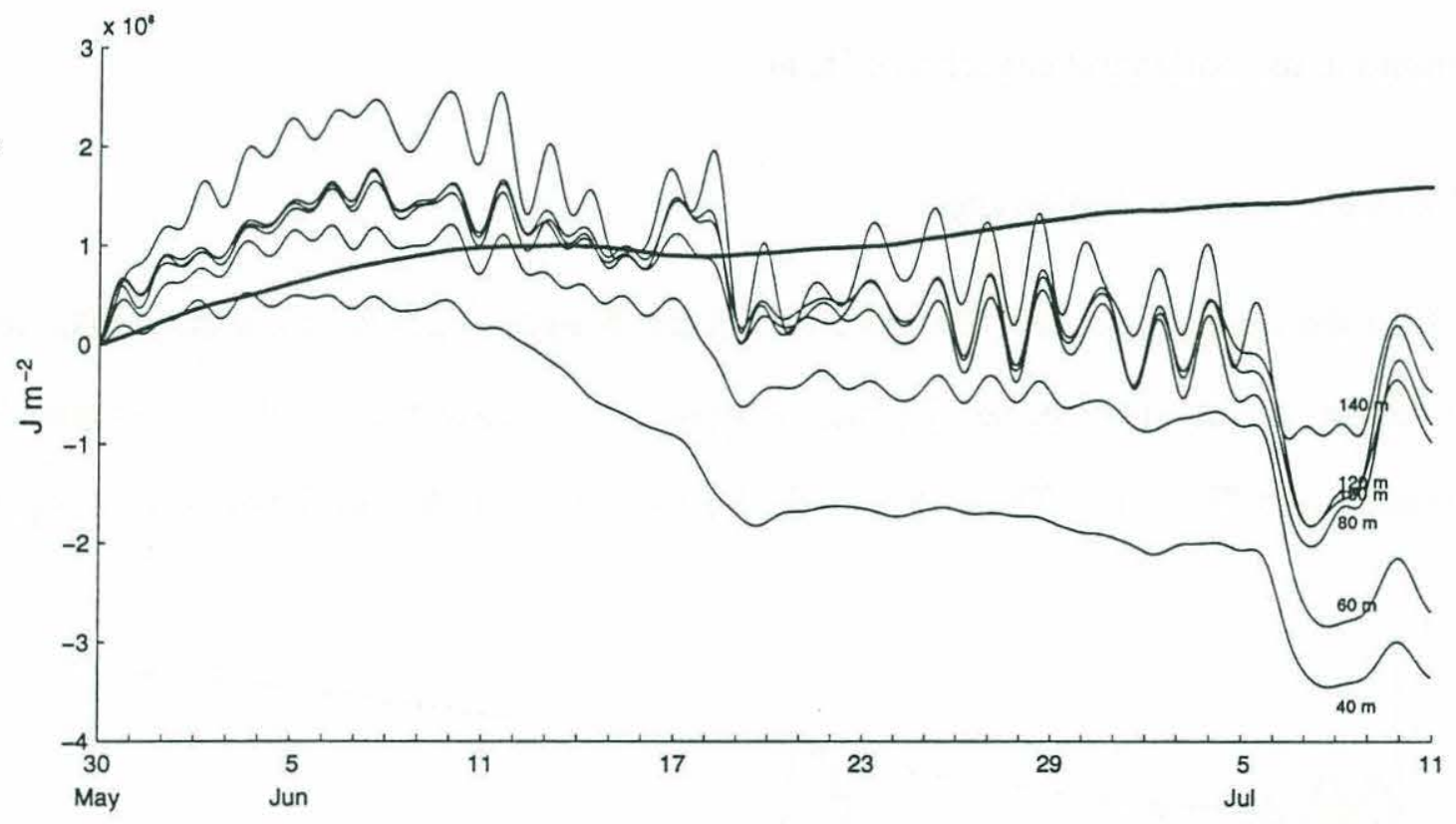

Figure 4.13 The terms of the one-dimensional heat budget, integrated to various reference depths. The term involving the surface heat flux (thick line) is not wellmatched the temperature trend term (thin line), no matter what reference depth is used. The heat content of the upper ocean is persistently less than that predicted by the local surface flux of heat.

to various reference depths. Despite the net positive heat flux over the period, the heat content of the upper ocean decreases over the corresponding time period. This is a generally broad deviation from the one-dimensional expectation, but there are two instances of more rapid change, around June 11-17 and on July 6-7. This general trend calls for an input of cooler water to the upper ocean, either by horizontal advection or vertical upwelling. During the first week of this period, the heat content integrated to the various reference depths 
diverge in time, suggesting that the primary deviation from the local balance here occurs deep below the mixed layer, and it is a warming over what is expected. This is borne out by the broadly warming temperature gradients observed in the upstream direction during the same time period (see Fig. 4.1). After June 11, the heat content trends integrated to the various depths are offset, but track each other fairly well. This suggests that the cooling of the water column that is the deviation from the local balance occurs primarily in the upper part of the water column, that near-surface gradients in temperature are the primary contributors to the horizontal advection of heat.

\subsubsection{One dimensional salt budget}

Like the heat budget, the one-dimensional salt budget (3.21) does not close. The net salt content of the upper ocean declines, although the surface flux would monotonically increase it (see Fig. 4.14). The overall budget is fairly independent of the depth of integra-

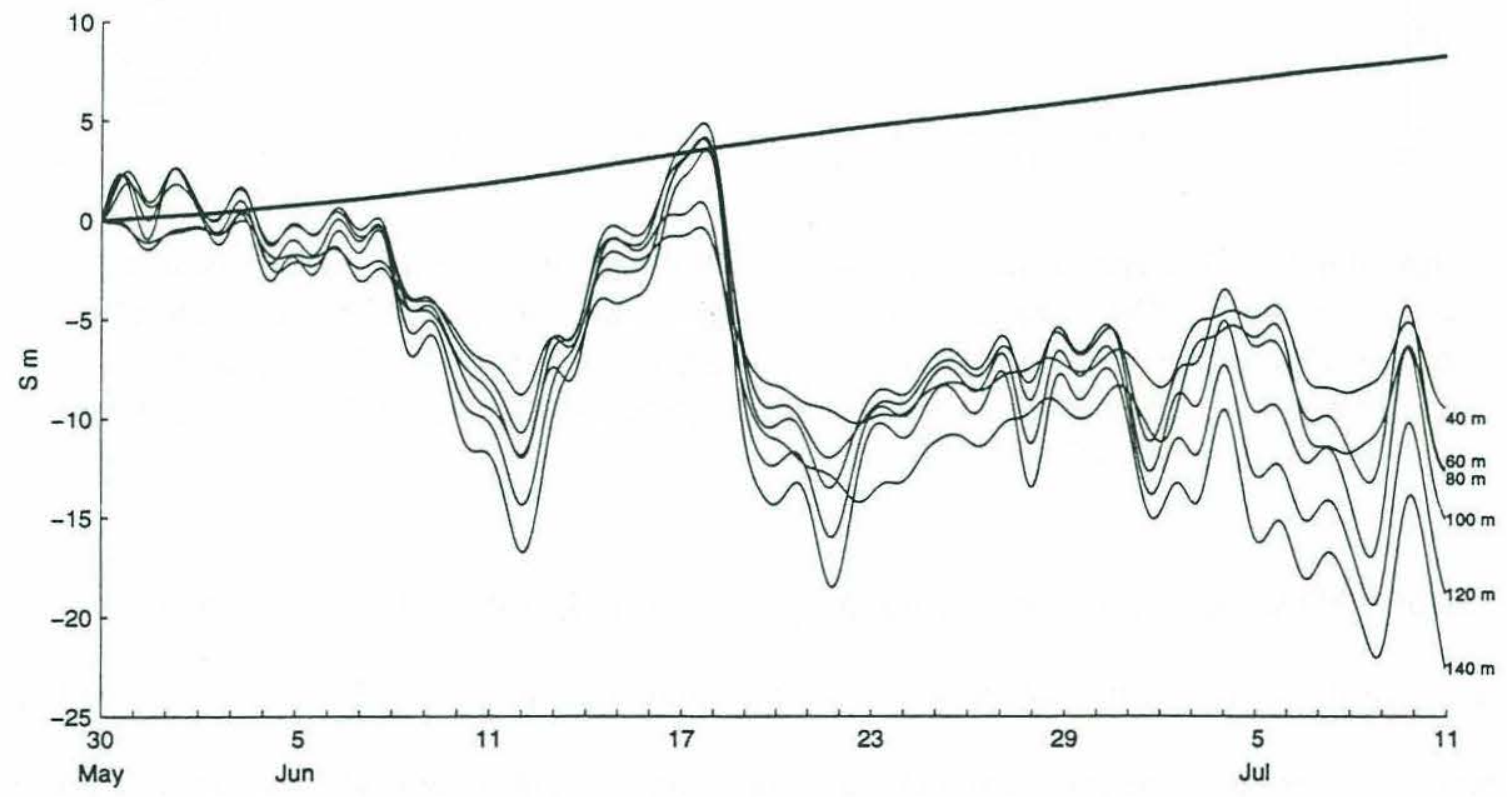

Figure 4.14 The terms of the one-dimensional salt budget, integrated to various reference depths. The influence of the freshwater flux (thick line) is not balanced by the salt content integrated to various reference depths (thin lines). There is persistently fresher water in the mixed layer. 
tion, suggesting that the primary deviation from the local budget occurs near the surface, in line with what was suggested by the local heat balance. The period of cool water input noted June 11-17 in fact corresponds to a period of salt input, followed by a quick correction Jun 18-19, which barely registers in the heat budget. The most rapid period of cool water input July 6-7 is only barely noted here as a period of fresh water input. But over longer timescales, the requisite input of cooler and fresher water to the upper ocean required by these one-dimensional budgets would have opposing tendencies on the density.

\subsubsection{Model experiment}

To further asses the role of local forcing the PWP model introduced in Section 3.5.3 is used. It was initialized with the observed profiles of temperature and salinity and zero velocity on May 30, at the beginning of our six-week period. The model was forced with the observed surface fluxes. The results are shown in Fig. 4.15. While the mixed layer depth calculation is fairly good, the model overpredicts the temperature and the salinity in the mixed layer. This latter prediction is consistent with the results from the budgets above. A comparison with the observations is made in Fig. 4.16. The mixed layer depth prediction is remarkably accurate. The SST and SSS comparisons are reminiscent of the one-dimensional budgets, with the requisite nonlocal fluxes of temperature and salinity required at the same times.

This suggests that though an advection of cooler and fresher water is mandated, the vertical density structure, or more importantly its stratification, is very similar to the water it replaces. The model entrains deeper and cooler water through the shear-instability mechanism. The wind input of momentum is deposited in the mixed layer through the model's instantaneous vertical mixing (according to the stability criteria), and the resulting 


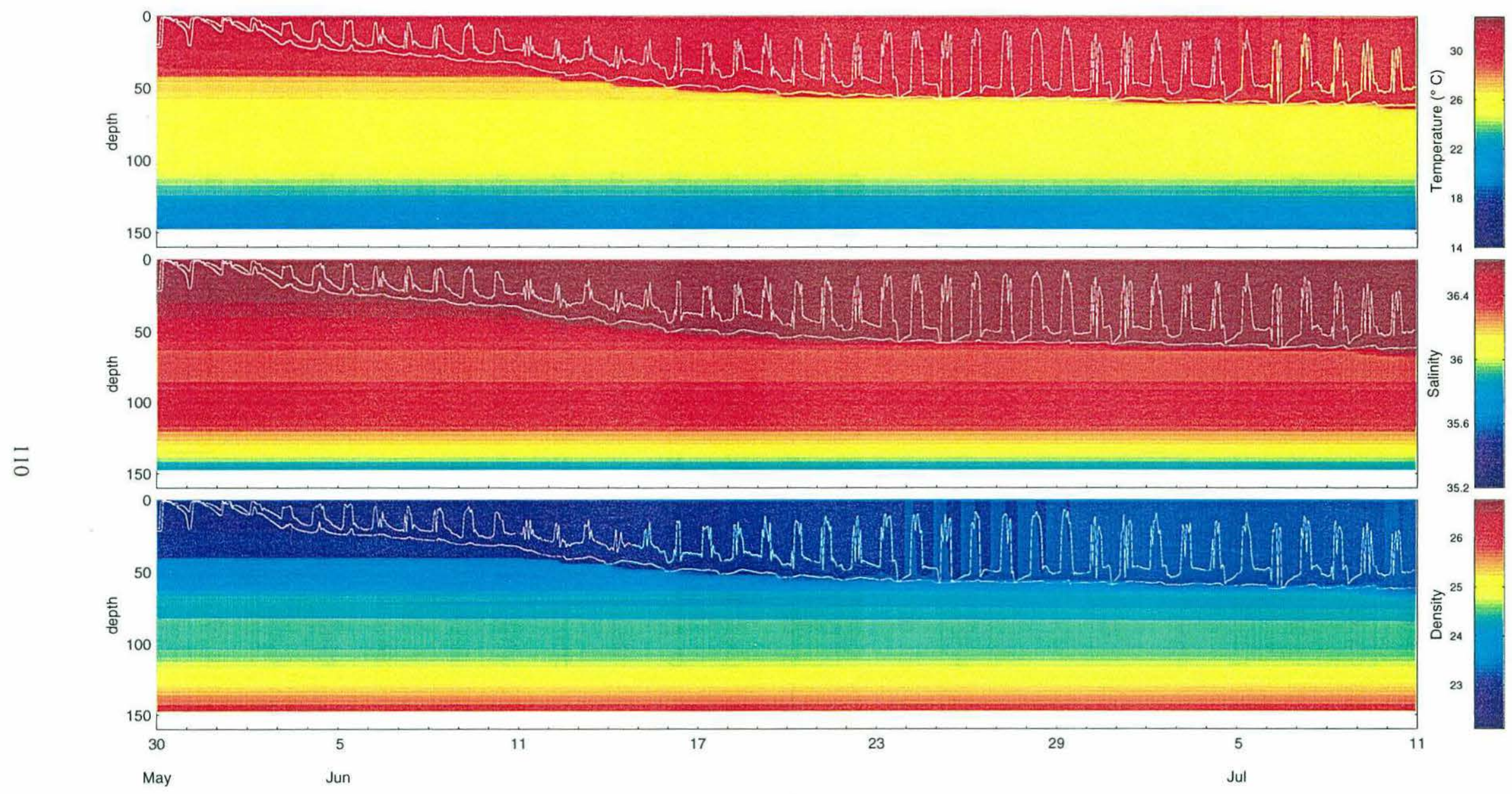

Figure 4.15 The temperature, salinity, and density from the PWP model run forced with observed surface fluxes. The two lines indicate the strict PWP model definition of the region of mixing and the mixed layer depth using the same criterion as in the observations. 


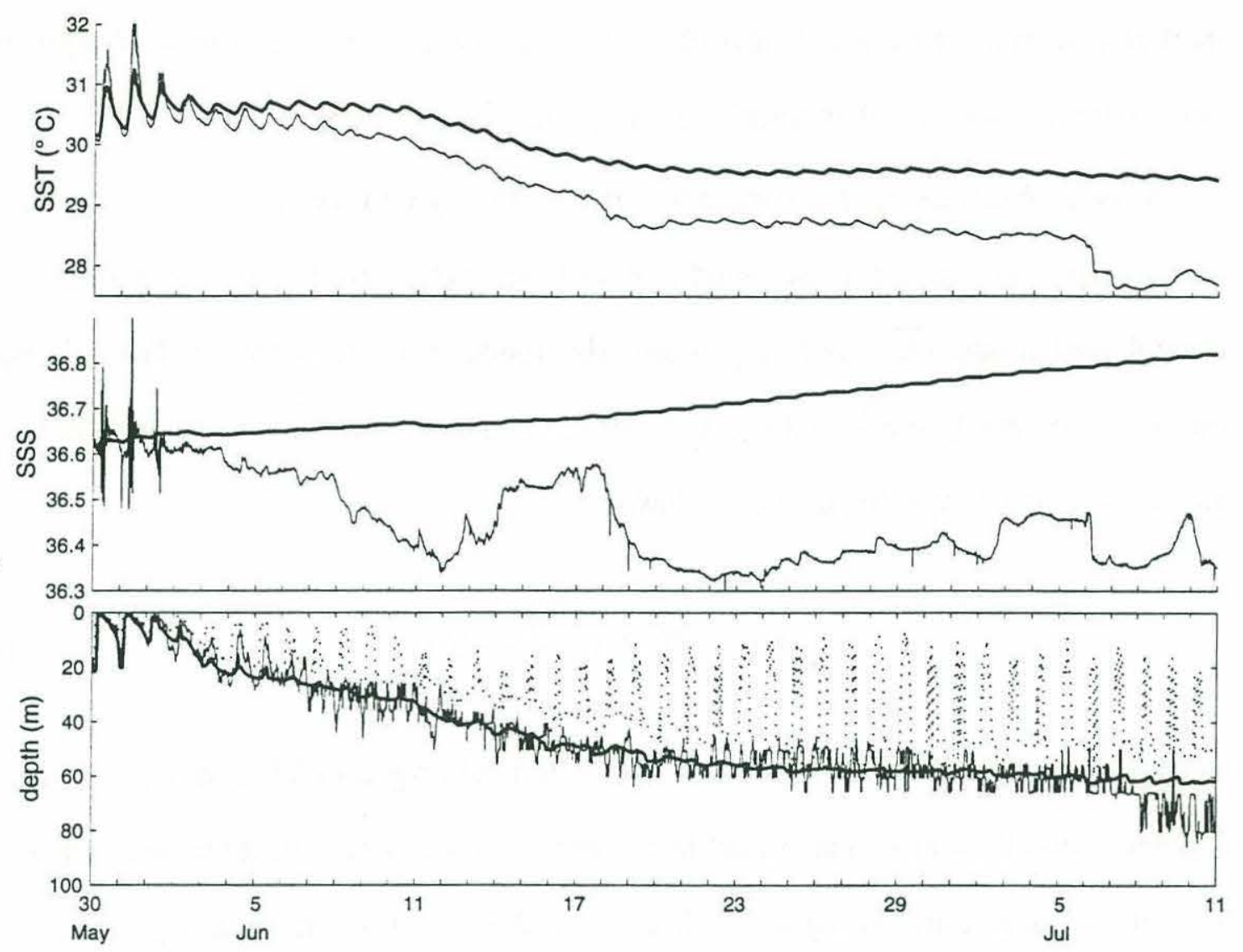

Figure 4.16 A comparison of the observed (thin lines) and modeled (thick lines) sea surface temperature (SST), sea surface salinity (SSS), and mixed layer depth. While the mixed layer depth prediction is very good, the observed character of the surface water is poorly predicted. This suggests the need for an advection of fresher and cooler water, while maintaining the same stability characteristic in the water column.

shear at the base of the mixed layer becomes strong enough to force the gradient Richardson number critical, mixing vertically.

\subsubsection{Inertial modulation of the shear at the ML base}

It is not immediately clear that the unidirectional southwest monsoon wind forcing should lead to a strongly inertially modulated velocity response. Other studies (Large and Crawford, 1995; Crawford and Large, 1996) have made much of the fact that strong vertical mixing, which is indicative of shear instabilities, tends to occur when the winds rotate 
clockwise (in the northern hemisphere). This tends to put the winds in resonance with the inertial currents. Large and Crawford (1995) observed several instances of high wind stress without rotation, when the oceanic response was very low.

In these observations, the wind stress is remarkably uniform in direction. To investigate whether this unidirectional wind stress has enough impulsive energy to give rise to inertial oscillations, I look at a very simple slab model of the mixed layer. The only equation is the vertically integrated equation for the conservation of momentum (3.22), with the addition of a simple linear friction law.

$$
\frac{\partial}{\partial t} \mathbf{u}=-f \hat{\mathbf{k}} \times \mathbf{u}-\frac{\vec{\tau}}{\rho_{0} h}-\sigma \mathbf{u}
$$

where the layer depth $h$ was taken to be $50 \mathrm{~m}$ and the drag coefficient $\sigma$ was based on a five day decay timescale. The model is integrated with a simple Euler forward timestep; the only sophistication being an evaluation of the Coriolis term halfway through the timestep. The model was forced with the observed wind stress, and the resulting slab velocity magnitude is shown in Fig. 4.17. This velocity can be interpreted as being proportional to a shear magnitude, since the deep layer below the slab in this model is motionless. The model exhibits strong inertial-period modulation of the velocity, especially strong between June 11 and 23, consistent with what is observed in the mixed layer.

Also in the figure is the prediction of shear from the PWP model forced with the observed surface fluxes, initialized at a state of rest. It also exhibits characteristic pulses of shear at the mixed layer base. These generally lead to deepening of the mixed layer. These model shears are strongest around June 25-29, but do not appear to lead to significant vertical mixing and deepening. There is a local maximum in $N^{2}$ at a depth of approximately $50 \mathrm{~m}$, which is consistent with the drop in the rate of deepening despite strong shears. The 

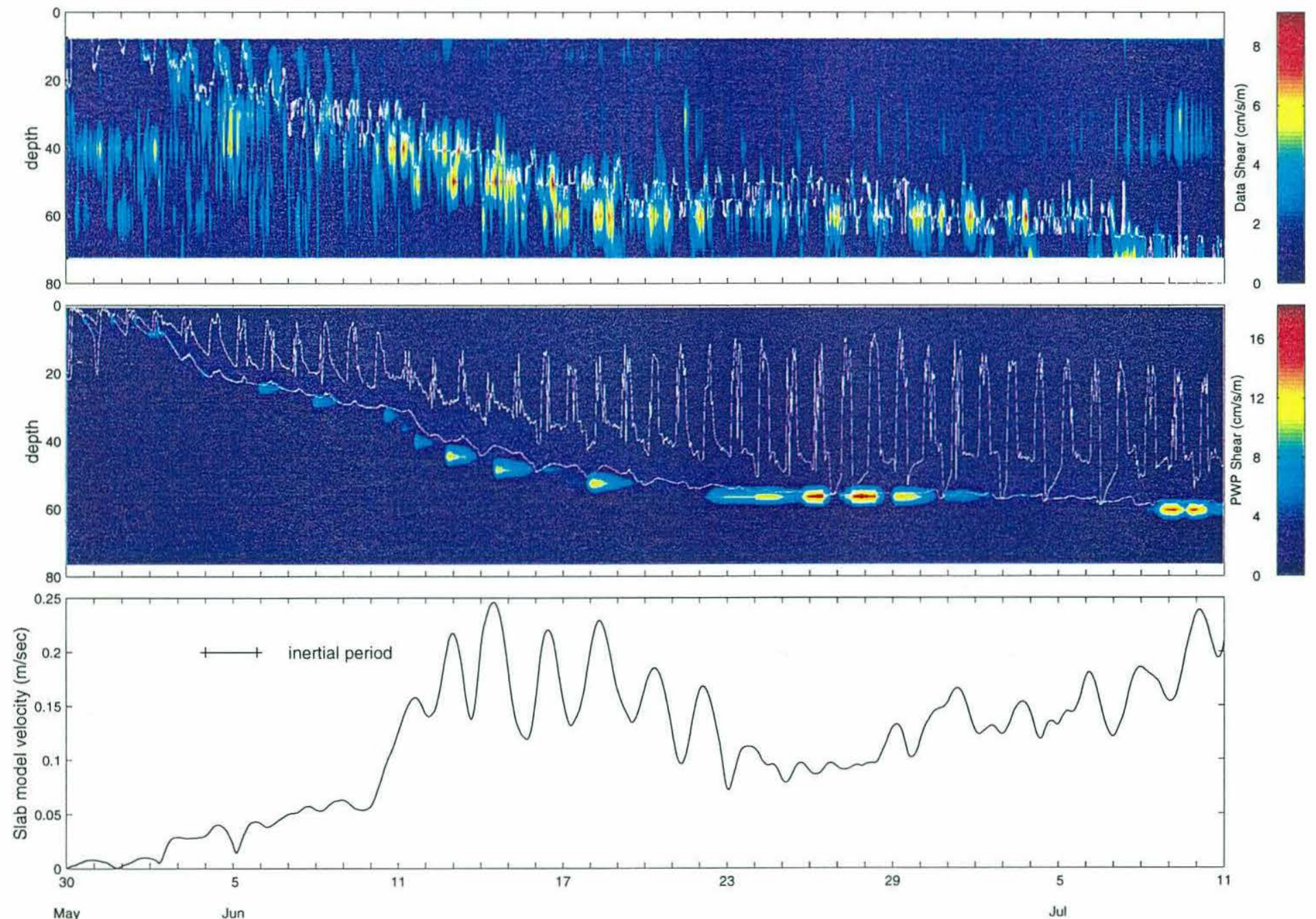

Figure 4.17 A comparison of the observed horizontal velocity shear (top panel) with that modeled by the PWP model (middle) and the layer velocity predicted by the simple slab model (bottom). The length of the inertial period is marked. Despite the unidirectionality of the wind, there is enough of an impulsive element to keep an ongoing inertial pulsing. 
simple slab model seems to characterize the time-dependence of the shear response as well as the far more sophisticated PWP model.

\subsection{Investigating nonlocal upper ocean forcing}

The previous analysis of the local forcing suggests that an input of cooler and fresher water is needed to close budgets of heat and salt. But it also suggests that the vertical stratification of this water should not change from the initial condition, since the PWP model can very accurately predict the extent of the mixed layer. Its deepening process is shear driven instability, which is very sensitive to the profile of $N^{2}$. Here I investigate what nonlocal processes can be responsible. Candidates include vertical velocities imposed by Ekman pumping or other processes, and horizontal advection. The observations are not consistent with an imposed vertical velocity, but rather with a horizontal advection of fresher and cooler water. Bounds on what the horizontal gradients must be are calculated.

\subsubsection{Thermocline diagnosis of vertical displacement}

During the NE monsoon, the structure of the stratification beneath the mixed layer changed significantly during the analyzed period. This allowed for the determination of a diagnostic vertical velocity which was used in modified budgets as well as to drive the model, as a proxy for horizontal advection, and generally quite successfully.

During the SW monsoon, sub-mixed layer vertical velocities do not appear to be important. The mixed layer and the depth of the $21^{\circ} \mathrm{C}$ isotherm (used in the NE monsoon case) as well as the $24^{\circ} \mathrm{C}$ isotherm (which is closer to the ML base in this case) are shown in Fig. 4.18. They remain essentially flat. This suggests, assuming that there is not significant vertical mixing below the mixed layer, that vertical displacements do not affect the upper ocean during this period. 


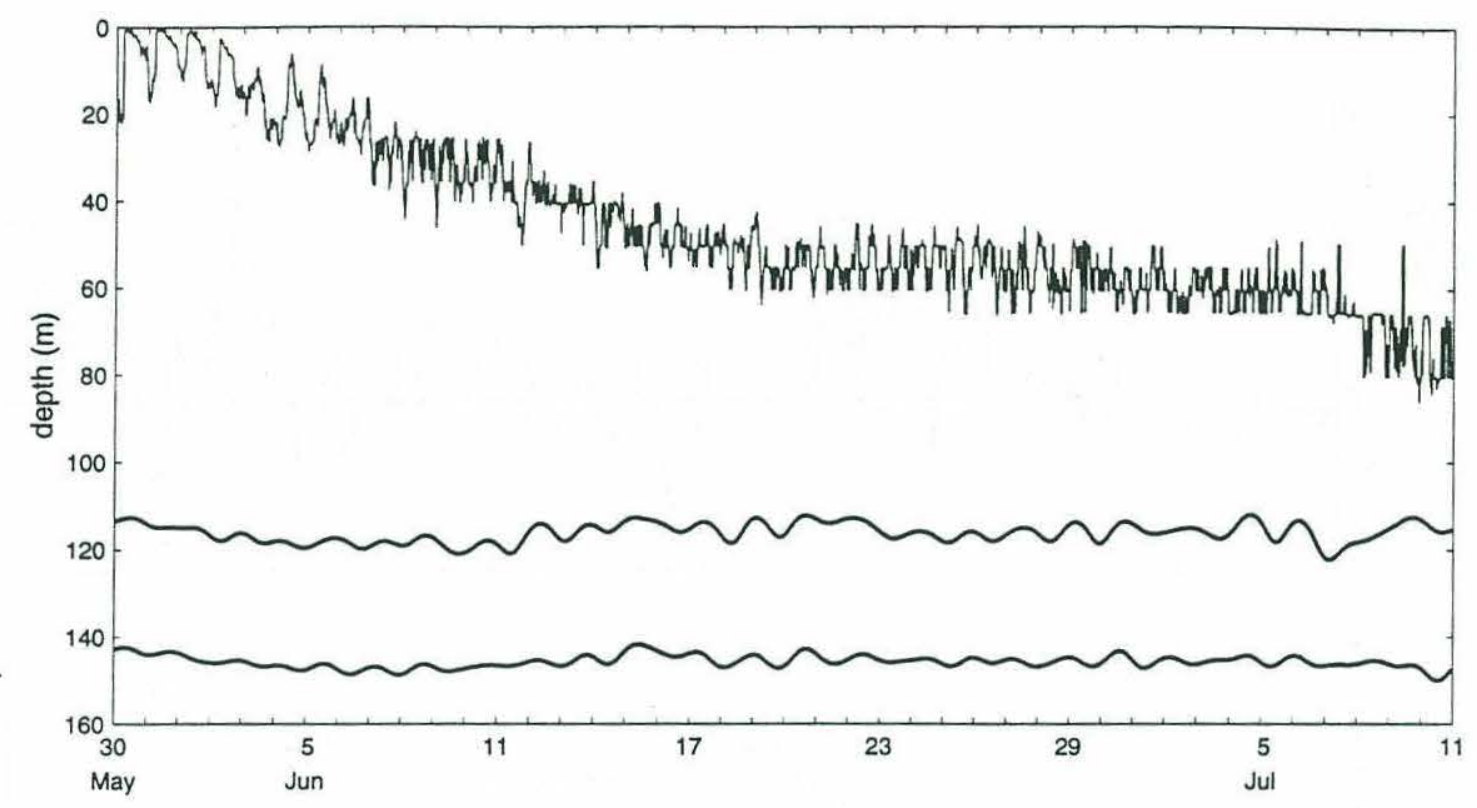

Figure 4.18 The mixed layer depth (thin) and the depth of the 21 and $24{ }^{\circ} \mathrm{C}$ isotherms (thick). There is little indication of a mean vertical transport in the water column.

\subsubsection{ECMWF analysis estimate of Ekman pumping}

Because of the strong and steady wind stresses during the SW monsoon, Ekman pumping has been postulated as an important dynamic element in the upper ocean evolution. But with the experimental location underneath the climatological maximum of the Findlater jet, this imposed vertical velocity might be expected to be reduced in relation to values on either side. The Ekman pumping velocity is here diagnosed from ECMWF analyses.

The timeseries of the vertical Ekman velocity $w_{\mathrm{Ek}}$ and the expected displacement are shown in Fig. 4.19. The peak value of this velocity is larger than what is found in the NE monsoon, but the expected displacement is of the same order, about six meters over the course of six weeks. In this case uplift or Ekman suction is expected. The dotted line in the figure shows the expectation of the displacement if only the curl of the wind stress is con- 


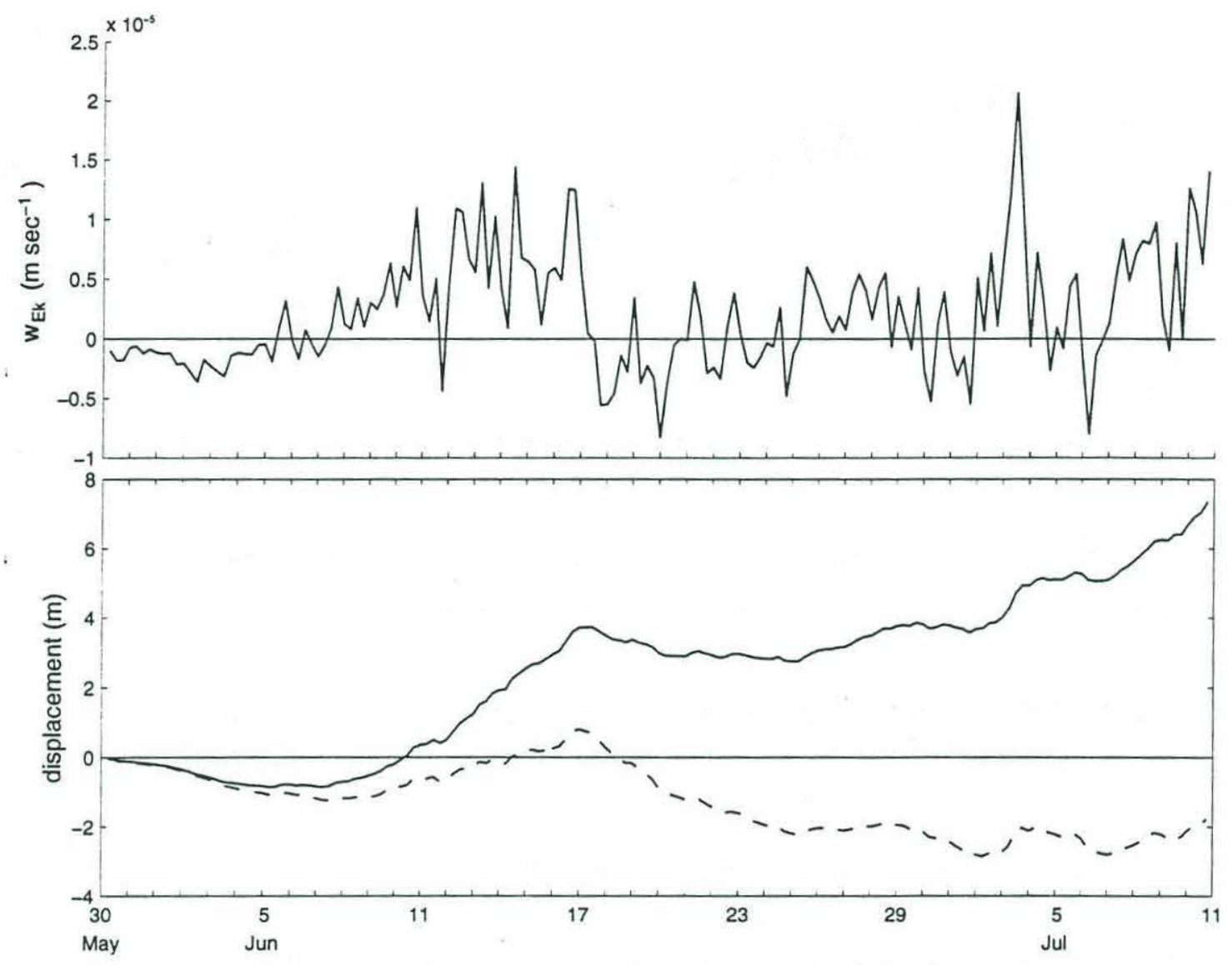

Figure 4.19 The Ekman pumping velocity (top) and expected displacement (bottom) as diagnosed from ECMWF analyses. The dotted line in the lower panel is the expected displacement diagnosed from only the wind stress curl, ignoring the change in Coriolis force with latitude. It is markedly different, due primarily to the strength and large scale of the winds during the SW monsoon.

sidered, ignoring the variation in the Coriolis parameter. It is in marked difference, predicting an Ekman pumping instead.

The size of the terms in the expression for the Ekman pumping velocity (3.31) can be scaled. If one assumes that the curl of the wind stress scales as $\tau / L$, where $L$ is now the length scale over which the wind stress changes, then the ratio of the often ignored beta term over the curl term is the familiar

$$
\frac{\beta_{f} L}{f}
$$


where at the latitude of $15.5{ }^{\circ} \mathrm{N}, f=3.89 \times 10^{-5} \mathrm{sec}^{-1}$, and $\beta_{f}=2.21 \times 10^{-11}$ $\mathrm{m}^{-1} \mathrm{sec}^{-1}$. If one assumes that the length scale over which the wind stress changes appreciably is about $100 \mathrm{~km}$, which is probably conservative, one finds a scaling of terms equal to 0.056 . Fairly small but significant. But this scaling is a bit misleading, since during the SW monsoon, the beta term has a contribution with a constant positive sign. The curl term jumps from positive to negative. So in the time-integrated sense, the beta term becomes very important. In the context of its importance as an effect during the SW monsoon, however, Ekman pumping appears to play little role.
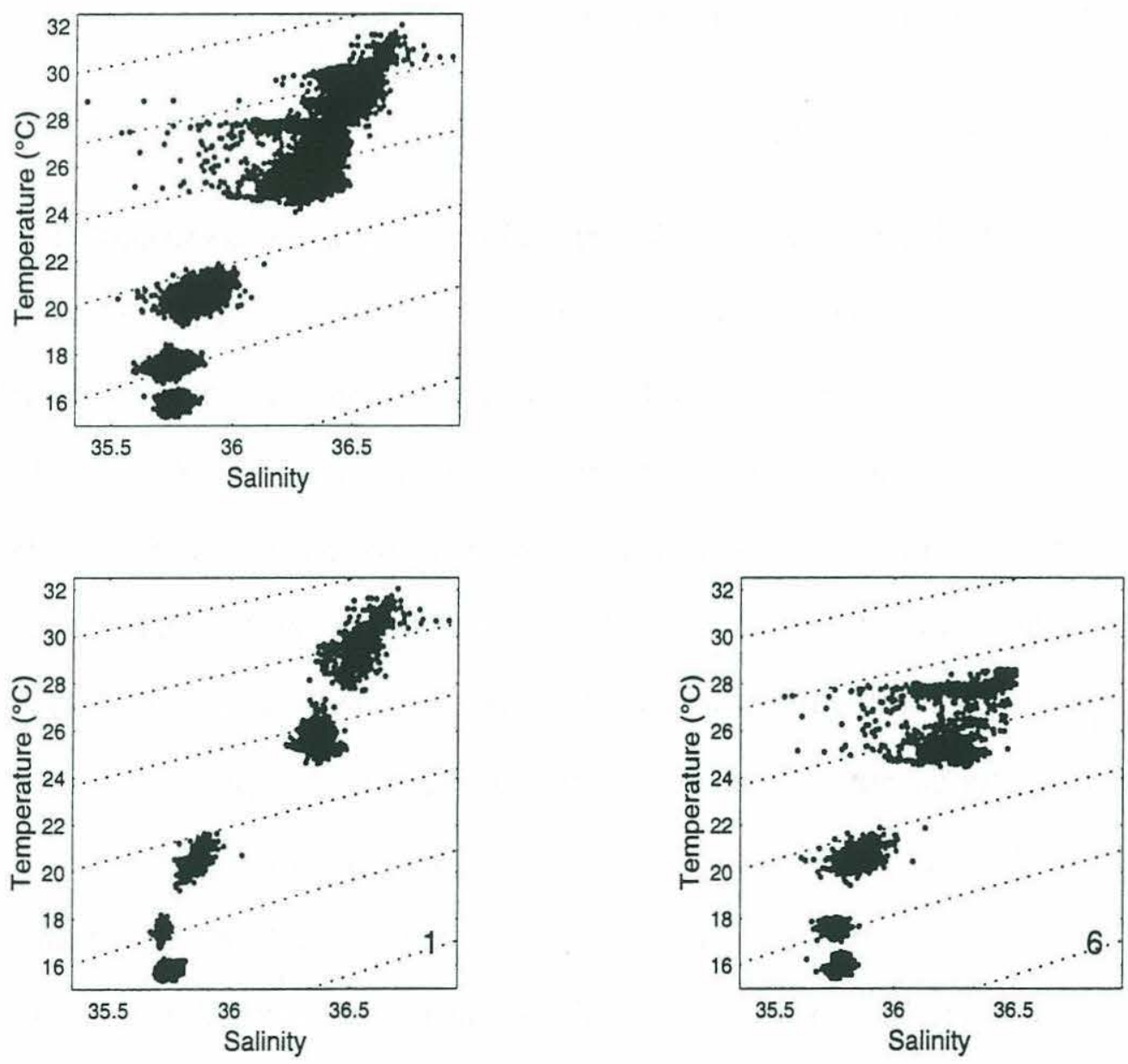

Figure 4.20 The changing TS properties in the upper ocean during the SW monsoon. The top panel has all six weeks of the studied period. Below are the first $(1)$ and last ( 6 ) weeks of the period. There is evidence of fresher and cooler water advecting below the mixed layer during this period. 


\subsubsection{TS Properties}

Vertical velocities appear not to be an important process influencing the upper ocean in the SW monsoon. This leaves horizontal advection of gradients as a last remaining, and logical given the observations, solution. The TS relationship at the mooring site has evidence of the horizontal advection of a cooler and fresher water mass (see Fig. 4.20). The change is limited to the upper water column, between 25 and $27^{\circ} \mathrm{C}$, which remains below the mixed layer. The changes in TS properties above about $27^{\circ} \mathrm{C}$ take place within the mixed layer and are due to the combination of vertical mixing and horizontal advection. The change is less dramatic than the change in the NE monsoon.

\subsubsection{Bounds on advective gradients}

It is clear at this point that the important nonlocal effect necessary to close the heat and salt budgets is a horizontal advection of gradients in temperature and salinity, gradients that are strongest close to the surface. In a parallel to what has been done for the NE monsoon, one can calculate what the bounds on this gradient must be to close the local heat and salt budgets. Again, since the gradient in temperature or salinity is taken to be a constant over the $100 \mathrm{~m}$ of vertical integration, these estimates must be considered a lower bound, since it is obvious from the array data that these gradients have vertical structure. The estimates for the temperature are displayed in Fig. 4.21. The general input required is an order $0.001{ }^{\circ} \mathrm{C}$ per $\mathrm{km}$ gradient that cools over a period of three days. This is roughly consistent with the estimates from the array, recalling the vertical structure of the true gradient. The same calculation is made from the residual of the local salt budget, and is displayed in Fig. 4.22. The general requirement over a timescale of three days to close the local salt budget is for gentle (order $10^{-5} \mathrm{salt} \mathrm{km}^{-1}$ ) gradients that freshen the upper ocean. 


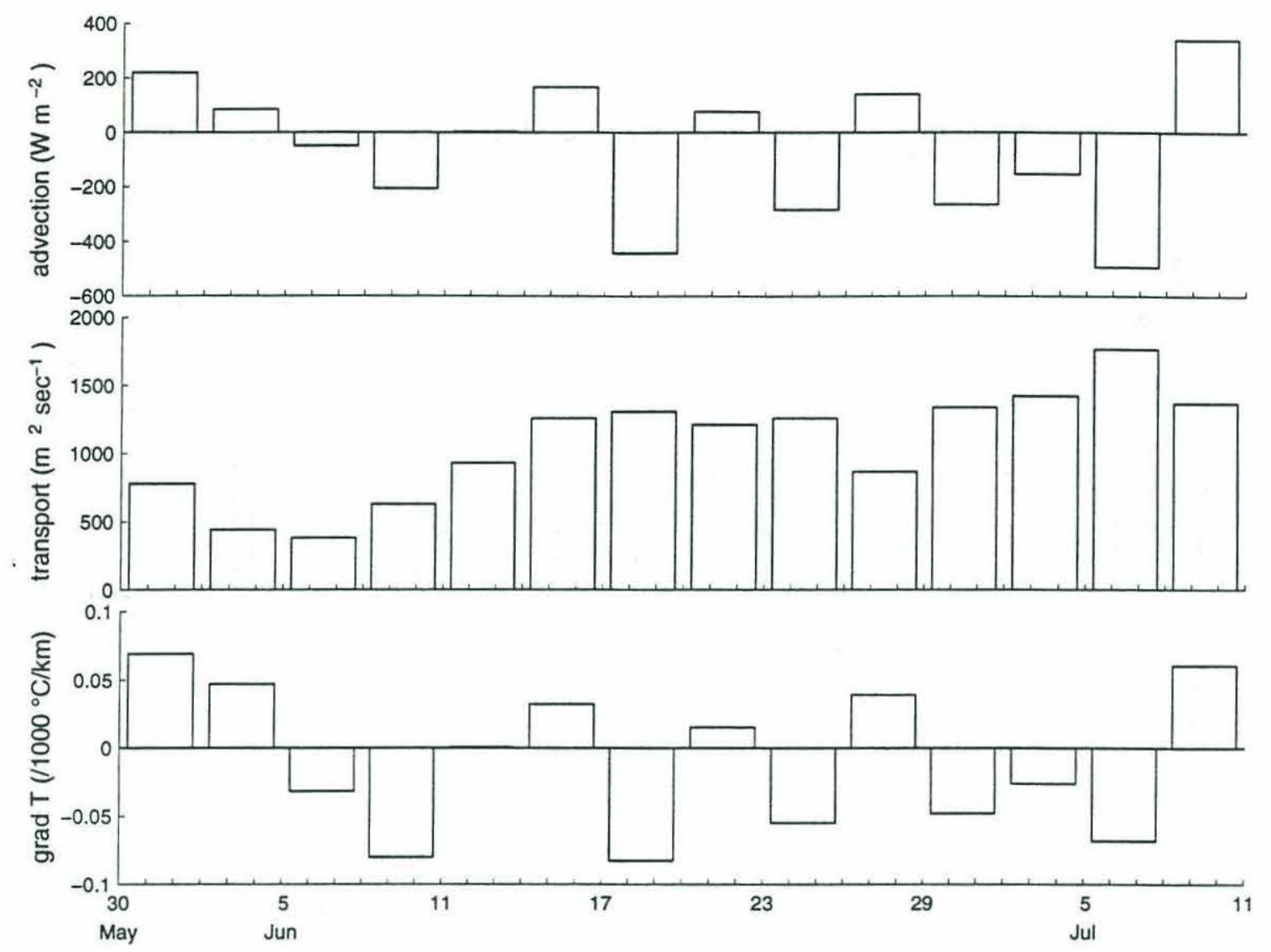

Figure 4.21 The required temperature gradient if horizontal advection is chosen to close the one-dimensional heat budget. From top: the residual of a local budget, the transport observed, and the gradient required to close the budget.

\subsection{Summary}

The southwest monsoon forces the upper ocean on a broad scale with extremely strong wind stresses and neutral-to-stabilizing buoyancy fluxes. The observed velocity response at the mooring site was largely the product of local winds. Due to the strength and steadiness of the wind forcing, these velocities were reasonably large and tended to the southeast. Satellite surface imagery, SeaSoar profiles, and altimetry all suggest that the SW monsoon is a period of high eddy activity in the Arabian Sea, including coastal jet instabilities that bring filaments and eddies of cold and fresh upwelled water far out into the interior. Horizontal gradients in the sea surface temperature then become significant. This was 


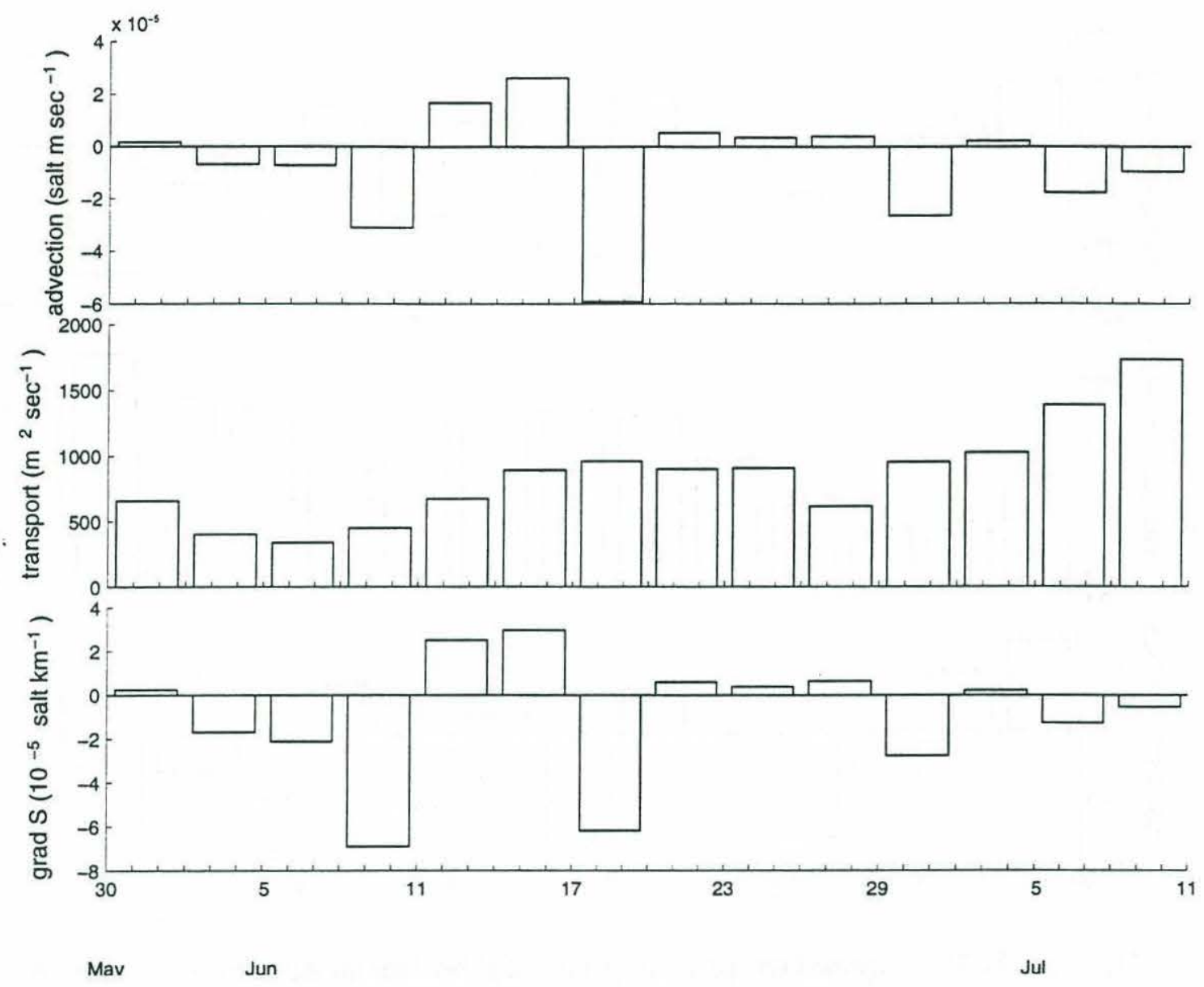

Figure 4.22 The required horizontal salinity gradient if horizontal advection is chosen to close the one-dimensional salt budget. From top: the residual, the transport, and the required gradient.

supported in part by the array data, although it lacked resolution into the upper part of the mixed layer.

The primary local forcing mechanism for the observed deepening and cooling appeared to be wind-driven entrainment through shear instabilities at the base of the mixed layer. This incorporated cooler and fresher water in the mixed layer. Local budgets of heat and salt showed that the locally driven entrainment at the mixed layer base could not account for the observed temperature and salinity evolution. There was no evidence of vertical velocities acting in the upper ocean, although ECMWF winds suggest an Ekman uplift of about $6 \mathrm{~m}$ over the studied period. This leaves horizontal advection of gradients in 
temperature and salinity within the mixed layer as the necessary mechanism for closing the local heat and salt budgets. A one-dimensional model predicted the mixed layer depth well, suggesting that these horizontal advections do little to change the vertical stratification at the mooring site. Finally, bounds on the necessary gradients were calculated, and were consistent with the observations. Modeling the sea surface temperature of the Arabian Sea requires good knowledge of the gradients in properties and the velocity fields that advect them. 


\section{Chapter 5 Discussion and Conclusions}

The Arabian Sea presents a dynamic environment, with large scales of surface forcing and an unusual twice-yearly cycle of sea surface temperature drop and mixed layer deepening under disparate forcing conditions.

At the site of the mooring, the winter monsoon with its gentler wind forcing and strong nightly heat losses finds an upper ocean whose surface properties are quite uniform. But the dynamic remnants of the previous summer monsoon remain in the form of eddies with energetic surface currents that are supported by large horizontal variations in the topography of the thermocline and the base of the mixed layer. The strong wind momentum forcing of the summer monsoon brings with it energetic currents and upwelling and jets along the Omani coast, both of which produce anomalous TS features that reach far into the interior of the Arabian Sea. In contrast with the NE monsoon, these are horizontal variations in properties within as well as below the mixed layer.

The surface fluxes observed at the mooring were quite different in each monsoon season. The northeast monsoon brought the signature of winter Asiatic air, with fairly low moisture and low temperatures. While the momentum flux from this wind was fairly mod- 
erate, the latent and longwave radiative heat losses from the ocean afforded by the low humidity were very high. Combined with a constant evaporative flux of salt, the net daily buoyancy flux was always destabilizing during the observed deepening phase at the mooring site. By contrast, the southwest monsoon half a year later brought with it warm and moist maritime air drawn from the deep tropics. A reduced solar insolation due to scattered cloud cover was observed, and yet a daily net positive heat flux into the ocean occurred. The nearly-saturated water vapor content of the atmosphere dramatically reduced latent and longwave radiative heat losses. When combined into a buoyancy flux, during the observed deepening phase at the mooring site the result was less clearly stabilizing, with larger periods of buoyancy loss, though the overall net was still of a buoyancy gain. The primary surface forcing remained the extremely strong momentum flux of the wind.

In concert with the observed surface fluxes during each season, the primary local physical deepening mechanism active at the site during the northeast monsoon was convective entrainment, while during the southwest monsoon it was wind-driven entrainment of the cooler and fresher waters below the mixed layer. The local upper ocean response at the site was consistent with these local forcing mechanisms, though in each season, local balances and processes could not fully explain the observed mixed layer evolution.

In each season, horizontal advection of horizontal gradients in the temperature and salinity played a key role in the observed evolution. But the character of the advection in each season was different. In the northeast monsoon the velocities at the site were large and obviously nonlocally driven, with a strong barotropic component. Properties at the surface and within the mixed layer had little horizontal variation. The strongest horizontal gradients occurred at the base of the mixed layer and into the thermocline, reflecting the topography necessary to support the observed nonlocally driven geostrophic currents. At 
the mooring site this horizontal advection resolved itself as a vertical displacement of the thermocline. When this observed vertical displacement was used to expand the simple local balances and model with a proxy for the horizontal advection, they were far more successful at predicting the observed upper ocean evolution. In the southwest monsoon, strong horizontal gradients were observed within the mixed layer, and one-dimensional budgets suggested that the strongest deviations from local balances occurred within the mixed layer, closer to the surface. Unlike the northeast monsoon, thermocline topography did not appear to play a significant role during the deepening phase at the mooring site, and the observed velocities were largely understood as being a response to the local forcing. Despite the horizontal advection within the mixed layer, the structure of stratification appeared to change little during the southwest monsoon, since predictions based on an initial stratification yielded extremely good values for the mixed layer depth.

In each season, Ekman pumping appeared to play only a minor role in the upper ocean evolution. With the site under the maximum of the Findlater jet this result might have been predicted, but work on either side of the jet (Brink, Lee, pers. comm.) seems to support this as a general statement for a larger area.

In terms of the goal of being able to predict the sea surface temperature in the Arabian Sea, the two different monsoon seasons present differing challenges. The key deviations from a local balance during the northeast monsoon came below the mixed layer, through the horizontal variations in the thermocline depth, though its vertical structure was fairly uniform. Sea surface temperature evolution driven by the destabilizing buoyancy flux is then simply predicted from a local balance. During the southwest monsoon, however, the primary deviation from a local balance came as horizontal advection within the mixed layer. The sea surface is less horizontally homogenous and the details of horizontal advection become important in locally predicting the sea surface temperature. 
During the southwest monsoon, after the period studied here, the wind stress continues at its strong pace, the sea surface continues to drop in temperature, but the mixed layer shoals somewhat slowly. At this time the local velocities deviate from what is expected in a local balance, and their magnitude increases dramatically. Reminiscent of what happens during the northeast monsoon, it is again the influence of an eddy-like feature, with associated horizontal gradients in the thermocline, making itself felt in the upper ocean. But in this case it does not augment the expected deepening, but rather counteracts it. It remains for further study.

The twice-yearly cycle of mixed layer deepening and cooling in the Arabian Sea is not only an oceanographic oddity, but has been shown to be important in feedbacks with the monsoon. An accurate prediction of both the sea surface temperature and mixed layer depth in each of the two monsoon seasons must then accurately predict horizontal gradients and the velocities advecting them. This is particularly crucial in the southwest monsoon, where horizontal gradients within the mixed layer appear to play a first order role in the local balance of heat. 


\section{References}

Anderson, S. P., M. Baumgartner, 1997. Radiative heating errors in naturally ventilated air temperature measurements made from buoys. Journal of Atmospheric and Oceanic Technology, submitted.

Bauer, S. G., G. L. Hitchcock, and D. B. Olson, 1991. Influence of monsoonally-forced Ekman dynamics upon surface layer depth and plankton biomass distribution in the Arabian Sea. Deep-Sea Research, 38, 531-553.

Brock, J. C., C. R. McClain, M. E. Luther, and W. W. Hay, 1992. Interannual variability in phytoplankton blooms observed in the northwestern Arabian Sea during the southwest monsoon. Journal of Geophysical Research, 97, 733-750.

Brown, O. B., J. G. Bruce, and R. H. Evans, 1980. Evolution of sea surface temperature in the Somali Basin during the southwest monsoon of 1979, Science, 209, 595-597.

Bruce, J. G., 1973. Large-scale variations of the Somali Current during the southwest monsoon, 1970. Deep-Sea Research, 20, 837-846.

Bruce, J. G., 1979. Eddies off the Somali coast during the southwest monsoon. Journal of Geophysical Research, 84, 7742-7748.

Bruce, J. G. and W. H. Beatty, 1985. Some observations of the coalescing of Somali eddies and a description of the Socotra eddy. Oceanologica Acta, 8, 207-219.

Bruce, J. G., D. R. Johnson and J. C. Kindle, 1994. Evidence for eddy formation in the eastern Arabian Sea during the northeast monsoon. Journal of Geophysical Research, 99, 7651-7664.

Crawford, G. B. and W. G. Large, 1996. A numerical investigation of resonant inertial response of the ocean to wind forcing. Journal of Physical Oceanography, 26, 873891.

da Silva, A. M., C. C. Young and S. Levitus, 1994. NOAA Atlas NESDIS 6. Atlas of Surface Marine Data 1994 Volume 1: Algorithms and Procedures. U.S. Department of Commerce, Washington, D.C., 73 pages.

Davis, R. E., R. deSzoeke, S. Halpern, and P. Niiler, 1981. Variability in the upper ocean during MILE. Part I: the heat and momentum balances. Deep-Sea Research, 28A, 1427-1451.

Davis, R. E., R. deSzoeke, S. Halpern, and P. Niiler, 1981. Variability in the upper ocean during MILE. Part II: Modeling the mixed layer response. Deep-Sea Research, 28A, 1453-1475.

Düing, W., and A. Leetmaa, 1980. Arabian sea cooling: a preliminary heat budget. Journal of Physical Oceanography, 10, 307-312. 
ECMWF Technical Attachment, 1994. The description of the ECMWF/WCRP level III-A global atmospheric data archive. European Centre for Medium-Range Weather Forecasts, Reading, U. K., 72 pages.

Evans, R. H. and O. B. Brown, 1981. Propagation of thermal fronts in the Somali Current system. Deep-Sea Research, 28A, 521-527.

Fairall, C. W., E. F. Bradley, D. P. Rogers, J. B. Edson and G. S. Young, 1996a. The parameterization of air-sea fluxes for Tropical Ocean-Global Atmosphere Coupled-Ocean Atmosphere Response Experiment. Journal of Geophysical Research, 101, 37343764.

Fairall, C. W., E. F. Bradley, J. S. Godfrey, G. A. Wick, J. B. Edson and G. S. Young, 1996b. The cool skin and the warm layer in bulk flux calculations. Journal of Geophysical Research, 101, 1295-1308.

Findlater, J. 1971. Mean monthly air flow at low levels over the Western Indian Ocean. Geophysical Memoirs, Vol. XVI, No. 115, 1-53.

Gadgil, S., P. V. Joseph, and N. V. Joshi, 1984. Ocean-atmosphere coupling over monsoon regions. Nature, 312, 141-143.

Hastenrath, S., and P. J. Lamb, 1979. Climate Atlas of the Indian Ocean. Part II: The Oceanic Heat Budget. The University of Wisconsin Press, Madison, 110 pages.

Hellerman, S. and M. Rosenstein, 1983. Normal monthly wind stress over the world ocean with error estimates. Journal of Physical Oceanography, 13, 1093-1104.

Jerlov, N. G., 1968. Optical Oceanography. Elsevier Publishing Company, Amsterdam. 194 pages.

Kershaw, R., 1985. Onset of the south-west monsoon and sea-surface temperature anomalies in the Arabian Sea. Nature, 315, 561-563.

Knox, R. A., 1987. The Indian Ocean: interaction with the monsoon. In: Monsoons, J. S. Fein and P. L. Stephens, editors, John Wiley \& Sons, New York, 3-32.

Kraus, E. B. and J. A. Businger, 1994. Atmosphere-Ocean Interaction (2nd Ed.). Oxford University Press, New York, 362 pages.

Large, W. G. and G. B. Crawford, 1995. Observations and simulations of upper-ocean response to wind events during the Ocean Storms Experiment. Journal of Physical Oceanography, 25, 2831-2852.

Lee, T. and J. Marotzke, 1997. Seasonal cycles of meridional overturning and heat transport in the Indian Ocean. Journal of Physical Oceanography, submitted.

Martin, P. J., 1985. Simulation of the mixed layer at OWS November and Papa with several models. Journal of Geophysical Research, 90, 903-916.

McCreary, J. P., P. Kundu, and R. L. Molinari, 1993. A numerical investigation of dynamics, thermodynamics and mixed-layer processes in the Indian Ocean. Progress in Oceanography, 31, 181-244. 
Mohanty, U. C., K. J. Ramesh, and M. C. Pant, 1996. Certain seasonal characteristic features of oceanic heat budget components over the Indian seas in relation to the summer monsoon activity over India. International Journal of Climatology, 16, 243-264.

Niiler, P. P. and E. B. Kraus, 1977. One-dimensional models of the upper ocean. In: Modeling and prediction of the upper layers of the ocean, W. B. Kraus, editor, Pergamon Press, Oxford, 143-172.

Oberhuber, J. M., 1988. An atlas based on the "COADS" data set: The budgets of heat, buoyancy, and turbulent kinetic energy at the surface of the global ocean. MaxPlanck-Institut fur Meteorologie, Rep. No. 15.

Paulson, C. A. and J. J. Simpson, 1977. Irradiance measurements in the upper ocean. Journal of Physical Oceanography, 7, 952-956.

Payne, R. E., 1972. Albedo at the sea surface. Journal of Atmospheric Science, 29, 959970.

Price, J. F., C. N. K. Mooers and J. C. Van Leer, 1978. Observation and simulation of storm-induced mixed-layer deepening. Journal of Physical Oceanography, 8, 582599.

Price, J. F., R. A. Weller and R. Pinkel, 1986. Diurnal cycling: observations and models of the upper ocean response to diurnal heating, cooling, and wind mixing. Journal of Geophysical Research, 91, 8411-8427.

Rao, R. R., 1986. Cooling and deepening of the mixed layer in the central Arabian Sea during MONSOON-77: observations and simulations. Deep-Sea Research, 33, 14131424.

Rao, R. R., R. L. Molinary and J. F. Festa, 1989. Evolution of the climatological near-surface thermal structure of the tropical Indian Ocean. 1. Description of mean monthly mixed layer depth, and sea surface temperature, surface current, and surface meteorological fields. Journal of Geophysical Research, 94, 10,801-10,815.

Rosenfeld, L. K. (Ed.), 1985. CODE-2: Moored array and large-scale data report. WHOI Technical Report No. 85-25, CODE Technical Report No. 38, p.21.

Rudnick, D. L. and R. E. Davis, 1988. Mass and heat budgets on the Northern California continental shelf. Journal of Geophysical Research, 93, 14,013-14,024.

Rudnick, D. L. and R. A. Weller, 1993. The heat budget in the North Atlantic subtropical frontal zone. Journal of Geophysical Research, 98, 6883-6893.

Schott, F., 1983. Monsoon response of the Somali Current and associated upwelling. Progress in Oceanography, 12, 357-381.

Schudlich, R. R., and J. F. Price, 1992. Diurnal cycles of current, temperature, and turbulent dissipation in a model of the equatorial upper ocean. Journal of Geophysical Research, 97, 5409-5422.

Shukla, J., 1987. Interannual variability of monsoons. In: Monsoons, J. S. Fein and P. L. Stephens, editors, John Wiley \& Sons, New York, 399-463. 
Simmons, R. C., M. E. Luther, J. J. O'Brien, and D. M. Legler, 1988. Verification of a numerical model of the Arabian Sea. Journal of Geophysical Research, 93, 15,43715,453 .

Swallow, J. C., 1984. Some aspects of the physical oceanography of the Indian Ocean. Deep-Sea Research, 31, 639-650.

Swallow, J. C., R. L. Molinari, J. G. Bruce, O. B. Brown, and R. H. Evans, 1983. Development of near-surface flow pattern and water mass distribution in the Somali Basin in response to the southwest monsoon in 1979. Journal of Physical Oceanography, 13, 1398-1415.

Wacongne, S., and R. Pacanowski, 1996. Seasonal heat transport in a primitive equations model of the tropical Indian Ocean. Journal of Physical Oceanography, 26, 26662699.

Webster, P. J., 1987. The elementary monsoon. In: Monsoons, J. S. Fein and P. L. Stephens, editors, John Wiley \& Sons, New York, 3-32.

Weller, R. A., D. L. Rudnick, R. E. Payne, J. P. Dean, N. J. Pennington and R. P. Trask, 1990. Measuring near-surface meteorology over the ocean from an array of surface moorings in the subtropical convergence zone. Journal of Atmospheric and Oceanic Technology, 7, 85-103.

Weller, R. A., D. L. Rudnick, N. J. Pennington, R. P. Trask and J. R. Valdes, 1990. Measuring upper ocean variability from an array of surface moorings in the subtropical convergence zone. Journal of Atmospheric and Oceanic Technology, 7, 68-84.

Weller, R. A., and S. P. Anderson, 1996. Surface meteorology and air-sea fluxes in the western equatorial Pacific warm pool during the TOGA Coupled Ocean-Atmosphere Response Experiment. Journal of Climate, 9, 1959-1990.

Weller, R. A., M. F. Baumgartner, A. S. Fischer, and J. Kindle, 1997. A one-year record of atmospheric forcing from the Arabian Sea, manuscript in preparation.

Wright, P. B., 1988. An atlas based on the "COADS" data set: Fields of mean wind, cloudiness and humidity at the surface of the global ocean. Max-Planck-Institut fur Meteorologie, Rep. No. 14. 